Portland State University

PDXScholar

6-1-2009

\title{
Education as Sustainability : an Action Research Study of the Burns Model of Sustainability Pedagogy
}

Heather L. Burns

Portland State University

Follow this and additional works at: https://pdxscholar.library.pdx.edu/open_access_etds

Part of the Educational Leadership Commons

Let us know how access to this document benefits you.

\section{Recommended Citation}

Burns, Heather L., "Education as Sustainability : an Action Research Study of the Burns Model of Sustainability Pedagogy" (2009). Dissertations and Theses. Paper 942.

https://doi.org/10.15760/etd.942

This Dissertation is brought to you for free and open access. It has been accepted for inclusion in Dissertations and Theses by an authorized administrator of PDXScholar. Please contact us if we can make this document more accessible: pdxscholar@pdx.edu. 


\section{DISSERTATION APPROVAL}

The abstract and dissertation of Heather Burns for the Doctor of Education in

Educational Leadership: Postsecondary Education were presented June 11, 2009, and accepted by the dissertation committee and the doctoral program.

COMMITTEE APPROVALS:

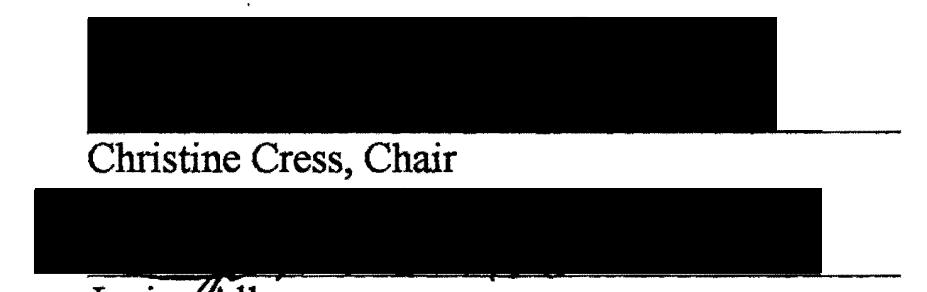

JanineAllen

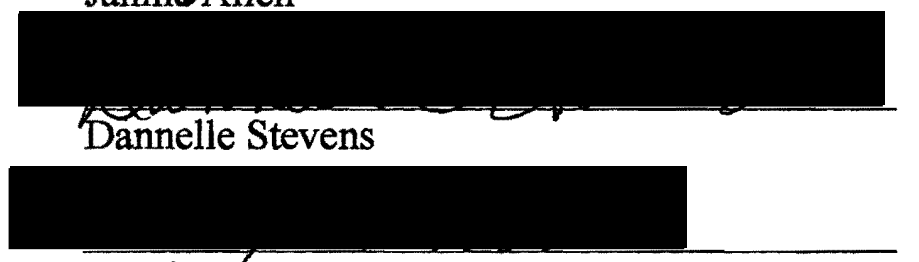

Rosalyn McKeown

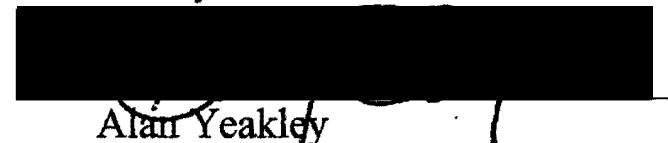

Alain Yeaklefy 1

Representative of the Office of Graduate Studies

DOCTORAL PROGRAM APPROVAL:

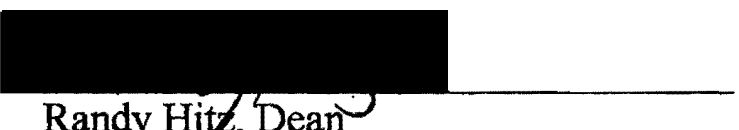

Graduate School of Education 


\begin{abstract}
An abstract of the dissertation of Heather Burns for the Doctor of Education in Educational Leadership: Postsecondary Education presented June 11, 2009.
\end{abstract}

Title: Education as Sustainability: An Action Research Study of the Burns Model of Sustainability Pedagogy

Postsecondary teaching and learning must be reoriented to equip learners with the knowledge, skills, and values they will need for creating a more sustainable world. This action research study examined the effects of implementing the Burns model of sustainability pedagogy in university courses taught by the researcher. This model is comprised of five key dimensions: (1)Content; (2)Perspectives; (3)Process; (4)Context; and (5)Design. The Burns model of sustainability pedagogy seeks to: (1) increase learners' systemic understanding of complex sustainability issues (Content); (2) provide learners with opportunities to think critically about dominant paradigms, practices and power relationships and consider complex ecological and social issues from diverse perspectives (Perspectives); (3) enhance learners' civic responsibility and intentions to work toward sustainability through active participation and experience (Process); (4) increase learners' understanding of and connection with the geographical place and the community in which they live (Context); and (5) utilize an ecological course design to create transformative learning (Design). This pedagogical model reflects education as sustainability, a transformative learning process through 
which learners' values and perspectives change so that they are able to embrace sustainability and take action for change.

Findings revealed that through the use of sustainability themes, students came to understand sustainability Content concretely, personally, and multidimensionally. Students understood multiple Perspectives and power relationships through experiential learning, through relationships with one another, by hopeful examples, and by learning to think critically. Due to a participatory and experiential learning Process, students expressed intentions to buy locally and to act directly for sustainable change. Through a focus on Context, students experienced stronger connections to their local community. A self-reflective teaching process and relational learning was important to the Design of a transformational learning process. The results show that the Burns model of sustainability pedagogy can be adapted to university courses in various disciplines.

This study contributes to the field of sustainability education by providing an example of an effective model for teaching sustainability at the university level. In order to prepare diverse learners for leadership roles in a sustainable world, attention must be focused on integrating transformative sustainability pedagogy throughout postsecondary education. 
c

EDUCATION AS SUSTAINABILITY: AN ACTION RESEARCH STUDY OF THE BURNS MODEL OF SUSTAINABILITY PEDAGOGY

by

HEATHER BURNS

A dissertation submitted in partial fulfillment of the requirements for the degree of

DOCTOR OF EDUCATION

in

EDUCATIONAL LEADERSHIP:

POSTSECONDARY EDUCATION

Portland State University

(C)2009 


\section{ACKNOWLEDGMENTS}

Many people have supported and applauded my efforts in completing this doctoral program. I thank my educator parents, Terry and Gail Burns, for being keenly interested in my work, for our many discussions on teaching and learning practice, and for their constant support of my educational endeavors. I also thank the many friends, family members and doctoral colleagues who, on long walks or over cups of coffee or pints of beer, helped me untangle what I was learning and gave me the encouragement to pursue the work I am passionate about. I especially want to thank my friend and coinstructor Celine for her support and for all the ways in which our collaboration as instructors has helped me to learn and grow. Of my friends, my partner Jeffrey also deserves special recognition. I am grateful to Jeffrey for being my strongest supporter, and for being a sounding board about my teaching and research whenever I needed one. He has truly walked beside me on this journey, pushing me to work hard but also offering me a place to rest and recharge.

My advisor, Dr. Christine Cress, has also been an invaluable source of support and encouragement throughout this process. I thank Christine for her clear direction and keen sense of humor, and the rest of my doctoral committee for encouraging and mentoring me in my doctoral work.

Finally, I also want to thank all the students who were participants in my study for their willingness to share their lives and learning with me. I have learned a great deal from each of them and admire their zeal for life and for making positive change in the world. I thank them for making my work and research such a fun and rewarding process. 


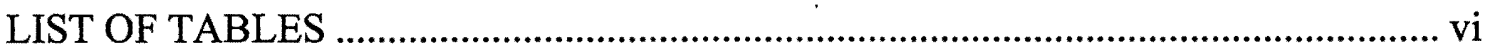

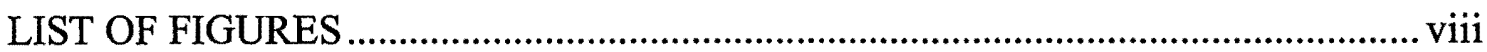

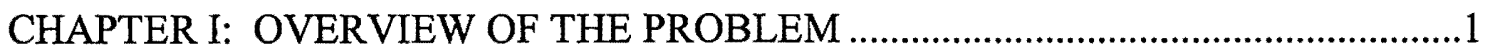

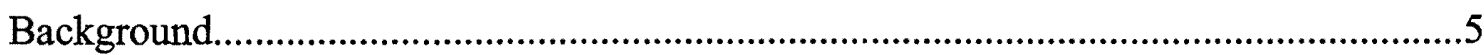

A Short History of the Sustainability Movement and its Applicability to

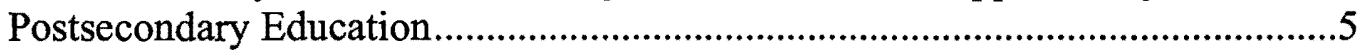

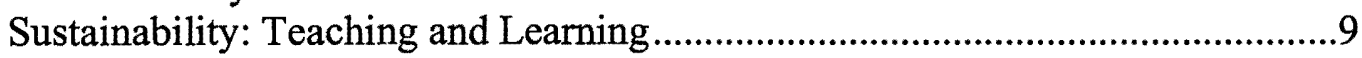

Reasons for Slow Progress ....................................................................................11

Towards Education as Sustainability: A Transformational Process.....................13

Purpose and Significance of the Study ......................................................................16

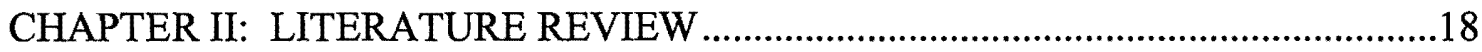

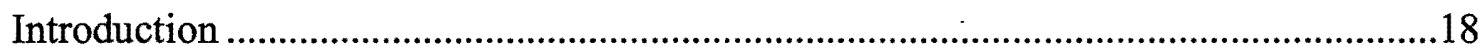

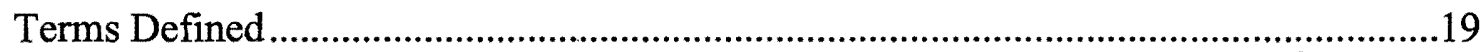

Conceptual Framework ...........................................................................................19

A Context for Sustainability Pedagogy: Recent Trends in Postsecondary

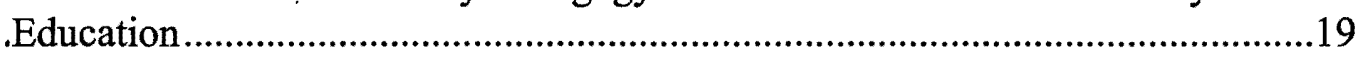

Teaching and Learning in Postsecondary Education:

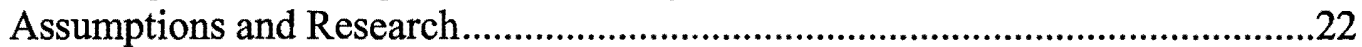

Recent Research about Teaching and Learning Sustainability in

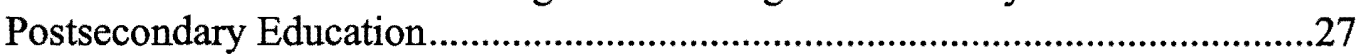

The Burns Model of Sustainability Pedagogy: An Overview of Goals ...........................32

The Burns Model of Sustainability Pedagogy: Dimensions..................................35

Dimension I: Content ............................................................................35

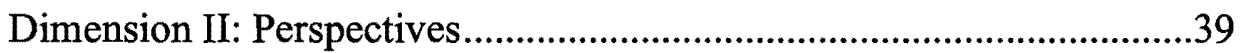

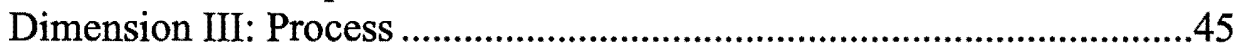

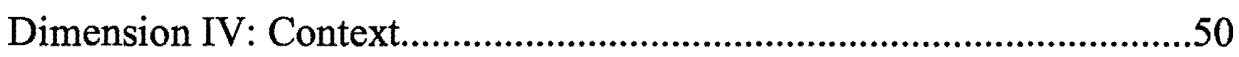

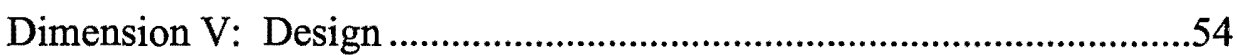

Summary of the Burns Model and Related Theory ................................................63

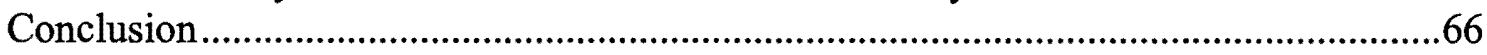

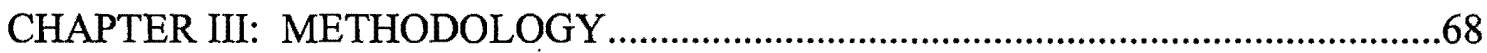

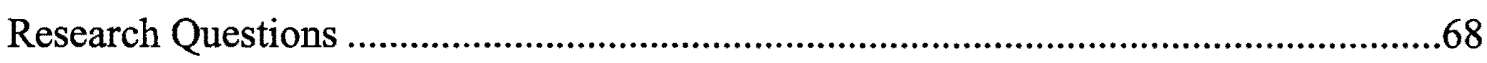




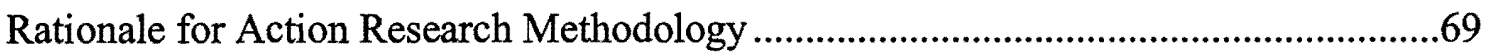

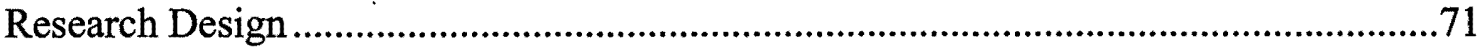

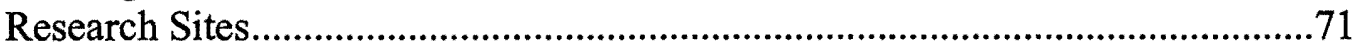

Course 1 ("The Border Course") ............................................................71

Course 2 ("College Writing")....................................................................77

Research Participants...........................................................................................84

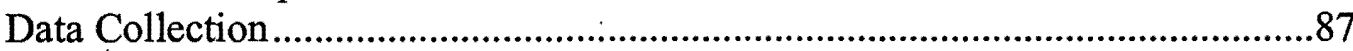

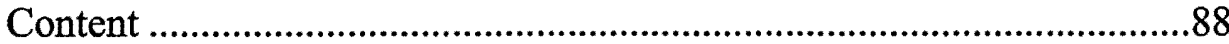

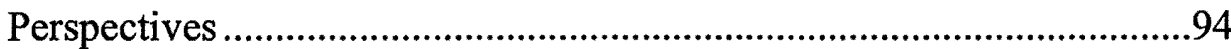

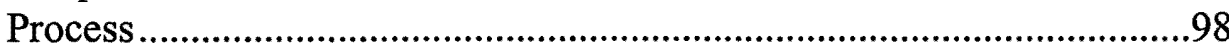

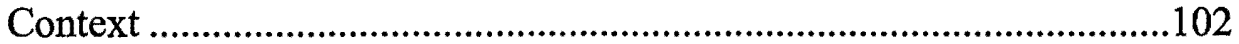

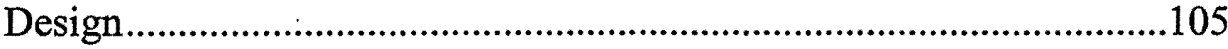

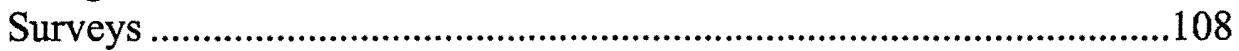

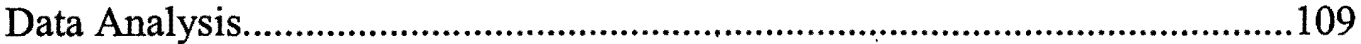

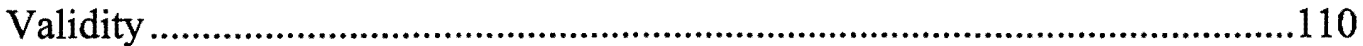

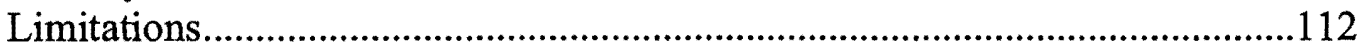

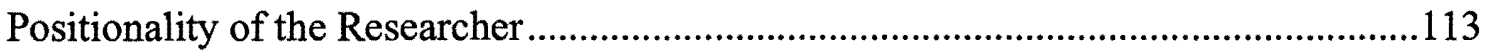

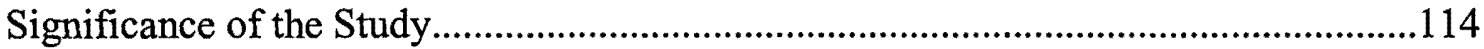

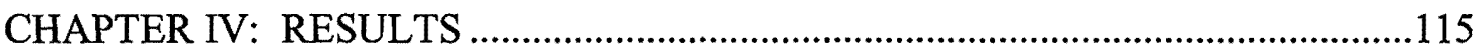

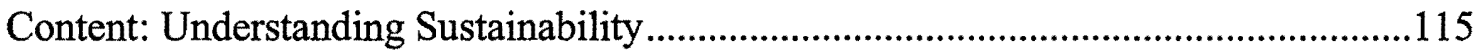

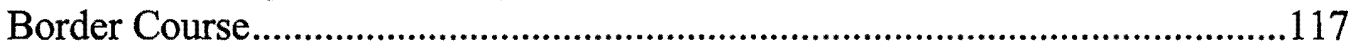

Understanding Sustainability Holistically and Concretely.....................119

Understanding Sustainability Personally and Emotionally ....................123

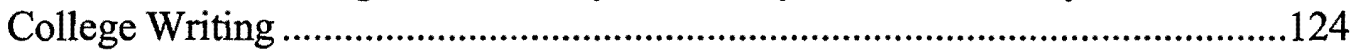

Understanding Sustainability Through a Change in Values...................126

Understanding Sustainability Through the Course Theme ...................127

Understanding Sustainability as Multidimensional...............................129

Pedagogical Implications: Connecting Content and Constructivism ..................132

Perspectives: A Critical Examination from Multiple Epistemologies ..........................133

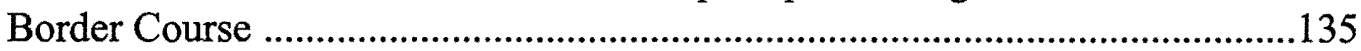

Learning Sustainability from Perspectives at the Border and

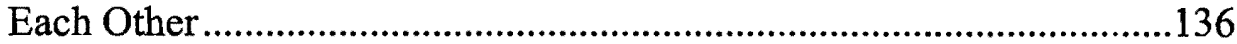

Gaining Hopeful Perspectives ............................................................138

Understanding Power Relationships and Dominant Paradigms

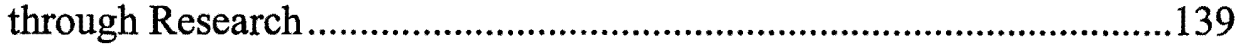

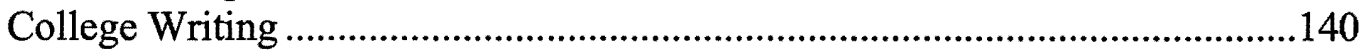

Learning from Community Perspectives ..............................................141

Learning to Think Critically .................................................................143

Pedagogical Implications: Connecting Perspectives and Critical Theory..........147

Process: Learning through Participation and Experience............................................149

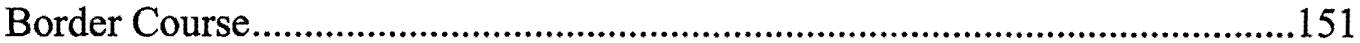

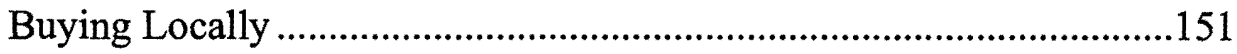


Direct Action for Change .......................................................................152

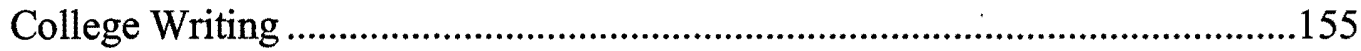

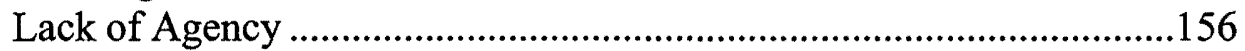

Buying Locally .....................................................................................157

Pedagogical Implications: Connecting Process to Experiential

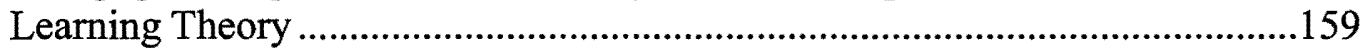

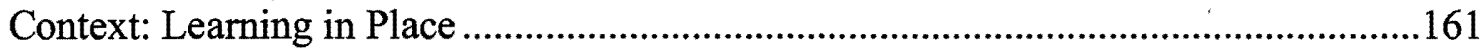

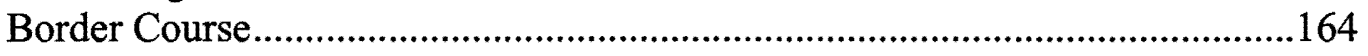

Stronger Connections to Home Community .......................................164

College Writing .................................................................................................166

Increased Connections to Local Food .....................................................166

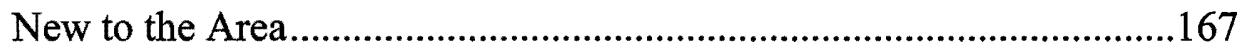

Pedagogical Implications: Connecting Context to Place-Based

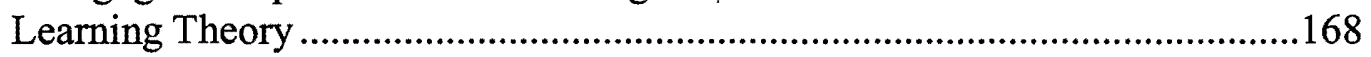

Ecological Design: Education as Sustainability for Transformational Learning ...........170

Reflective Practice and Assessment ..............................................................171

Relational Learning ....................................................................................173

Transformational Learning ..........................................................................178

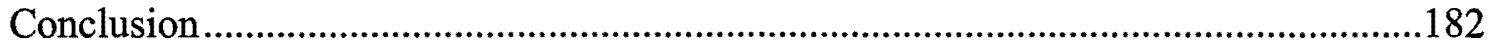

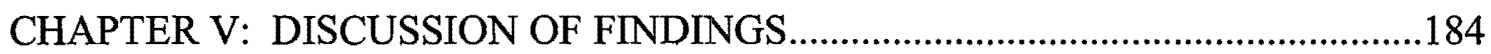

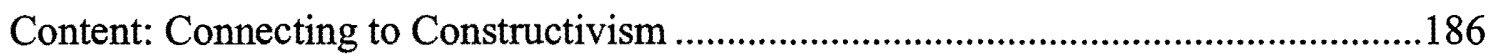

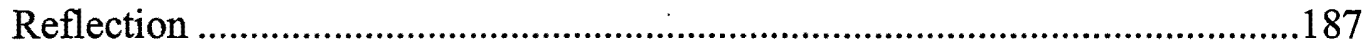

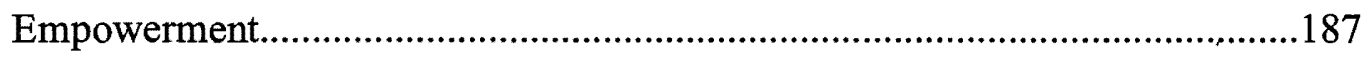

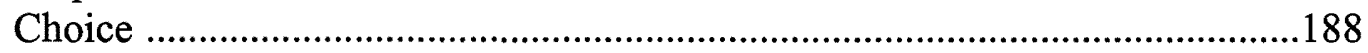

Perspectives: Connecting to Critical Theory ..............................................................189

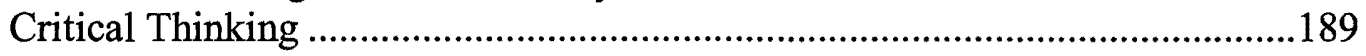

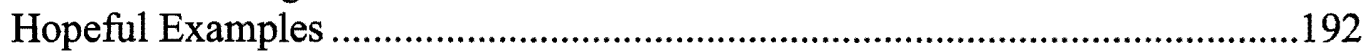

Process: Connecting to Experiential Learning ...........................................................192

Relationship Building .....................................................................................193

Learning Beyond the Classroom .......................................................................194

Context: Connecting to Place-based Learning .............................................................195

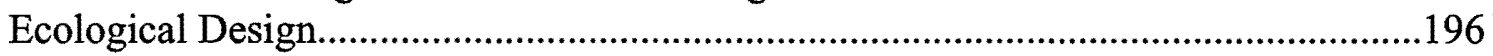

Education as Sustainability for Transformational Learning..............................196

Self-reflective practice................................................................................199

Summary of Key Pedagogical Implications ...............................................................203

Pedagogical Recommendations for Implementing the Burns Model.............................204

Organic Nature of Classrooms, Communities, and Campuses:

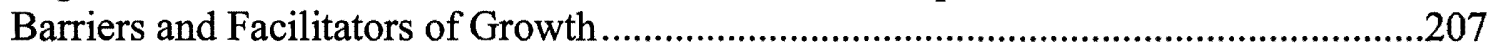

Fertile Soil: Creating Political Receptivity.....................................................208

Optimal Growing Conditions: Understanding Organizational Structure ...........210

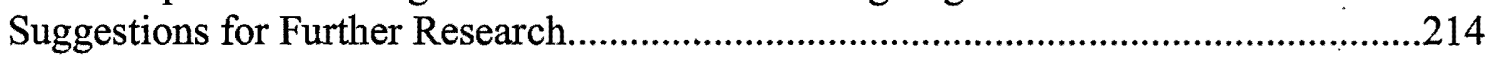

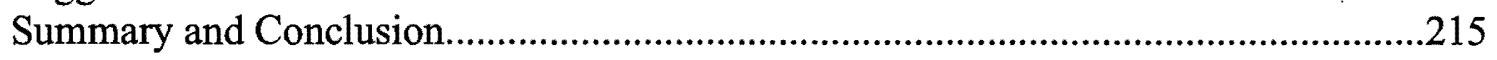




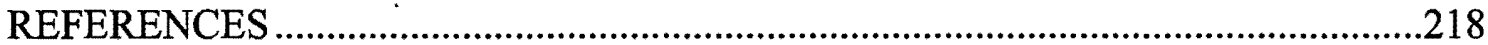

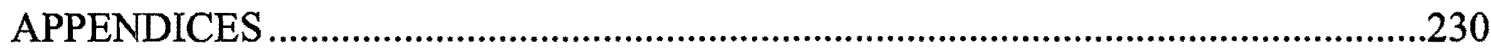

A. Informed Consent Forms ........................................................................230

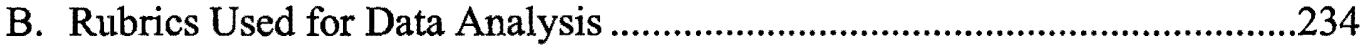

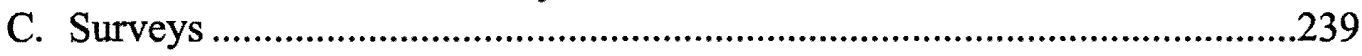

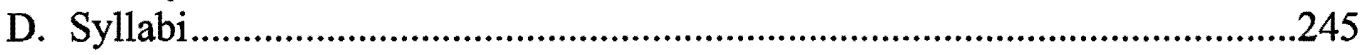


Table

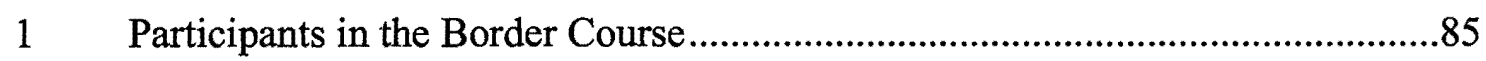

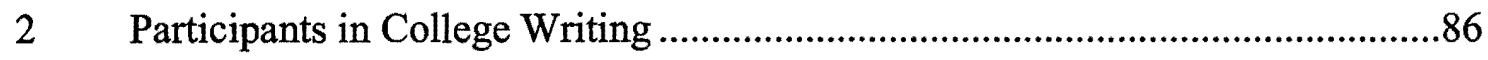

3 Content Dimension: Data Collection................................................................93

$4 \quad$ Perspectives Dimension: Data Collection ............................................................97

$5 \quad$ Process Dimension: Data Collection ................................................................. 101

6 Context Dimension: Data Collection.................................................................104

7 Design Dimension: Data Collection...............................................................108

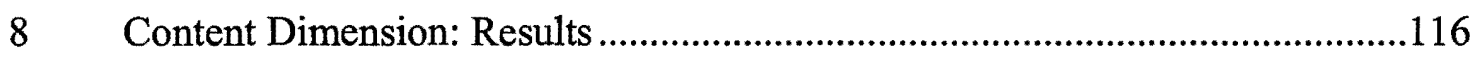

9 Comparisons: Pre and Post Student Knowledge Survey .....................................119 (Course One: "The Border Course")

10 Comparisons: Pre and Post Student Knowledge Survey ..................................131 (Course Two "College Writing")

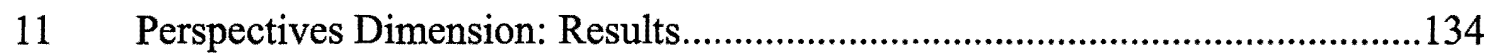

12 How much was learned from the following teaching..........................................138 and learning techniques (Post Course Survey ResultsCourse One: "The Border Course")

13 How much was learned about the course theme, Sustainable. 142 Local Food Systems, from the following Teaching and Learning Techniques (Post Course Survey ResultsCourse Two: "College Writing")

14 Process Dimension: Results .150 
15 How students rated their learning based on the

dimensions of the Burns model of Sustainability Pedagogy (From Post Course Survey- Course One:

"The Border Course")

16 How students rated their learning based on the

dimensions of the Burns model of Sustainability

Pedagogy (From Post Course Survey- Course Two:

"College Writing")

17 Context Dimension: Results 163

18 Teaching philosophy: The Burns Model of Sustainability Pedagogy .201 


\section{LIST OF FIGURES}

Figure

Page

1 The Burns Model of Sustainability Pedagogy ……….............................................33

2 The 7 Cs Leadership Development Model.......................................................61

3 The Burns Model of Sustainability Pedagogy with

Levels of Development.

4 The Burns Model of Sustainability Pedagogy and

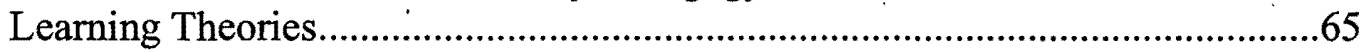

5 The Burns model: Summary of Design for "the Border Course" ........................73

6 The Burns model: Summary of Design for "College Writing" ..............................79

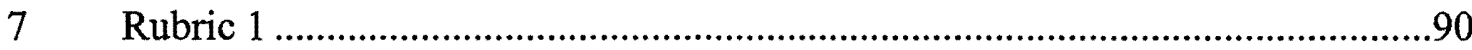

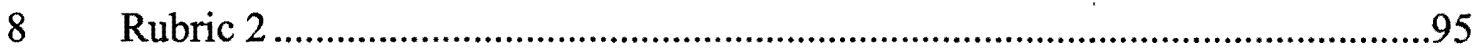

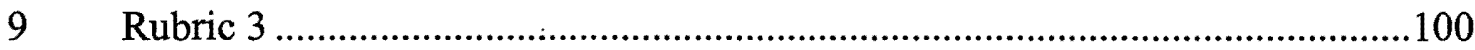

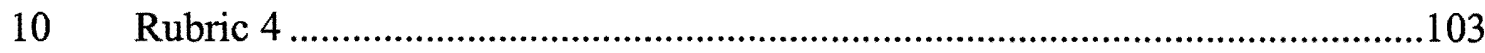

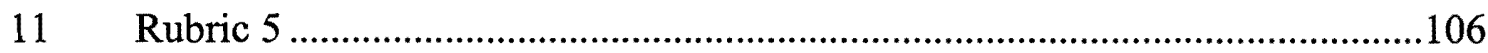

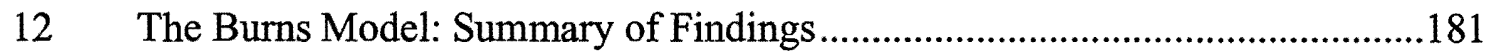

13 The Burns Model: Pedagogical Implications ...................................................185 


\section{CHAPTER I \\ OVERVIEW OF THE PROBLEM}

Over twelve years ago, E. F. Schumacher (1997) wrote, "The volume of education...continues to increase, yet so do pollution, exhaustion of resources, and the dangers of ecological catastrophe. If still more education is to save us, it would have to be education of a different kind: an education that takes us into the depth of things..." (p. 208). Perhaps never before has the need for a kind of deeper, integrated education been more important. In the last half-century, the accelerated growth of industrialization and globalization has created an explosion of technology, energy use, resource extraction, population growth, urbanization, and consumerism, literally transforming our world. Unfortunately, the side effects of this rapid and unchecked growth are being revealed worldwide in the form of devastating ecological and social crises.

Graduates of postsecondary institutions are faced with incredible challenges that will affect their lives in very real ways. For example, continuous economic growth (even sustainable development) on which the global economy is based, is largely reliant upon the myth of inexhaustible natural resources (Sarkar, 2001) and on the use of cheap and unrenewable sources of energy. Growing levels of industry, global transportation, and urban households around the world are responsible for numerous socio-ecological disasters such as mountaintop removal (coal mining for electricity production), high levels of air pollution (industrial chemicals and diesel exhaust), global warming (carbon dioxide produced by transporting food and other 
consumer goods), and toxic watersheds (agricultural pesticides and fertilizers) to name a few (McDonough \& Braungart, 2002; Ryan \& Durning, 1997; Norberg-Hodge \& Gorelick, 2006; Steingraber, 1997). Additionally, in the last thirty years urban centers of industry have drawn millions of people seeking survival or economic advancement (Platt, 1994). This rapid increase in urbanization has resulted in a greater gap between rich and poor; widespread food insecurity; the development of new energy sources such as big dams; the loss of rural communities, economies, and family farms; and the loss of forests and wetlands to urban development (Shiva, 2001; Platt, 1994).

Are graduates prepared, not only to deal with the ecological and social reparation that is necessary, but with the skills needed to transition to a lower energy future based on renewable resources? Do graduates understand that both lifestyle changes and systemic changes are necessary to stave off ecological and social collapse and begin to regenerate local communities and places? David Orr (2004) soberly remarks, "We are still educating the young as if there were no planetary emergency...more of the same kind of education can only make things worse" (p. 27). Unless we want more of the same kinds of problems, we must begin to educate future leaders to be able to address these issues and make effective changes. Learners must be equipped not only with knowledge, but with the skills, values and attitudes needed to address current ecological and social realities (McKeown, 2002). Paul Hawken (2007) suggests that at this point in our ecological and socio-cultural freefall, we need to learn to "preserve what remains and dedicate ourselves to restoring what we have lost" (p. 172). 
There is currently a growing awareness of the need for sustainability at both local and global levels, defined as "a systemic concept...a means of configuring civilization and human activity so that society, its members and its economies are able to meet their needs and express their greatest potential in the present, while preserving biodiversity and natural ecosystems, and planning and acting for the ability to maintain these ideals indefinitely" (Project: Sustainability, 2008, p. 1).

In his book, Blessed Unrest, Paul Hawken (2007) explains that sustainability "is about stabilizing the currently disruptive relationship between earth's two most complex systems - human culture and the living world. The interrelation between these two systems marks every person's existence and is responsible for the rise and fall of every civilization" (p. 172). According to sustainability educator and activist Starhawk (2008), in order to create sustainability "we need to understand that...everything exists in communities and nothing stands alone. We can't benefit one part of a community at the expense of another and expect that community to last.... But if we consider how to create beneficial relationships among all aspects of a community, the health and abundance of the entire system will increase" (p. 1). O'Riordan \& Voisey (1998) propose that the sustainability transition is also about new ways of knowing and being human. Many activists and educators have also acknowledged that sustainability issues are rooted in deep ethical and spiritual commitments (Hawken, 2007), and that a sustainability transformation will begin with spiritual awakening and growth. 
Education has long been linked to change and has indeed been linked to the need for sustainability at the global level since the 1970 s (Sterling, 2004). Education, after all, is a strong influēnce on the direction of our world as it profoundly shapes learners' worldviews, economic potential, attitudes and participation levels in the community, decision-making, and interactions with the ecosystem (McKeown \& Hopkins, 2002). Faced with the mounting pressures of complex global problems, postsecondary education would therefore be extremely irresponsible not to place priority on sustainability education, learning that prepares graduates with "new knowledge and new ways of thinking needed to achieve economic prosperity, participate democratically, secure justice and equity, and all the while regenerate the health of the ecosystems, the gift upon which all life and all production depend" (The Cloud Institute for Sustainability Education, 2008, p. 1).

While sustainability education is needed at all levels, those who have access to postsecondary education (and commonly take on leadership and decision-making roles within local communities), should be well versed in sustainability in order to be able to actively address the complex issues faced by their local and global communities. Postsecondary education can certainly not be expected to achieve a sustainable society on its own, but it is an important place to begin to teach sustainability because of postsecondary education's ability to influence attitudes towards ecological and social justice, as well as its influence on cultural values and policy change.

In recent years, institutions of postsecondary education everywhere are indeed recognizing that they do have an ethical responsibility towards the goal of 
sustainability (Leal Filho, 2002). Not only are postsecondary institutions integral parts of global and local economies, they are preparing citizens and future leaders who will be positioned to influenee the direction our societies will take. Therefore, some would even say that the success of postsecondary education in the twenty-first century might be judged "by its ability to make sustainability a cornerstone of academic practice" (Leal Filho, 2002, p.9).

Clearly, there is a need for postsecondary education to begin working in earnest toward the goal of sustainability if it is to teach students how to function in a world of finite resources and to mobilize them to participate in systemic solutions to meet the urgency of global and local challenges. In particular, teaching and learning at the postsecondary level must be reoriented towards sustainability if there is to be transformative change. Fortunately, this effort toward sustainability education at the postsecondary level has begun to take place within a larger, global movement towards sustainability.

\section{Background}

\section{A Short History of the Sustainability Movement and its Applicability to Postsecondary Education}

Since the 1970s, a number of global efforts have been made toward the advancement of sustainability education, although this movement has been slow. The United Nations' Belgrade Charter of 1975 charged the field of environmental education with developing a population that is "aware of, and concerned about, the environment and its problems, and with the knowledge and commitment to work toward solutions and the prevention of new problems" (UNESCO, 1975, p. 3). The 
Tblisi documents, which were finalized at the 1977 Intergovernmental Conference on the Environmental Education in Tblisi, USSR, provided goals for how to carry out the mandate of the Belgrade Charter. At this point, the focus of these documents centered primarily on environmental problems and environmental education, while society and economics were less emphasized (McKeown \& Hopkins, 2003).

A decade later, the 1987 Brundtland Report of the World Commission on Environment and Development (WCED) made popular the concept of sustainable development as "development that meets the needs of the present without compromising the ability of future generations to meet their own needs" (Report of the World Commission on Environment and Development, 1987, p.1). Closely following, the first Earth Summit took place in Rio in 1992, the UN Conference on Environment and Development (UNCED). This summit was responsible for the Agenda 21, a comprehensive blueprint of action to be taken for a sustainable future globally, nationally and locally. Agenda 21 addressed ways in which humans impact the earth, covering topics ranging from agriculture to biodiversity to hazardous waste to ecotourism. Soon after the Earth Summit, the terms education for sustainable development (ESD) and education for sustainability (EFS) emerged internationally, both of which recognized the social dimensions of ecological problems (Sterling, 2004).

Education for Sustainable Development refers to learning that leads to human, social and economic development that is integrated with environmental concerns in a holistic interdisciplinary way (Hopkins, Damlamian, \& Lopez Ospina, 2004). 
Education for Sustainable Development (ESD) has been largely concerned with learning that is in line with the goals of sustainable development, wherein technological and institutional development meet present and future needs (Scott \& Gough, 2004). Similarly, Education for Sustainability (EFS) has been defined as a process of societal transformation that prepares everyone to "care for the planet by respecting justice, local identity and fundamental requirements of well-being" (O'Riordan, 2004, p. 34).

In the early 1990s, the Talloires declaration was also developed. Created by international university leaders, this declaration aimed to define and promote sustainability within postsecondary education. The Talloires declaration, a voluntary action plan for building a sustainable university states, “... universities bear profound responsibilities to increase the awareness, knowledge, technologies, and tools to create an environmentally sustainable future" (Calder \& Clugston, 2003, p. 6). Other international declarations followed the Talloires declaration but nearly all shared the following themes: promoting sustainability in all disciplines; researching sustainability issues; the "greening" of university operations; increasing inter-university cooperation; forming partnerships with government, non-governmental organizations and industry; and addressing the moral obligations of postsecondary education to work for a sustainable future (Calder \& Clugston, 2003).

Despite these strides, leaders at the 2002 World Summit on Sustainable Development (WSSD) in Johannesburg noted that there were few signs of concrete global progress toward the reorientation of education for sustainability, as had been 
called for in the Rio Summit's Agenda 21 (Sterling, 2004). The WSSD, therefore, called for "a deeper, more ambitious way of thinking about education" (UNESCO, 2002, p.8). The United Nations has since declared 2005-2014 the decade of Education for Sustainable Development and seeks to "integrate the principles, values, and practices of sustainable development into all aspects of education and learning....[to] encourage changes in behavior that will create a more sustainable future in terms of environmental integrity, economic viability, and a just society for present and future generations" (UNESCO, 2008, p. 1).

Some colleges and universities have stepped up to this sustainability challenge and are pledging to create change at their institutions. Over 350 universities in over 40 countries have signed the Talloires declaration (Association of University Leaders for a Sustainable Future, 2007). Recent examples of progress include: the creation of sustainability coordinator positions; the building of LEED (Leadership in Energy and Environmental Design) certified classrooms, research centers, and dormitories on campuses; and the development of alternative energy sources including the use of solar arrays, wind power, and biodiesel (AASHE bulletin, 2007). As of May 2008, 526 postsecondary institutions had signed the American College \& University Presidents' Climate Commitment, an agreement to develop comprehensive plans for achieving climate neutrality (Bodner, 2008). In a 2008 report, 65 percent of universities had written sustainability commitments or planned to do so, compared with only 43 percent in 2001 (Carlson, 2008). 


\section{Sustainability: Teaching and Learning}

While there has been some progress toward enhancing the sustainability of campus operations, postsecondary institutions have been much slower to tackle the academic side of sustainability and to address important questions about how teaching and learning can be re-oriented towards sustainability, particularly at the undergraduate level. A 2008 survey of colleges and universities found that teaching and learning about sustainability has been in decline since 2001 (Carlson, 2008). This may be because sustainability, which focuses on broad, systems-oriented approaches to social and ecological problems, does not easily fit into sharply divided disciplines (Carlson, 2008).

According to Sterling (2004), a common way to address sustainability thus far has been to simply attach it to existing educational systems. Thus, universities have seen the development of sustainability programs within specific departments such as business, engineering and architecture. While this is a good starting point, sustainability needs to be central to learning in all disciplines. Sterling (2002) posits that more education (particularly factual and conceptual learning) is not necessarily the answer to the crisis. Rather, it is time for a change of educational culture toward one that will enable a transition to a more sustainable world by shifting to holistic, systemic, connective and ecological ways of thinking and learning (Sterling, 2002).

This shift requires moving from teacher-centered and transmissive models of education to models that are learner-centered and transformative. A traditional form of postsecondary education in which expert professionals transfer content to willing 
students is not sufficient for teaching sustainability issues because of their complexity and deeply challenging nature (Sterling, 2002). Further, best practices in adult education point to evidence that adults learn best when engaged in learning through relationship and dialogue (Vela, 1994). Adult learners will also improve their knowledge, attitudes and skills in relationship to their life experience (Knowles, 1970).

Traditional hierarchical relationships found in teacher-centered or transmissive learning do not lend themselves to acknowledging and utilizing learners' own experiences (Vela, 1994). Effective adult education optimizes learning through safe and trusting environments where learners are respected and relationship building is emphasized. Effective learning must also include engagement and action with opportunities for reflection, attention to the affective and emotional aspects of learning, and application of what is learned (Vela, 1994). Further, if learners are to be prepared to engage in social change, they must have learning experiences that are more community-referenced (Cress, 2004).

A number of educators have suggested that teaching and learning that is focused on sustainability must rely less on the transmission of information and more on relationship, process and context. Orr (2004) suggests that postsecondary education must emphasize learning that teaches citizenship in the biotic community and the responsibility of human relationships within that community. According to Rauch (2004), a sustainable society will "only be achieved through a social process of searching, learning and shaping" (p. 150). He posits that contradictions, moral 
dilemmas and conflicting goals are inherent within sustainability and must be constantly renegotiated in a process of discourse between participants. Jickling (2004) also argues that we must enable students to "debate, evaluate, and judge for themselves the relative merits of contending possibilities" related to sustainability (p. 137). However, effective sustainability education will not take place within a traditional teacher-centered or transmissive form of learning. A shift in teaching and learning practices will be necessary.

\section{Reasons for Slow Progress}

Dominant cultural and economic paradigms significantly influence the implementation of sustainability within academia. One of the reasons there has been little global progress towards sustainability may be because the major causes of global environmental and socio-cultural degradation can be linked to patterns of growing consumption and production instituted by industrialized countries (International Forum on Globalization, 2007). These patterns are often aided by less industrialized nations of the Global South who are pressured through sizeable foreign debt and "free" trade agreements to maintain a system of cheap labor and to ignore environmental regulations so that multinational corporations can continually increase their profits. The International Forum on Globalization (2007) has described the double bind of economic globalization and sustainability this way:

...as long as global institutions and national governments simultaneously attempt to pursue economic globalization, no goals for a healthy planet, or equity and justice for people, are remotely achievable. Globalization, trade and investment designs and structures reinforce a model of development - centered on free trade, hyper economic growth, and export-oriented production - which is inherently unsustainable in ecological and social terms. They also destroy viable localized 
and regional systems that may have the greatest long-term promise for future sustainability (p.1).

Any form of postsecondary education that is focused on sustainability will therefore need to take into account its embedded relationship within the current global economy which relies on multinational corporations, export economies, and destructive resource extraction. Indeed, the dominant educational paradigm prepares learners to be successful within and to perpetuate unsustainable economic and social systems (Orr, 1992).

Peters (2008) notes that a lack of ecological literacy and a continued reliance on progress and technology on the part of academics is hampering sustainable change. Educators must begin to acknowledge their role in preparing learners to enjoy the benefits of these endeavors without questioning them or understanding the effects of their daily actions, thereby advancing the ethic of mass production and overconsumption that has led to the destruction of many ecosystems and communities. Furthermore, most students carry these dominant paradigms with them into and throughout their postsecondary learning experience. These dominant cultural and economic paradigms contribute to the slow progress of sustainability in postsecondary teaching and learning.

Additionally, another factor that affects the implementation of sustainability education within postsecondary settings is that the concept of sustainability is often unclear. Leal Filho (2002) states that within postsecondary education, "there are still some people who cannot define [sustainability] and describe what it means" (p. 21). Educators not only struggle with vague and conflicting definitions of sustainability 
(Clugston, Calder \& Corcoran, 2002), but with the complexity involved in implementing sustainability education (Leal Filho, 2002). There is still a lack of consensus about what end goals should look like, and a lack of prestige or support attached to this issue (Calder \& Clugston, 2003).

Similarly, in their research about academics' understandings of sustainability across a variety of disciplines, Reid and Petocz (2006) concluded that efforts to incorporate education for sustainable development into academics were challenged by a lack of shared understanding of and language for discussing sustainability issues, and in some cases a lack of enthusiasm for incorporating these issues into courses. Nevertheless, as Sauvé (2004) notes, consensus is not necessarily a precondition of collaborative work towards sustainability education.

\section{Towards Education as Sustainability: A Transformational Process}

Despite slow progress, there is undoubtedly a need to integrate sustainability teaching and learning into postsecondary education. However, developing effective sustainability education will require shifting from a traditional transmissive teaching and learning process to a transformational learning process. Kitano (1997) posits that the process of change in teaching and learning within academic courses can be viewed as a movement through three levels: exclusive, inclusive or transformative. An exclusive course, "presents and maintains traditional, mainstream experiences and perspectives on the discipline" (Kitano, 1997, p. 24) and is mainly directed by the instructor with little focus on learner participation. This could be considered teachercentered or transmissive learning. 
An inclusive course adds alternative perspectives to traditional ones and the instructor uses a variety of teaching methods to support active and participatory learning. Students engage in critical thinking and social issues are processed in the classroom. An inclusive pedagogy could be considered student-centered teaching and learning.

In contrast, a transformed course is one that "reconceptualizes the content through a shift in paradigm or standard" (Kitano, 1997, p. 24). In such a course the students and instructor learn from each other, concepts are analyzed against personal experiences, and power relationships are considered. Learning is participatory, focuses on diverse perspectives, reflection, and the personal development and growth of the learner. The learning experience may be structured on issues-oriented approaches and action-oriented projects (Kitano, 1997).

Sterling (2002) advocates for transformed sustainability teaching and learning and makes a point to distinguish between education about or for sustainability and education as sustainability. Education about sustainability is simply an awareness raising exercise or theoretical discussion (McKeown \& Hopkins, 2003), and as such may be considered an exclusive pedagogy (Kitano, 1997). As an inclusive pedagogy (Kitano, 1997), education for sustainability emphasizes learning for change (as can be seen in the "greening" of schools and colleges) and involves some reformation of the existing paradigm to reflect sustainability. However, this type of pedagogy does not necessarily question hidden values of the dominant cultural and economic paradigm such as modernism and mechanism. Furthermore, learning for sustainability may not 
recognize what the learners bring to the learning experience and tends to dwell more on prescribed and deterministic knowledge (Sterling, 2004).

Alternatively, education as sustainability is a transformative pedagogy (Sterling, 2002). While this position incorporates education about and education for sustainability, education as sustainability emphasizes the process and quality of learning (Sterling, 2002). The process of education as sustainability is that of learning as change and therefore involves a shift in paradigms and values. Education as sustainability transforms learners' values and perspectives so that they are able to embrace sustainability as a new paradigm or a lens through which to view the world and make change.

The transformative pedagogy of education as sustainability engages the whole person, and embraces emergence, ambiguity, uncertainty, creativity and participation (Sterling, 2002). The learning process is dynamic, and rather than engaging just the mind, the process engages the whole person. Instead of looking at the world as a series of linear events with clear cause and effect relationships, education as sustainability embraces a relational paradigm, noticing systemic interrelationships, and honoring what emerges from the learning process that may not have been planned or expected. Instead of starting with all the answers, this process encourages ambiguity and uncertainty. Instead of being teacher-centered, the process of education as sustainability requires creativity and participation from learners. According to Sterling (2004), in education as sustainability the context of learning is also seen as sustainability. Sterling (2004) refers to education as sustainability as an "ecology of 
learning," (p. 70) which emphasizes the development of the capacity, integrity, and resilience of learners.

In order for education as sustainability to be effective, teaching and learning strategies must become more student-centered and, indeed, transformational. According to Mezirow (2000), a transformational learning process involves making sense of one's values, beliefs and assumptions, and creating meaning systems that are more inclusive, open, capable of change, and reflective. Transformational learning is important part of education as sustainability because as Mezirow (1992) notes, transformational learning leads to "alliances with others of like mind to work toward effecting necessary changes in relationships, organizations, and systems" (p. 252). The necessary transition from a transmissive teaching and learning process to one that is transformational is perhaps one of the greatest sustainability challenges faced by postsecondary education. Yet it is a challenge that must be met, considering the tremendous need for learning as change; learning that embodies a shift in paradigms and values, and ultimately, changes for a more sustainable future.

\section{Purpose and Significance of the Study}

Despite the challenges surrounding sustainability education at the postsecondary level, there remains a need for courses and programs to develop student leadership and citizenship for active change toward sustainability. Students may leave higher education with career preparation, but may be ill equipped with the knowledge or skills to address complex socio-ecological problems such as energy use and global warming, water pollution, affordable housing, land-use policy, deforestation and more. 
Students' learning experiences must allow them to develop the capacity to be able to understand and address complex sustainability problems holistically, the ability to ask critical questions and understand diverse perspectives, to participate in finding solutions, and to develop personal connections to the places in which their biological, social, and economic lives are grounded. Considering this tremendous need, how specifically can teaching and learning be reoriented towards education as sustainability within postsecondary settings? This dissertation seeks to answer this question.

A sustainability pedagogy that is applicable to any discipline, which takes an integrated and transformational approach to teaching and learning complex sustainability issues is critically needed. To this end, this dissertation offers the Burns model of sustainability pedagogy. This model of education as sustainability is discussed in greater detail in the next chapter, which will also provide the theoretical context and research background for this study. The purpose of this study is to: (1) explicate a pedagogical design based on the Burns model of sustainability pedagogy, and (2) examine the dimensions of the Burns model of sustainability pedagogy in relationship to student learning. 


\section{CHAPTER II \\ LITERATURE REVIEW \\ Introduction}

Teaching and learning sustainability in postsecondary settings is imperative for our future. Therefore, attention must be focused on developing an effective sustainability pedagogy. This pedagogy must include transformational approaches to teaching and learning complex sustainability issues so that learners will be prepared to engage in making change.

However, before addressing the proposed model of sustainability pedagogy, a review of relevant literature provides a conceptual framework and context for this model. First, the terms used in this dissertation are defined. Then, an examination of recent trends in postsecondary education and the goals of liberal education today supplies an important backdrop for sustainability pedagogy. Third, a review of teaching and learning in postsecondary settings shows that research supports the movement from transmissive models of learning towards student-centered learning and engaged pedagogies that have the potential to foster transformational change. Fourth, a review of studies related to teaching and learning sustainability is presented, showing that there is a lack of research in this area and a need for clarity and direction. The Burns model of sustainability pedagogy is then introduced, and a description of each of its five dimensions are discussed in detail. A number of learning theories provide important theoretical underpinnings for each dimension of this model of 
sustainability pedagogy including constructivism, critical theory, experiential learning, a critical theory of place, and transformational learning.

\section{Terms Defined}

"Sustainability education," "education for sustainable development" and "education for sustainability" are terms often used interchangeably and indeed reflect many of the same goals. "Sustainability education" is the term selected for this study to reflect education as sustainability. While the term "education for sustainable development" is an internationally recognized term and is currently the focus of the decade-long effort to reorient education toward sustainability (UNESCO, 2008), this term refers to a number of broad-based global educational goals which include: improving access to basic education; reorienting education to address sustainable development, developing public awareness and understanding; and providing training for all sectors of society. Since this dissertation focuses specifically on just one of these goals, reorienting teaching and learning within postsecondary courses, the term "sustainability education" better reflects this focus. Similarly, the terms "teaching and learning sustainability" or "sustainability pedagogy" will be used rather than "teaching and learning for sustainability." The term "sustainability pedagogy" refers to the process of teaching and learning sustainability.

Conceptual Framework

A Context for Sustainability Pedagogy: Recent Trends in Postsecondary Education The recognition of the importance of sustainability in postsecondary education has taken place within a larger context of change for postsecondary education in the 
last thirty to forty years. For one, postsecondary education has seen a dramatic expansion of student numbers since the 1970 s. While there were only approximately six and a half million undergraduate students in the U.S. in 1970, these numbers rose to over 15 million by 2005 (Institute of Education Sciences, 2008). By many estimates, undergraduate populations as a whole will increase again by 2.6 million by 2015 (Schroeder, 2003). According to the National Leadership Council for LEAPLiberal Education \& America's Promise (2007), 75 percent of high school graduates already enroll in college within two years of graduation, while 67 percent of students begin postsecondary education immediately after completing high school.

Within this climate of constant growth, postsecondary education has struggled to widen participation, increase flexibility, and increase diversity within its student bodies (Clouston, 2005). Augmented federal financial aid in recent years has fueled increases in ethnic and racial diversity within postsecondary education, which is expected to increase even more in the next five to ten years. According to Schroeder (2003), students today are "diverse, not only in terms of age, ethnicity, socioeconomic level, sexual orientation, and part-time or full-time status, but also in terms of expectations, attitudes, intellectual capabilities, and learning styles" (p.55).

This continued growth of an increasingly diverse postsecondary population has resulted in changes in teaching and learning. According to Hartley (2005), a mix of educational, political and economic pressures (including globalization) has resulted in an increased emphasis on employability skills such as teamwork, interpersonal relationships and critical reflection. Additionally, focus on student retention and 
participation has given rise to methods such as work-based learning and problembased learning which have the potential to enable active, participatory students with the necessary skills of critical analysis and lifelong learning (Clouston, 2005).

To further meet the needs of both diverse employers and students, some teaching and learning has moved beyond the classroom to embrace the flexibility of on-line coursework, international internships, and the civic education gained through service learning within local communities. As the demand for learning employable skills has increased, so too has the demand to know whether or not the desired outcomes are actually gained. In recent years, evidence of student learning outcomes has become a principal gauge of the effectiveness of postsecondary education (Council for Higher Education Accreditation, 2007).

In 2005, the Association of American Colleges and Universities (AAC\&U), an organization that works with over a thousand universities in the United States and focuses solely on the quality of student learning, launched a decade-long initiative, termed Liberal Education and America's Promise (LEAP): Excellence for Everyone as a Nation Goes to College. This initiative spells out learning outcomes and guiding principles for college students that are intended to meet the challenges of the new global century. In the report, "College learning for the new global century," The National Leadership Council for LEAP (2007) defines liberal education as “a comprehensive set of aims and outcomes that are essential for all students because they are important to all fields of endeavor. Today, in an economy that is dependent on innovation and global savvy, these outcomes have become the keys to economic 
vitality and individual opportunity" (p. 14).

The LEAP report goes on to identify essential learning outcomes, which are intended to "prepare learners as fully as possible for the real-world demands of work, citizenship, and life in a complex and fast-changing society" (p. 14), and include the following four key areas: (1) knowledge of human cultures and the physical and natural world; (2) high-level intellectual and practical skills; (3) an active commitment to personal and social responsibility; and (4) the demonstrated ability to apply learning to complex problems and challenges. These learning aims, the National Leadership Council argues, must be incorporated within general education, but also within all majors. While these outcome goals share similarities with the goals of sustainability education, the purpose of liberal education in postsecondary settings is not yet focused specifically on sustainability, as the primary LEAP goals demonstrate (The National Leadership Council for LEAP, 2007). Rather, the focus is on preparing learners to be effective and responsible citizens within today's global economic system.

Postsecondary sustainability education is emerging within a context of growth, diversity, flexibility, and focus on learning outcomes that meet the needs of a complex global society. Within this growing population of diverse postsecondary learners, there is a need for teaching and learning that specifically addresses complex global and local sustainability issues. There is a need for a pedagogy that brings sustainability to the forefront of postsecondary education.

Teaching and Learning in Postsecondary Education: Assumptions and Research Moving postsecondary teaching and learning towards sustainability will require 
a shift from traditional assumptions about teaching and learning. Within postsecondary education, the most basic assumptions about teaching and learning largely remain unchallenged. One of the strongest beliefs is that students are expected to absorb knowledge from someone who is wiser, be able to show that they've absorbed this information, then move on (Smith, 2004). Otherwise known as the "banking" method of education (Freire, 1970), this deeply embedded positivist perspective relies on the postulation that professors are experts who possess certain knowledge to be passed on to students. Student success is measured by the mastering of information or skills that have been pre-determined (Galbraith, 1998).

This basic assumption about teaching can even be seen in the design of college classrooms. The design of learning spaces are mostly guided by the idea of "facultycentered instruction in the oral tradition; that is, content delivery via lecture" (Kopp, Seestedt Stanford, Rohlfing, \& Kendall, 2003/2004, p. 1). However, teacher-centered education, and the traditional lecture style teaching practice that most often accompanies it, contradicts much of the research about how people learn best. It also ignores the increasing diversity of student populations and the needs of diverse learners (Smith, 2004). If we are to move towards learning that transforms all students and prepares them to make sustainable changes, basic assumptions about teaching and learning must be examined, and pedagogies of engagement must be implemented.

A movement towards student-centered learning is necessary if there is to be any progress toward addressing real sustainability issues. Student-centered learning challenges some of the long-held pedagogical beliefs and places learning, rather than 
teaching, at the center of education. According to Harden and Crosby (2000), studentcentered learning focuses on what students do, rather than on what the teacher does, and emphasizes action on the part of the student. Moving away from teacher-centered instruction towards learner-centered practice requires a shift in assumptions about learning and new pedagogies of engagement.

Pedagogies of engagement have broad applications for student-centered learning in postsecondary settings (Smith, 2004). For example, active learning is one strategy for increasing student engagement and enhancing learning. Active, experiential learning is also a central element in transformational learning (Mezirow, 2000) and therefore is important in a shift towards education as sustainability.

In one study of faculty across the United States, MacGregor, Cooper, Smith, and Robinson (2000) found that instructors who used active learning activities in their courses did so because they believed that these activities result in long-term learning, contribute to meaningful student engagement, and promote the formation of a student community. Research shows that the degree of retention and retrieval of knowledge is also increased by active learning (Yazedjian \& Boyle Kolkhorst, 2007). Umbach and Wawrzynski (2005) found that students on campuses where faculty used active learning had greater levels of social development, engagement, general knowledge, and practical proficiencies than students on campuses that did not incorporate active learning.

According to Yazedjian and Boyle Kolkhorst (2007), other useful strategies that have been shown to be effective active learning tools include large group discussions, 
brainstorming, debates, and subgrouping techniques such as write-pair-share activities. Additionally, faculty who implemented small-group work reported increases in critical-thinking abilities, conceptual understanding, attendance, and student confidence (MacGregor et al., 2000). These strategies enhance student learning by not only providing opportunities to become active rather than passive learners, but also by allowing for social interactions within the classroom (McKeachie, 1999). Social interaction is important because opportunities to interact with other students are beneficial in the processing of course content (Davis, 1993). According to bell hooks (1994), this interaction with other students is essential because of the transformational process that is possible when students dialogue with one another as a community of learners.

Active and student-centered learning strategies transform students from passive recipients to active participants in learning. This active participation is key to preparing learners to not just understand, but to take action to address sustainability problems. According to studies by Ebert-May and Brewer (1997), and Springer (1997), students who participated in active learning activities, compared to those who received traditional instruction, appeared to have greater abilities to connect abstract concepts to real world and practical applications.

Active, real world learning applications are embodied by strategies such as problem-solving scenarios, community-based learning, and service-learning. According to Dresner and Seamans Blatner (2006), the ability to solve complex problems is an important set of skills for understanding the relationships between 
environmental systems and the social and political contexts that surround them. Thus, active learning through problem-solving is essential to sustainability learning.

Battistoni (2001) also identified participation and communication skills as critical for students to practice if learning is to foster civic engagement. Participation and enhanced communication skills can be gained through active student-centered learning and service within the local community. One study of service-learning outcomes showed that interacting with people in the community was a positive predictor of cognitive learning, intellectual development, civic engagement, spiritual values, and community impact (Steinke, Fitch, Johnson, \& Waldstein, 2002).

According to Moore (2005) many alternative (non-teacher centered) pedagogies are already being practiced at universities around the world. Based on her research about how academic institutions can shift toward sustainability education, Moore (2005) identifies a number of recommendations for infusing sustainability into the classroom including more interactions between students promoted through student cohorts, peer tutoring, and collaborative group work. Moore (2005) contends that a shift toward more student-centered learning, reflective learning, problem-based learning, and collaborative group work is desirable because these pedagogies share the goals of learning through inquiry, experience and reflection.

On the whole, teaching and learning within postsecondary education must move away from transmissive teacher-centered approaches, and embrace pedagogies that are student-centered and promote active learning for transformation. In order for students to actually be prepared to address complex sustainability issues, they will need to have 
hands-on, collaborative opportunities to learn. Research supports the idea that active, experiential and reflective learning that is based in the community leads to engaged learners with increased civic responsibility. Therefore, there is a need for a sustainability pedagogy that exemplifies active student-centered learning with the goal of preparing students to engage in sustainability issues.

\section{Recent Research about Teaching and Learning Sustainability in Postsecondary Education}

Since teaching and learning that focuses on sustainability is a new area of study, there is little research and few published examples of research on teaching and learning sustainability specifically. We don't yet know much about how sustainability is taught and learned at the classroom level, and what the effects are on learners. According to Corney and Reid (2007), research about the classroom-related practice of sustainability is still limited and research is needed to provide more empirical evidence about the nature of teaching and learning in sustainability education. The following, however, are some initial examples of research that provide some insight into the practice of teaching and learning sustainability in postsecondary settings.

Alvarez and Rogers (2006) write about their experience teaching sustainability in Australia. They point out that much of the current teaching about sustainability focuses on definitions of sustainability, or on establishing what is unsustainable and how to make practices more sustainable using lists and indicators. Over time, however, their approach to teaching sustainability became an interpretive one, in which students were exposed to conversations with people within a specific community in order to make sense of sustainability. Through this process, Alvarez and 
Rogers assert that sustainability became "a complex set of discourses and practices that interweave through and over people's lives rather than a check list of appropriate practices" (p. 1). By getting out of the classroom, students became more aware of and involved in the messy and complex reality of sustainability, and instructors became facilitators of a process, rather than teachers of sustainability as though it had a fixed definition. This perspective of teaching sustainability as discourse, the authors argue, is a more comprehensive way of understanding sustainability because students are confronted with complexity, a more accurate reflection of the multiple ways that sustainability is interpreted and developed in real lives in a specific place.

Another recent case study describes how a college partnered with a local EcoVillage to teach sustainability (Allen-Gil, Walker, Thomas, Shevory, \& Elan, 2005). Through the development of four sustainability courses, Ithaca College developed place-based and project-based sustainability learning opportunities in partnership with EcoVillage at Ithaca, an intentional community dedicated to exploring and modeling innovative approaches to ecological and social sustainability. The learning approaches associated with these courses included: learning through dialogue, community and collaboration; student-centered reflective learning and critical thinking; place-based learning through direct observation and interaction with natural systems and human communities; learning by doing and serving; systems learning; and learning through play and creativity.

The authors report that the development of these courses in partnership with EcoVillage Ithaca has led to increased student involvement in sustainability courses 
from a variety of disciplines, as well as the development of faculty workshops and grants for sustainability learning projects. Additional outreach and education about these courses has resulted in greater participation in sustainability efforts both on campus and within the local community, suggesting that campus-community sustainability partnerships can have wide reaching ripple effects. While this study does document some outcomes of this project and how sustainability learning occurred, it does not provide information about how the courses were designed or implemented.

Another study indicates that students in a university setting grew to understand and value sustainability through a variety of teaching methods (Davis, Edmister, Sullivan \& West, 2003). This research was conducted at two postsecondary institutions, which were nationally recognized for their efforts to integrate sustainability into both academic and operational functions. The authors examined the participants' understanding of concepts of sustainability, and the methods used to incorporate these concepts into teaching. This study found that participants' understanding of sustainability was general and that students tended to focus more on the ecological aspect of learning sustainability.

Faculty's understanding of sustainability, however, focused on not only ecological aspects, but on the social and economic aspects of sustainability as well. Methods most commonly used to incorporate sustainability in teaching were class readings, discussions, class projects and case studies. Problem-based field trips, speakers and storytelling were also used but less frequently. While this study does 
provide a general overview of methods used to teach sustainability, it does not take into account the context and content of these courses, or the complexity of sustainability teaching and learning.

A case study conducted at the University of Plymouth in England sought to examine lecturers' beliefs about appropriate pedagogies for accommodating sustainable development across diverse disciplines, which may not all have obvious sustainable development foci (Cotton, Warren, Maiboroda, \& Bailey, 2007). This study sought to answer the following questions, "What are lecturers' current understandings of sustainable development? What are their current attitudes towards sustainable development? What are their beliefs about incorporating sustainable development into the higher education curriculum?" (p. 6).

In response to the third question, the results of an online survey and semistructured interviews indicated that $55 \%$ of respondents agreed or strongly agreed that sustainable development was central to their teaching interests and over $50 \%$ of respondents predicted including elements of sustainable development in their teaching. A number of respondents answered that because of the complex and controversial nature of the sustainability, they felt it demanded non-transmissive teaching methods. Others noted that teaching ESD required experiential learning and practical methods such as problem-based learning and hands-on learning. A small number of respondents linked teaching sustainable development with empowering students to take action (transformative education). 
In this study, as in the previous example, the findings indicate a predisposition towards understanding ESD within the context of environmental issues as compared with social and economic issues. This study indicated that sustainable development is both important and relevant to scholars from across disciplines, but the researchers note the "obvious challenges of translating principled or rhetorical support into teaching and learning practice" (Cotton, Warren, Maiboroda, \& Bailey, 2007, p. 592). Many of the teaching methods suggested by respondents for teaching ESD, such as discussion, role-play, and simulations, mirror current trends of good practice in postsecondary education and are not necessarily specific to sustainability education. While this study offers some interesting insight into faculty attitudes and willingness to teach sustainability, it considers pedagogy only in terms of teaching methods, without taking into consideration course design, or the context or process of learning sustainability.

On the whole, research that is focused on teaching and learning sustainability at the postsecondary level is very limited and remains rather conceptual. This research does not indicate much about how sustainability teaching and learning is designed or implemented, and whether or not learners actually become prepared to take action to address sustainability challenges in their community places. However, it is imperative that postsecondary learners be prepared with the knowledge, skills, and values to be able to address complex ecological and social problems in the places where they live and work. More research is needed about how sustainability teaching and learning can be effectively implemented in postsecondary settings. In fact, a more clear 
understanding of what it means to teach sustainability would be a good first step. To this end, a model of sustainability pedagogy is proposed that offers more than just teaching methods for sustainability. Rather, the Burns model of sustainability pedagogy builds on postsecondary trends toward transformational learning, but contributes a unique and comprehensive approach. The following provides an overview of this model and an exploration of its key elements.

The Burns model of sustainability pedagogy: An Overview of Goals

While the term sustainability pedagogy may be new, many writers and educators of sustainability, environmental science, ecology and environmental education have articulated one or more of the various aspects of teaching and learning sustainability. The Burns model is a more comprehensive and holistic approach to sustainability pedagogy.

Five key dimensions constitute the Burns model of sustainability pedagogy and help to further articulate the goals of this pedagogy. These are: (1)Content; (2)Perspectives;(3)Process; (4)Context; and (5)Design. A visual depiction of this model and its dimensions is displayed in Figure 1. 
Figure 1. The Burns model of sustainability pedagogy.

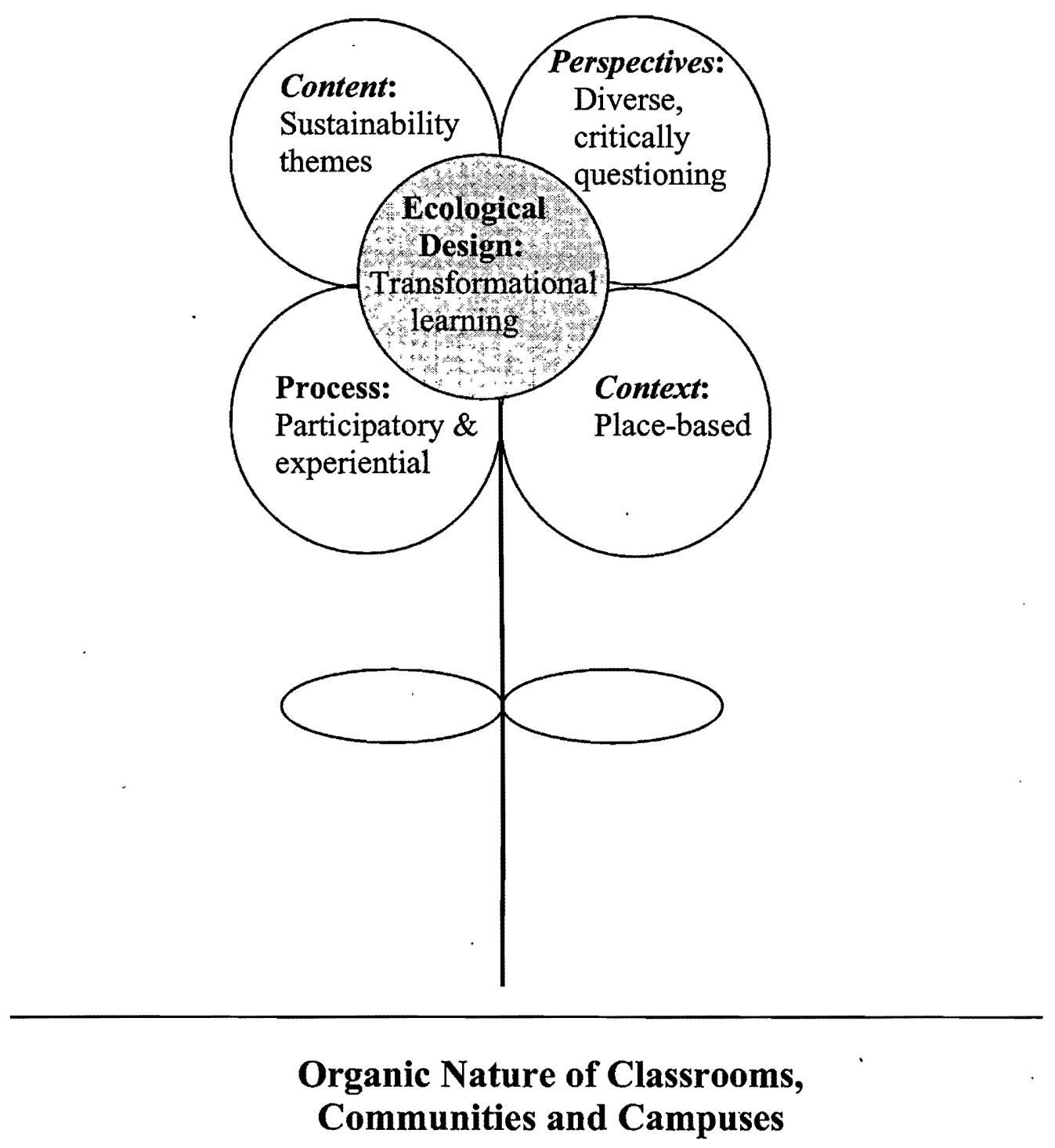

This model of sustainability pedagogy specifically builds on the pedagogical strategies for making sustainability a foundation of learning and practice as described by Cortese (2005). The following pages provide more detailed description of the Burns model of sustainability pedagogy which is an ecological teaching Design that brings together Content that is thematic and multidisciplinary, Perspectives that are 
diverse and critically question dominant paradigms and practices, a Process that is participatory and experiential, and a Context that is place-based.

This sustainability pedagogy model holds multiple goals for learners. It seeks to: (a) increase learners' systemic understanding of complex sustainability issues (Content); (b) provide learners with opportunities to think critically about dominant paradigms, practices and power relationships and consider complex ecological and social issues from diverse perspectives (Perspectives); (c) enhance learners' civic responsibility and intentions to work toward sustainability through active participation and experience (Process); (d) increase learners' understanding of and connection with the geographical place and the community in which they live (Context); and (e) utilize an ecological course design process that intertwines the other four dimensions to create transformative learning experiences (Design).

The ultimate purpose of the Burns model of sustainability pedagogy is to empower and inspire learners to be able to solve complex problems and make changes that regenerate and sustain places and communities.

The dimensions and goals of the Burns model of sustainability pedagogy are in line with UNESCO's Guidelines and Recommendations for Reorienting Teacher Education to Address Sustainability (2005). In this document, UNESCO recommends the following:

3C.1 Require interdisciplinary coursework on sustainability for student teachers and make materials available for student teachers on local and global sustainability issues.

3C.2 Demonstrate pedagogical techniques that foster higher-order thinking skills, support decision-making, involve participatory learning, and stimulate formulation of questions. 
3C.3 Emphasize to student teachers that citizenry in a sustainable community requires active participation and decision-making; challenge them to create ways to incorporate participation and decision making into their classroom procedure and curriculum.

3C.4 Discuss social equity (e.g., gender, racial, ethnic, and generational) with student teachers and identify ways in which the local community exhibits social tolerance, societal intolerance, equity, and discrimination.

3C.5 Request that student teachers analyze the mandated curriculum they will be teaching to identify topics and themes related to sustainability and those that are linked to local sustainability issues.

3C.6 Provide student teachers with opportunities to explore their own values and attitudes towards local sustainability problems and those of the surrounding region.

3C.7 Promote understanding of global sustainability in order to encourage critical thinking and decision making that influence personal lifestyle and economic choices... (p.43-44).

The following section explores each dimension of the Burns model in further depth, and delineates the links between the dimensions and related learning theories. The Burns model of sustainability pedagogy: Dimensions

\section{Dimension I: Content}

The first dimension of the Burns model of Sustainability Pedagogy is Content. Sustainability issues that are related to a course or discipline must become central to the learning in the course. The objectives of a course can be reoriented to sustainability in a multidisciplinary way through its Content. Sustainability must be addressed multidimensionally in order to take into account systemic relationships between the biological and cultural dimensions of life. The current Western mechanistic worldview and language typically cause us to perpetuate dichotomies such as local/global, humans/nature, cause/effect, and create categorizations such as political, economic, and social (Sterling, 2002). As a result, Sterling (2002) points out, "we often fail to see connections and patterns" (p. 16). 
In contrast, sustainability is concerned with recognizing relationships, patterns and dynamics, and maintains "a keen focus on the interdependence between humans and more than human world of beings, sensations and processes" (Fawcett, Bell \& Russell, 2002, p. 224). Smith and Williams (1999) emphasize that education must involve a cultural shift that takes into account "the ineluctable relationship between specific biosystems and culture" (p. 4). Similarly, Parajuli argues that the goal of sustainability is to "prepare human communities to live as members of the biosphere." (personal communication, May 15, 2005). According to Parajuli, this is "an active process of teaching and learning in which we cultivate knowledge, skills, feelings, values, and worldviews adhering to the principles of ecology and we redesign our livelihoods (social, economic, political and educational systems) accordingly" (personal communication, May 15, 2005). Learners must be introduced to a holistic understanding of pertinent issues because, as Dresner and Seamans Blatner (2006) note, “...policy decisions reflect social values, political considerations, psychology, economics, and global processes" (p. 214). In order to be equipped to understand and make decisions about important issues that face local communities, students must learn about these issues in a non-fragmented manner. In order to fully understand and address the interrelated issues we are facing today, sustainability Content must therefore provide a multidisciplinary approach.

While the disciplinary nature of most postsecondary education is a challenge to using a multidisciplinary approach, the goals of the Burns model of sustainability pedagogy could initially be achieved by structuring Content around a salient 
sustainability theme(s) within an existing course. Choosing a thematic approach can be an effective way to teach sustainability in a multidisciplinary way. For example, stream restoration seminars in geography courses have focused on sustainable relationships between people, places, and environments (Moran, 2002).

Education for livable cities has also been used as a theme in which students explore sustainability through personal experience, observation, action and reflection (Pruneau, McLaughlin, Langis, \& Gravel, 2002). A livable cities theme could be applied within a variety of disciplinary courses with emphasis on elements such as transportation, energy use, housing, community building, watersheds, or land use. The food system can also be used to teach sustainability within a wide array of disciplines (Harmon, 2002) such as English, Economics, or Sociology.

Additionally, sustainability goals could be achieved by combining courses from various disciplines into joint courses or clusters that focus on a single theme or issue from various perspectives with a community-based learning component. For example, a required sustainability colloquium at one institution is co-taught by professors from across the institution with a focus on a sense of place, ecological literacy, and a sustainable future (Bogan, 2002). An urban sustainability course in Toronto uses a cross-disciplinary focus with experiential learning opportunities (Savan \& Bell, 2002).

Sustainability Content may be applied to a course in any discipline, using a sustainability theme that is applicable to the discipline or course. However, in the Burns model of sustainability pedagogy, the Content is just one element of five. 
Rather than simply providing information about sustainability, or tacking sustainability Content onto other disciplinary content, whatever is to be learned about sustainability will be accomplished in relationship with and through the other dimensions of the pedagogy including the Perspectives, Processes, Context, and Design of the course. While the learning objectives of a course may contain specific sustainability Content (information, issues, perspectives, beliefs, skills, and values to be gained), this Content cannot be separated from the other elements of the pedagogy.

Effectively reorienting a course to incorporate sustainability Content will require an educator to begin with what learners already know and believe about sustainability, and then help them to build a stronger understanding of sustainability issues. Constructivism is thus a learning theory that is embedded in this model of sustainability pedagogy. Constructivism recognizes that knowledge is not just passively received, but that it is actively built up by the learner (Ernest, 1993). Constructivists believe that learners do not learn through passive absorption of knowledge (Philips, 2004), but that knowing is based on previously constructed knowledge, "the building up of structures from pre-existing pieces..."(Ernest, 1993, p.2). Thus learners do not enter the learning environment as blank slates, but come with a whole range of previously constructed knowledge, feelings, attitudes, and biases.

Perhaps most relevant to sustainability pedagogy is social constructivism, which contends that while people are formed by their own individual learning processes, their knowledge is also constructed through interaction and conversation 
with others (Ernest, 1993). Vygotsky (1978) argues that knowledge is constructed through social and interpersonal interactions, influenced by culture and societal contact. Longino (1990) contends that knowledge cannot be conceived of in a wholly individual manner, because the individual learner cannot be stripped of interests, biases, and other socially determined traits. Thus, knowledge is constructed by an "interactive, dialogic community" (Longino, 1993, p. 112). In addition, the construction of knowledge is an active process, either mentally, physically or both (Philips, 2004). This active process can be carried out by groups or communities (Nelson, 1993).

In order to learn new Content related to complex sustainability issues, learners must be able to connect new knowledge to previous understanding, and construct new meaning within a complex socio-cultural discourse. Sustainability Content is thus constructed within relationship to other learners. Educators must provide learners with opportunities to interact with each other and discuss sustainability Content, including how what they are learning relates to their previous experience and knowledge about sustainability. In order for sustainability Content to be learned effectively, learners must be able to construct meaning through relationships. These relationships will, in turn, challenge students' current views and help them to be able to consider multiple Perspectives on sustainability issues.

\section{Dimension II: Perspectives}

A second dimension of the Burns model of sustainability pedagogy is that diverse Perspectives must be incorporated into the design of a course. When 
incorporating sustainability Content into a course, diverse Perspectives should be included in order to provide multiple ways of understanding a sustainability issue. This includes questioning and reflecting on dominant ways of seeing the world. Cortese (2005) posits that doing so requires reflection on the systemic causes of unsustainable practices, noting that in a world where physical, social, ecological and economic impacts are often largely invisible, it is important to make these impacts visible. By questioning and examining dominant ways of seeing the world, sustainability pedagogy recognizes that many aspects of ecological crises can be attributed to human behavior and are cultural in nature (Bowers, 1999). Without questioning and critiquing the underlying cultural assumptions and economic and power relationships that create unsustainable and harmful practices, there can be little hope of change.

For example, if a sociology course adopted the theme of global warming to teach sustainability, it would be important to reflect on dominant systems such as driving cars, the global production and shipping of food and goods, and coal-burning energy production which contribute to global warming. These systems, while causing major ecological damage, require cultural acceptance and daily participation by millions of people. Learning about global warming would require examining the underlying causes and assumptions of dominant patterns and practices such as reliance on continual economic growth, nonrenewable resources, and the maintenance of huge social inequities. Learning about global warming would also include listening to Perspectives that provide alternatives to these dominant practices. This may include 
inviting speakers such as a bicycle transportation advocate, or a business owner of a service or product that is produced locally and sustainably. Visiting an alternative energy project such as a wind farm or even a small-scale project such as a home with a micro-hydro turbine or solar panels would provide another Perspective.

In order to question assumptions and power relationships, it is important for learners to be introduced to and consider a variety of diverse Perspectives. Problems within local communities and places are complex and not easily understood from a single perspective. According to Dresner and Seamans Blatner, (2006) the types of problems that are routinely encountered in life are fragmented and therefore require the learner to consider information about the problem, and adjust perceptions about the problem as more information is gathered.

Many Perspectives are therefore needed in order to interpret the information, and there is no single right answer. Dresner and Seamans Blatner (2006) posit, "problems possess multiple solutions and multiple criteria for evaluating possible solutions, and require students to engage in a cycle of problem definition, redefinition, and using multiple problem representations" (p. 214). This requires learners to identify multiple stakeholder Perspectives, positions, and preferred solutions. Cortese (2005) suggests that including a variety of less-heard Perspectives including intergenerational, multi-cultural, local and ecological Perspectives will be important to the process of understanding local issues. Considering diverse Perspectives can also be applied within the classroom, where there may be diverse learners who can provide unique and underrepresented Perspectives. 
Incorporating diverse Perspectives into a course may be accomplished in a variety of ways. For example, in a business course that is using the theme of sustainable entrepreneurship, students could be introduced to a variety of Perspectives through texts and speakers. Texts with examples of people who started sustainable business, and speakers such as an indigenous craftsperson, or an elderly person experienced in sustainable household economies could provide valuable Perspectives. Hearing from a variety of Perspectives, especially those that are not typically heard in academia, allows learners to gain a broad understanding of sustainability.

The Perspective dimension is rooted in critical theory, which is essential to the Burns model of sustainability pedagogy. Critical theory contends that educators help learners discover the moral and political dimensions of a just society and the means to create it (Giroux, 1988). A critical approach to sustainability pedagogy is key because it centers on naming and exposing mechanisms of power in order to find ways to resist them (Fenwick, 2000) and attempts to create education in which students are reflective and active agents of their own learning, thus preparing them to be change agents for a sustainable world. This kind of learning requires an environment in which there is adequate time for discussion and reflection on diverse Perspectives. It also requires that educators acknowledge the Perspectives and experience that learners and community experts bring to the learning experience. Freire (1998) proposes that learners should be engaged in "continuous transformation through which they become authentic subjects of the construction and reconstruction of what is being taught, side by side with the teacher, who is subject to the same process" (p. 33). In this kind of 
learning environment, learners can develop the skills, relationships, and confidence needed to actively make changes in their lives and work.

Critical theory has several other important characteristics that serve to help learners to understand diverse Perspectives within their communities and to be prepared to act for change. While critical theory highlights ways of knowing that arise from socially marginalized positions, such as those of women, indigenous peoples, or working class people, learners are also encouraged to question their own contexts and encounter the realities of racism, sexism, classism, and anthropocentrism. By understanding the power relationships embedded in diverse Perspectives, learners also understand how personal feelings related to sustainability issues, such as despair and conflict, are shaped by historical and cultural dynamics (Fenwick, 2000).

Merchant (1992) advocates that learners start from their own family perspective and history in order to explore the marginalization of non-dominant paradigms. She asks learners the following questions:

What large social or economic movements have shaped your family's lives? How did your family use land and relate to nature? What historical forces (immigration, urbanization, social mobility or educational opportunities) have helped to create your own economic position? What environmental values have you developed as a result? Have you experienced sexism or racism in your daily life? (p. 2-6).

According to Merchant (1992) pondering such issues can bring awareness about "deep seated contradictions in the ways different classes of people use the land" (p. 2), and help learners understand how their own gender or economic class is linked to sustainability issues. Merchant (1992) posits that understanding how we are 
imprinted with social patterns (such as racism, sexism, classism and anthropocentrism) is key to understanding society.

This kind of critical questioning and exploration of learners' personal connections to power relationships could be explored within sustainability themes in many kinds of courses. For example, in a literature course focused on the theme sustainable communities, students could be asked to write an essay that focuses on some of the above questions in relationship to a novel or other text that also raises issues of marginalization within a particular community. In a U.S. history course, reflection on learners' personal history and relationship to land and economic status could be connected to a historical trend such as westward expansion and the genocide of indigenous people, or U.S. industrialization. Making these personal sustainability connections to broader historical trends or literature can help learners recognize that we are all reflections of the norms and values of the larger society. According to Merchant (1992) this will help us "begin to articulate an ethic that either sustains or reforms the institutions around us" (p. 6).

Critical thinking and questioning skills must be developed over time. King and Kitchener (1994) posit that reflective thinking builds in a sequence, and they identify seven stages that people move through in the process of justifying beliefs about complex problems. In the first three stages, knowledge is seen as coming from authorities, and problems are dualistic. In the middle stages, knowledge is less certain and people are more subjective, but ambiguity is still difficult to deal with. In stages seven and eight, the reflective thinking stages, knowledge is generated by the learner 
and is understood in context. Judgments or decisions remain open to reevaluation and subjective knowledge is valued. Helping learners to move through these stages and build reflective thinking skills will be imperative if they are to be ready to create sustainable change.

Critical theory is clearly important to sustainability pedagogy, which aims to question dominant power structures and practices. But critical theory is also important because of its emphasis on understanding diverse and less-heard Perspectives, a vital element to finding systemic solutions to unsustainable practices. Understanding diverse Perspectives also lays a foundation for the meaningful interpersonal dynamics necessary for a participatory and experiential learning Process.

\section{Dimension III: Process}

The third dimension of the Burns model of sustainability pedagogy is Process. In this model, Process signifies opportunities for direct participation and experiential learning. In adopting thematic sustainability Content, and by challenging dominant assumptions and power structures and considering diverse Perspectives, sustainability pedagogy is inherently focused on change, and making change requires engagement with one's self, with others, and with places. Within a sustainability paradigm, change is viewed as finding new ways (or adopting more traditional ways) of living and working so that human systems are in harmony and balance with ecological systems. This change will require a transformational learning Process that will prepare students to take action for sustainable change. 
According to Cortese (2005), one pedagogical strategy for sustainability emphasizes active, experiential, and participatory learning. Serrano (2000) posits that participatory and empowering learning helps build the capacity and power of people to confront problems and change the present situation. This capacity building and empowerment can be specifically expressed as increasing learners' civic responsibility and desire to work for sustainability. However, gaining these values is a Process.

As Kaza (1999) notes, learners in postsecondary education today often experience despair, denial, and self-absorption when exposed to facts about socioecological problems, and this is not enough to inspire action for social change. Kaza (1999) suggests that learners must also be given the opportunity to engage in the issues, in order to positively apply their feelings to a relevant topic of concern, thereby participating in transforming their world. Service-learning, due to its participatory and experiential nature with goals of civic engagement and leadership, serves as an excellent application of sustainability pedagogy. Service-learning integrates meaningful community service with instruction and reflection, and serves to enhance both the learners and the service site. Steinke, Fitch, Johnson and Waldstein (2002) explain that a sustainable democracy depends on the active engagement of an enlightened citizenry and that service-learning may provide a particularly effective way to give learners a sense of responsibility for civic engagement.

Within the Burns model of sustainability pedagogy, participation includes the opportunity for learners to participate in sustainable practices both in local communities, and in their own lives and on postsecondary campuses (Cortese, 2005). 
This may be facilitated by opportunities for creative thinking and problem-solving in small groups about sustainable practices. The importance of active participation for change implies that sustainability pedagogy must be situated within its immediate context. The civic responsibility that may evolve from sustainability pedagogy can be a natural extension of learners' relationships within the places and communities where they live.

Opportunities for participation and direct experience should be incorporated into courses that focus on sustainability. For example, visits to a particular site such as a riverbank, a farm, a park, an office, a social service agency, or even a grocery store can serve to give students direct interaction with the issues they are learning about. In a course with a sustainable food systems theme, a food-inventory shopping activity in a grocery store can reveal much about the availability (or lack) of local food, and the cost of feeding a family of four on a minimum wage job.

In a course with a sustainable watersheds theme, a visit to a parking lot with bioswales, and to one without, can provide an experiential example of how rainwater is viewed as a resource and how rivers can be stewarded. Science and math classes with sustainability themes could incorporate active participation in campus gardens, or in biofuel development projects. Marketing courses could include projects in which students research and promote information about sustainable living. English or Communication courses could incorporate projects in which students interview people within local organizations that are working for sustainability and write essays or create presentations about these agencies. 
A participatory, experiential learning Process is a key dimension of the Burns model of sustainability pedagogy because this Process prepares learners with skills, values and relationships that can only be developed through direct participation. Participatory learning can also promote several of the key outcomes of liberal education including gaining practical skills, an active commitment to personal and social responsibility, and the ability to apply learning to complex problems (National Leadership Council for LEAP, 2007).

Experiential learning theory is fundamental to the Process dimension of the Burns model of sustainability pedagogy. This theory describes learning as "the process whereby knowledge is created through the transformation of experience. Knowledge results from the combination of grasping and transforming experience" (Kolb 1984, p. 41). According to Kolb's (1984) theory, a Concrete Experience (CE) is followed by Reflective Observation (RO) which in turn leads to Abstract Conceptualization (AC), and finally to Active Experimentation (AE). A concrete experience of participation therefore, must also be followed by reflection and conceptualization and can then lead to action. A postsecondary educator's role is to create and facilitate active and experiential learning experiences for learners that also include reflection on this direct experience. This is because, as Dewey (1938) argued, learning is the result of coordinated action and reflection. Through this Process, students' conceptions about sustainability may change, and they may gain an increased sense of civic responsibility and desire to take action towards sustainability.

Learning experientially meets the needs of diverse learners and provides 
opportunities for learners to gain new skills, and to be exposed to new epistemologies, both important aspects of sustainability learning. Merriam (2004) suggests that rather than focusing solely on rationality through critical reflection, non-rational approaches to learning such as connected, affective and intuitive dimensions should be included in the learning process. Palmer (1998) goes further to argue that reality is constituted by events and relationships; that these cannot be separate and therefore, community is an essential form of reality. The idea of learning in communities is closely related to connected knowing. According to Clinchy (2000), connected knowing, in which connections are cultivated "among students, between students and teachers and between students and their work" (p. 33), should be more fully integrated into the practices of postsecondary education. Experiential learning provides opportunities for connections in which diverse learners can understand multiple ways of knowing and can thus become prepared address sustainability challenges in local and global communities.

When learning sustainability, concrete experience often means participating in the local community in some way. Thus, situated experiential learning theory is a derivative of experiential learning theory in which the location of the learning is important. Fenwick (2001) describes situated experiential learning as "rooted in the situation in which a person participates...knowing and learning are defined as engaging in changing processes of human activity in a particular community" (p. 41). Situated learning therefore implies that individuals learn as they interact with a community. The object of learning is to become a full participant in a community of 
practice, including its history, values, relationships, language, images, and norms. An educator provides real-life conditions, activities, and problems in which learners engage in and work through (Fenwick, 2001). Becoming a full participant includes developing the capacity to create sustainable change in relationship to one's place or Context, which is the fourth dimension of the Burns model.

\section{Dimension IV: Context}

Context is central to thematic sustainability Content, critical questioning and understanding diverse Perspectives, and the Process of active learning, and is thus an essential dimension of the Burns model of sustainability pedagogy. In order for engagement to take place, effective sustainability pedagogy must be rooted in the place where learning is happening. Therefore, the Context of sustainability is critical. According to Cortese (2005) the goal of sustainability education is working towards healthy, socially vibrant, economically secure and environmentally sustainable places. Place-based learning is therefore an application that specifies the importance of Context.

Place-based learning specifically focuses on "how the local landscape, community infrastructure, watersheds, and cultural traditions all interact and shape each other" (Sobel, 2004 p. 9). By making use of the history, folk, culture, social problems, economics and aesthetics of a community, place-based learning seeks to create opportunities for learners to be actively involved in confronting and grappling with issues of bioregional sustainability. In addition, place-based learning not only 
incorporates projects that actively connect learners to the local community (Sobel, 2004) but questions relationships within that community.

Bowers (1999) argues that if educators are not introducing students to a placebased ecological understanding of viewing relationships, then they are maintaining the status quo, which socializes learners to the industrial revolution's agenda of using technology to exploit and control the environment [and human communities]. At the same time, place-based learning does not ignore international economic, ecological, and political relationships, but rather explores these relationships through the lens of local communities and places.

Orr (1992) explains that the integration of place into education is important for several reasons. First, it requires the combination of intellect with experience, allowing learners the opportunity for direct observation, investigation and experimentation essential for the development of the whole person. Second, placebased education helps to mitigate the problems of overspecialization and the division of subjects into disciplines because it focuses on understanding interrelatedness. Orr (1992) comments, "places are laboratories of diversity and complexity, mixing social functions and natural processes" (p. 129). Another advantage of the study of place lies in reeducating people in the art of living well where they are, in learning to be an inhabitant of a place from which an organic reciprocal relationship with place can grow. Orr (1992) puts it this way, "knowledge of a place - where you are and where you come from - is intertwined with knowledge of who you are. Landscape, in other words, shapes mindscape" (p. 130). Place-based education not only helps learners 
understand who they are, but to value the places they live and thus to value themselves within that place.

The dimension of Context can be incorporated into a postsecondary course focused on sustainability. For example, within a statistics course using a sustainable communities theme, students could use statistics from their own community to examine income levels in various neighborhoods and make connections to sustainability issues such as watershed health, local food accessibility, or waste disposal. Students could also create and analyze their own statistics through the development and dissemination of a survey tool focused on a particular sustainability issue in their community. In a nursing course, students could research and make presentations about sustainable health related resources in various neighborhoods such as community centers, community gardens, walking trails, clinics, natural food co-ops, and yoga or meditation centers. In an economics course, students could learn about small-scale sustainable economies that operate around the world and how these are being applied or might be applied within their bioregion.

Place-based education can infuse learning with applicable meaning. Kawagley and Barnhardt (1999) suggest that education is not currently showing learners how they can transform information into useful knowledge to make a living or understand how to live meaningful lives. They posit, "all learning should start with what the student and community know and are using in everyday life" (p. 119). This immersion in a community of relationships and nature is inherent in traditional indigenous education, which can be used as a model to move education from a focus 
on workplace to ecoplace (Cajete, 1999). This means that instead of simply focusing learning on gaining skills to get a job, importance is placed on learning how to live and work sustainably within an ecosystem and community.

A critical theory of place is a learning theory that helps to describe the importance of Context in the Burns model of sustainability pedagogy. Grunewald (2003) argues for a "critical pedagogy of place in which people must be challenged to reflect on their own concrete situationality in a way that explores the complex interrelationships between cultural and ecological environments" (p.6). Since human communities and places are political areas in which power structures marginalize certain people and ecosystems, place-based educators must identify and confront "the ways that power works through places to limit the possibilities for human and nonhuman others. Their place-based pedagogy must, in other words, be critical" (Grunewald, 2003, p. 7). Grunewald (2003) argues that a critical pedagogy of place "aims to (a) identify, recover and create material spaces and places that teach us how to live well in our total environments (reinhabitation); and (b) identify and change ways of thinking that injure and exploit other people and places (decolonization)" (p. 9).

Grounding educational experiences in the particular attributes of a place is in line with critical pedagogues like Freire (1970) who advocates, "reading the world." Places can become political "texts" that are intertwined with literal texts and are • examined and decoded through personal experience. This pedagogy focuses on people telling their own stories specifically connected to a place or community and connects 
these stories to patterns of domination and resistance. Through critical reflection grounded in place, learners can then understand how to use this understanding of place to transform society. (Friere, 1970; Grunewald, 2003). For example, in a course with a sustainable watersheds theme, learners can be introduced to various stories about watersheds within a local Context. These stories, told by speakers, documentaries or texts, can provide an understanding of how local watersheds have been places of domination and resistance through dam building, housing development, floods, and wildlife preservation or destruction.

A critical theory of place can be used to understand privilege and multiple levels of identity by introducing students to the complex realities of a local place. By analyzing and sifting through the complex layers of privilege and oppression rooted in place, learners can better understand their own relationship to place and diversity. A critical theory of place shifts from trying to "cover" material, to uncover the relationships at work in a place. This uncovering can then serve to help learners understand how to best take action to address sustainability problems within their communities and ecosystems. A critical theory of place is thus an important fundamental theory of the Burns model sustainability pedagogy because of the clear focus on the Context of learning.

Dimension V: Ecological Design

Fifth and finally, the central dimension of the Burns model of sustainability pedagogy is Design. The Design of a course that is focused on sustainability is an important dimension because this Design intertwines the other four dimensions of the 
pedagogical model. This Design is an ecological one in which the dimensions interact with and build on one another. Rather than forming a linear relationship, these dimensions form a web of interrelationships. The Design is based on the goals of the Burns model of sustainability pedagogy, but reflects a holistic approach to reaching them. An ecological Design reflects sustainability by: not separating knowledge into disciplines; not separating cause from effect, not separating feelings and knowledge, and not perpetuating the standard of humans as separate from the rest of the biological world, or worse, that human domination of the earth is acceptable (Orr, 1992). All the dimensions of the Burns model (Content, Perspectives, Process, and Context) are linked and interconnected by the ecological Design, which is fundamental to providing opportunities to learn sustainability as multidimensional, complex, and meaningful.

McDonough and Braungart (2002) advocate for holistic Design, rather than perpetuating designs and systems that are fragmented and result in patterns of consumption and separation of cause and effect. This systemic approach takes into account not only how something is made and used, but the item's whole life cycle including what will become of it after it is no longer being used. As a case in point, examining why toxic landfills are full of everyday products that we continue to buy and use, may help us understand how little attention we generally pay to systemic relationships. When applied to teaching and learning, Design should consider systemic relationships, both between the dimensions of sustainability pedagogy, but also between learners and their own life cycles. 
Ecological Design, according to Hemenway (2000), includes five basic steps which include: (1) observation; (2) visioning; (3) planning;(4) development; and (5) implementation. While this general Design process was intended for creating a permaculture garden, the process can be adapted to any teaching and learning situation. The process is not necessarily linear, however, and steps can be revisited throughout the process of designing and implementing a postsecondary course.

1) Observation-what do we have to work with and what are the conditions and constraints? This is the stage in which an educator should consider what salient sustainability theme could reasonably be incorporated into a course. This includes considering what community and campus resources can be integrated, and what constraints might apply to instituting this theme. Developing a sustainability theme can begin with thoughtful observation of the educational institution and its people. Who are the students? What is the climate/culture of the institution and its surrounding community? Who and what are the resources in the area of sustainability? What is already happening in this realm? Over time and through thoughtful observation, Design can evolve based on the needs of the site and the resources available.

Developing a course that addresses sustainability too shallowly may fail to meet local needs. Creating an asset map, lists, or charts may be helpful. What resources are readily available? What are the particular strengths of the educator and what areas may require additional outside resources?

2) Visioning-What should the Design do? What do we want? How should it feel? This includes considering the learning goals of the Burns model of sustainability 
pedagogy and considering what the most important outcomes of the course will be. At this point, narrowing the sustainability topic will be essential. Choosing to explore one theme in detail will weave together many goals and will create a focal point that is not overwhelming. Considering relationship building between learners and the tone of the course are also important at this stage.

3) Planning-What do we need to implement our ideas? How should the pieces be assembled? At this point the educator can consider what texts, community resources, field visits, speakers, and classroom activities can be incorporated into the course in order to effectively teach sustainability through the chosen theme. Community projects should be carefully chosen for proximity, applicability, and time/energy of the community organization. A detailed consideration of how to incorporate diverse Perspectives, critical questioning of dominant paradigms and power relationships, active participation and direct experience, and place-based understanding is key at this point.

4) Development-What will the Design look like and how will it be implemented? This stage involves focusing on the details of the Design and how Content, Perspectives, Process, and Context will be incorporated on a day-by-day basis. This involves making decisions about assignments and learning activities. It also involves writing a syllabus that reflects the ecological Design of the course and the chosen sustainability theme. Will there be weekly themes? Will all learning center around one main project? How will the learning be structured and sequenced? 
5) Implementation- installing the Design. Installing the Design involves teaching the course, and in doing so, making adjustments based on further observation, visioning, planning, and development to enhance sustainability learning. Implementing the Design also involves assessing whether or not it is flexible enough to meet potential surprises in the classroom. Assessing student learning is an organic learning process for the designer. Assessment provides ongoing opportunities for development of the course, and changes to the Design.

An ecological course Design links the other four dimensions of the Burns model of sustainability pedagogy with the purpose of creating learning that has the potential to transform learners' attitudes and values, and ultimately to transform unsustainable systems within unsustainable cultures. Thus, transformational learning is the central underlying theory of this model of sustainability pedagogy. Mezirow (2000) describes transformational learning as a process by which "we transform our taken-for-granted frames of reference...to make them more inclusive, discriminating, open, emotionally capable of change, and reflective so that they may generate beliefs and options that will prove more true or justified to guide action" (p. 7-8). One of the most clear underlying assumptions of sustainability learning is to understand that our taken for granted perspectives and mind-sets are too narrow (unsustainable), and to generate new beliefs that guide sustainable action. While this is an individual process of transformation, it may also lead to community transformation.

Dirkx's (1998) four-lens approach to transformational learning is another useful way to understand the importance of transformational learning theory to the 
Burns model of sustainability pedagogy. Dirkx's four lenses of transformational learning are: (1) empancipatory education in which learners become conscious of how social structures are oppressive; (2) Mezirow's cognitive-rational transformational approach in which perspectives are changed through revised understanding based on experience; (3) a developmental perspective in which learning is concerned with sense-making within a contextual interpersonal and holistic approach; (4) the spiritual dimension in which feelings, images and soul-based learning is emphasized. Together, these four lenses are important and applicable to the transformational process of sustainability pedagogy. The following examines each lens briefly using the example of an experiential postsecondary course on the topic of sustainable food systems.

First, an emancipatory lens is important to sustainability as learners encounter through direct experience the complexity and oppressive nature of many social structures. By meeting with local farmers and local food producers, learners could come to understand how the social and economic structures of food production and distribution favor the white middle class of the global North, while destroying ecosystems and dehumanizing workers in the global South. Additionally, a cognitive rational approach would allow learners to think about and discuss their understanding of food systems after experiencing a variety of local institutions and places and hearing from local people with a variety of perspectives, perhaps with contradictory messages about food production. Opportunities to both hear and discuss diverse Perspectives could serve as ways for participants to participate in an active learning Process in community and from one another. Furthermore, a developmental 
Contextual approach would give learners the opportunity to make meaning of the Content and their own participation in food systems from cultural and/or economic Perspectives, and understand in Context how relationships with food systems may fluxuate. Finally, a spiritual dimension would also have its place in this learning environment as learners would seek to negotiate their feelings about what they are learning, to deal with paradox and symbols, and to move beyond the rational to learning that is emotional and intuitive. This might take place through storytelling or journaling and through sharing these experiences within a community of learners.

As demonstrated by this four-lens approach, transformational learning relates to various aspects of learning and student development, and can address both the empowerment of individuals, and emancipation from oppressive socio-cultural structures. Inglis (1997) defines empowerment as "people developing capacities to act successfully within the existing system and structures of power" and emancipation as "critically analyzing, resisting and challenging structures of power" (p. 4). Through this transformational learning process, learners can begin to understand existing systems and real problems within their own community, and feel empowered to make individual and community-based changes toward sustainability.

Similarly, the Social Change Model of Leadership Development created by Astin and Astin (2000) focuses on three levels of leadership development: individual, group and community/society. These three levels of leadership development can be applied to transformational learning as sustainability. Within a transformational learning experience, emphasis is placed on fostering an individual's growth and 
capacity to make sustainable change. But, there is also emphasis placed on the development of an effective group process, and on service activities that connect individual learners and groups of learners to the community both locally and globally.

According to Astin and Astin (2000), these three levels of leadership development are comprised of the "seven C's." At the individual level, Consciousness of self, Congruence, and Commitment are important to develop. At the group level, Collaboration, Common Purpose, and Controversy with civility are central. At the community/society level, Citizenship is the focus of development.

Figure 2. The 7 C's leadership development model.

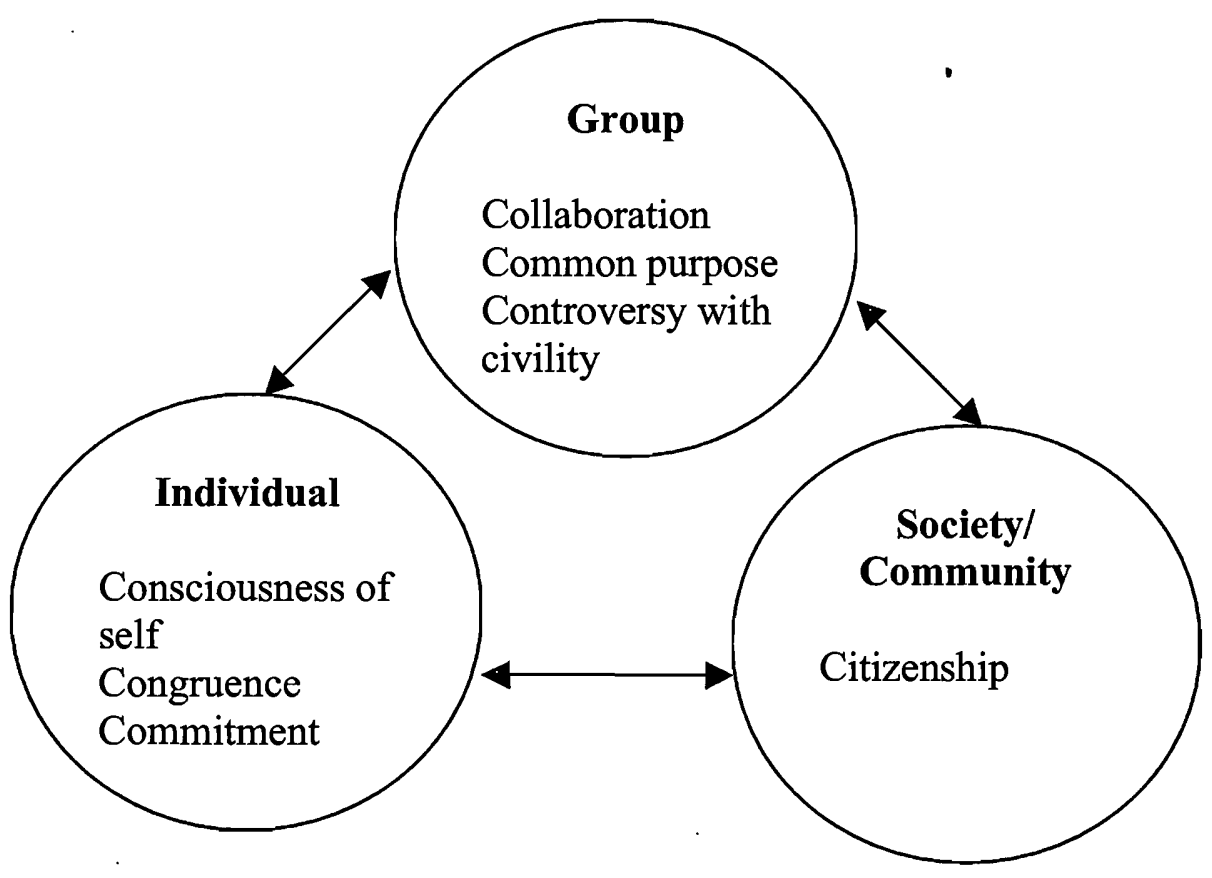

These three levels of leadership development, individual, group and community, are included in the Burns model of Sustainability Pedagogy as the leaves of the flower (see Figure 3). As a foundational part of the flower, these leaves feed the 
central Design dimension of the model. The Design must include leadership development and transformational learning for individuals, groups and local and global communities in order to ultimately create sustainable change. While transformational learning is certainly important for leadership development at the individual level, effective groups will also need to provide leadership for sustainability within local and global communities. UNESCO's decade long focus on reorienting education toward sustainability highlights to the need for worldwide leadership development to prepare learners to address immense sustainability challenges. Learning that incorporates the $7 \mathrm{C}$ 's model aims to prepare all learners to act as leaders who can affect change. 
Figure 3. The Burns model of sustainability pedagogy with levels of development.

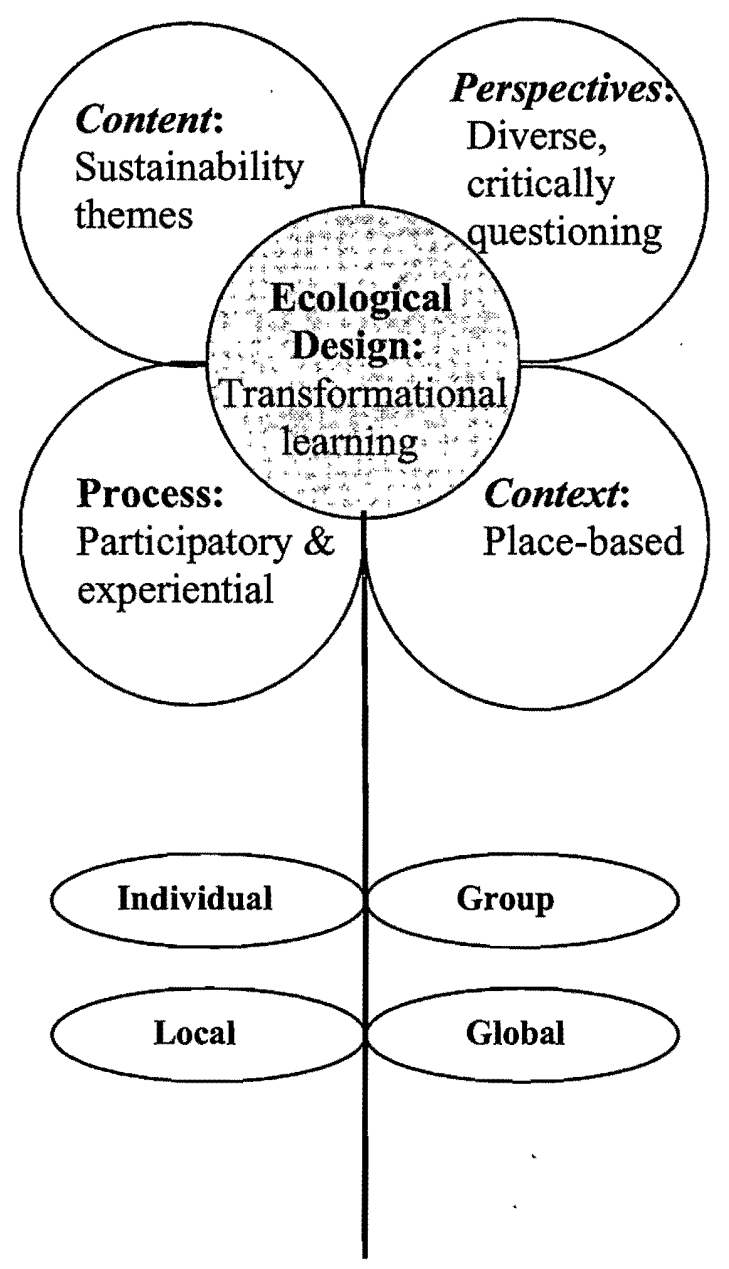

\section{Organic Nature of Classrooms, Communities and Campuses}

Summary of the Burns Model and Related Theory

The Design dimension of the Burns model of sustainability pedagogy is crucial in that it facilitates the transformational learning process that is at the heart of learning 
as sustainability. The Design dimension, therefore, is situated at the center of the Burns model of sustainability pedagogy. This ecological course Design brings together Content that is thematic and multidisciplinary, Perspectives that are diverse and critically question dominant paradigms and practices, a Process that is participatory and experiential, and a Context that is place-based. Each of these five dimensions is embedded in a relevant learning theory (see Figure 4), although this construct is somewhat artificial as these learning theories overlap dimensions and in reality may relate to multiple dimensions. 
Figure 4. The Burns model of sustainability pedagogy and learning theories.

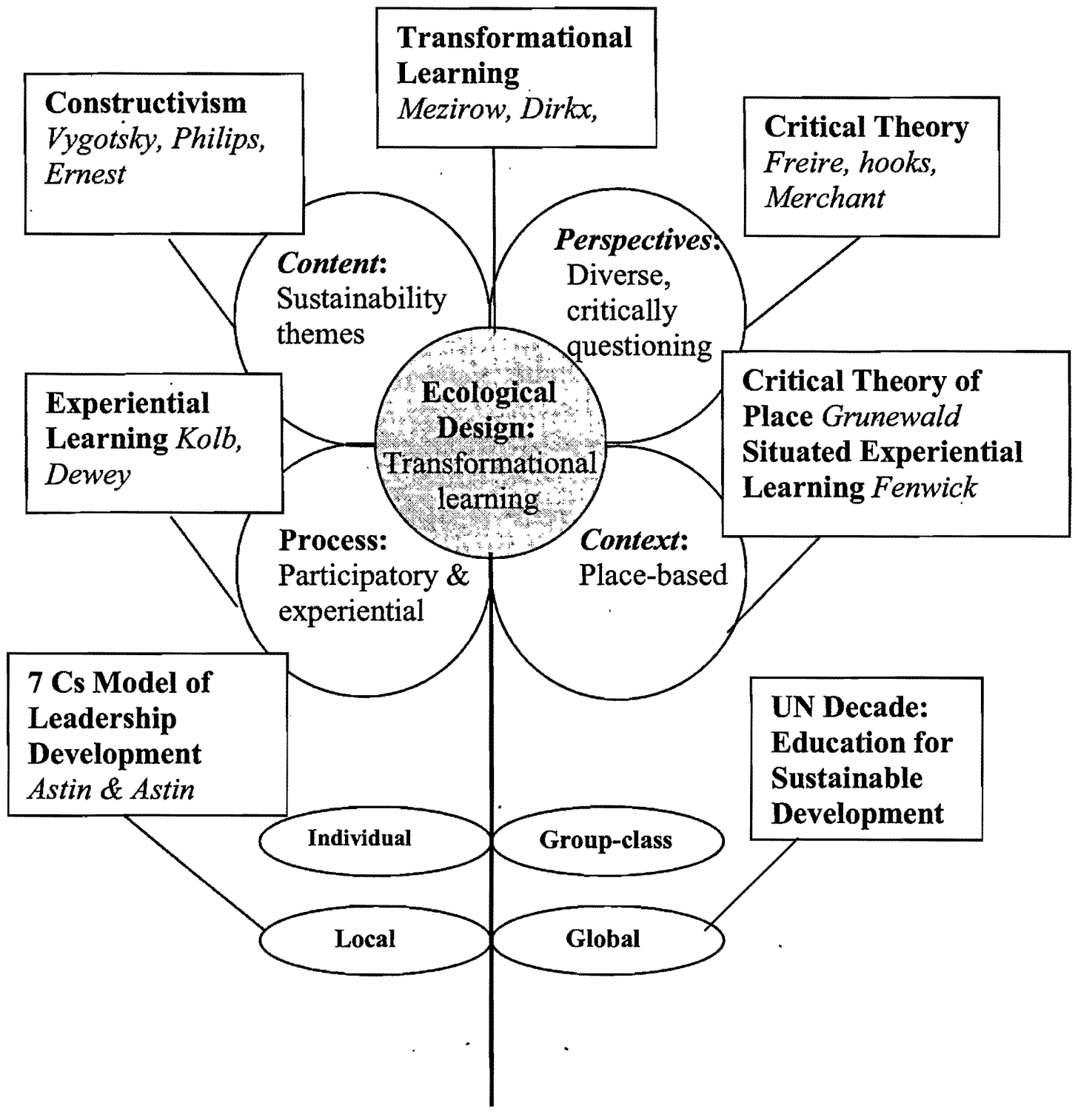

Organic Nature of Classrooms, Communities and Campuses 


\section{Conclusion}

In summary, colleges and universities can and must begin to reorient teaching and learning to address sustainability if we have any hope for a sustainable future. Within the recent context of tremendous growth and diversity, postsecondary institutions can play an important role in educating a wide variety of learners and future leaders about sustainability. Clearly there is much need for incorporating sustainability into teaching and learning within postsecondary education. But while there is some theorizing about the benefits of teaching and learning sustainability within postsecondary education, there is little research and many unanswered questions about how to most effectively equip learners with the knowledge, skills, and values they will need for creating a more sustainable future. How can educators best prepare and empower learners to meet urgent socio-ecological needs and solve complex sustainability problems within communities? This issue must be understood in order to move from the current goals of liberal higher education of preparing learners to live and work successfully within the current economic system, towards sustainability goals which include making much needed changes that affect ecosystems and communities.

The Burns model of sustainability pedagogy provides the theoretical and practical framework that is needed to move away from teacher-centered transmissive education towards transformative education as sustainability that empowers learners to be able to make immediate sustainable changes. Examining the applicability of the Burns model of sustainability pedagogy contributes rich information about teaching 
sustainability in postsecondary settings. The following chapter provides an overview of the research methods used for this study. 


\section{CHAPTER III}

\section{METHODOLOGY}

This chapter provides an overview of this research about the Burns model of sustainability pedagogy. First the purpose of the study and the research questions are presented. Then, a rationale is given for using action research as a methodology for this study. The subsequent research design section describes the research sites, the participants, and the data collection and analysis strategies. Finally, the validity and limitations of the study are addressed, as well as the positionality of the researcher.

\section{Research Questions}

This study examined the implementation of the Burns model of sustainability pedagogy in two postsecondary courses and in doing so, filled a gap in the research on sustainability teaching and learning. The purpose of this study was to describe and explain how students responded to the Burns model of sustainability pedagogy when it was implemented within two university courses.

Specifically, the first research question is: What are the effects of implementing the Burns model of sustainability pedagogy in university courses? The following additional sub-questions address each of the first four dimensions of the Burns model including Content, Perspectives, Process and Context, and are intended to better understand student responses over time. These questions include: (1) How do learners understand sustainability issues? (2) How do learners think about dominant paradigms, practices and power relationships, and consider complex sustainability issues from diverse perspectives? (3) What are the learners' intentions to work toward 
sustainability? (4) How do learners understand their personal connections to the place where they live?

The second major research question is: How can an ecological Design process bring together the other four dimensions of the Burns model of sustainability pedagogy and create transformative learning experiences for students?

$$
\text { Rationale for Action Research Methodology }
$$

This study made use of action research methodology in order to examine the implementation of the Burns model of sustainability pedagogy. Action research is not related to any particular discipline and has various proponents and strands including participatory action research, action science and human inquiry. In addition, action research incorporates both qualitative and quantitative methods, depending on the situation and participants (Greenwood \& Levin, 2007). McCutchen and Jung (1990) describe the goals of action research as "understanding the practice and the articulation of a rationale or philosophy of practice in order to improve practice" (p.148).

Greenwood and Levin (2007) explain that action research has three elements: (1)action, (2)research, and (3)participation. They posit, "action research is a research strategy that generates knowledge claims for the express purpose of taking action to promote social analysis and democratic social change. Action research aims to increase the ability of the involved [participants] to control their own destinies more effectively and to keep improving their capacity to do so within a more sustainable and just environment" (Greenwood \& Levin, 2007, p. 5). 
Action research has long been used in educational settings to improve practice and this dissertation follows in the tradition of Action Research in Education, described by Herr and Anderson (2005) as having a history of reflective practitioners or teachers as researchers, who sought to improve their own practice and solve problems within local educational settings. Improving practice was an important element of this study in that the results have given me insight into teaching sustainability.

But perhaps more importantly, action research is appropriate for this study of sustainability pedagogy because of its goals of promoting social change. The research methods used to study this pedagogy should perhaps best reflect the goals of the pedagogy itself: thematic, diverse, participatory, and contextual. This study sought to enact change in the educational system (implementing sustainability pedagogy), while also providing research about this process and emphasizing the importance of the participation of others in the research process. Action research was appropriate for this study because action research aims to solve problems within a given context and thus engages in systems-based pragmatic social science (Greenwood \& Levin, 2007). Action research is also appropriate because it is a methodology that typically takes on complex problems, focuses on specific contexts, and focuses on the capacity to resolve problems in real life situations (Greenwood \& Levin, 2007). Considering the complex, contextual nature of teaching sustainability in postsecondary settings, and the need to solve the problem of how to effectively do so, action research was an appropriate methodological choice for this study. 


\section{Research Design}

This study took a descriptive stance and an in-depth look at the implementation of the Burns model of sustainability pedagogy within two postsecondary courses. In addition, studying the Burns model within two courses provided some comparison and contrast since the courses are from different disciplines, Science and English, are offered at two different types of postsecondary institutions, public and private, and are courses taken at different levels of college, approximately first year and third year. This study used an insider approach, which is inherent in action research.

\section{Research Sites}

The Burns model of sustainability pedagogy was studied within the context of two courses taught by the researcher in Portland, Oregon. In general, Portland is considered a very progressive city that is on the forefront of sustainability issues in areas such as urban planning, food systems, transportation, and housing. Thus, Portland is an affirming and unique city in which to conduct research related to sustainability pedagogy. The two courses were: Pollution Carries No Passport: Sustainability in the US-Mexico Border Region, a four credit course offered at Portland State University, and College Writing, a three credit course offered at the University of Portland.

Course One: "The Border Course"

This course is an eleven-week course taught once a year that explores sustainability issues in the US-Mexico border region. This course is offered at Portland State University (PSU), the largest state university in Oregon whose core 
mission is to "Let Knowledge Serve the City." The course includes 7 weekly two hour class sessions at PSU, and then a five day immersion experience that takes place in the twin towns of Nogales, Senora (Mexico) and Nogales, Arizona where multinational factories, a free trade zone and a major border crossing provide a rich setting in which to explore topics of global sustainability. The trip is followed by two more class sessions at PSU. The immersion trip is organized and facilitated by the nonprofit organization BorderLinks, a bi-national organization with centers in both Tucson Arizona and Nogales Mexico. BorderLinks seeks to "raise awareness and inspire action around global political economics. BorderLinks brings people together to build bridges of solidarity across North and Latin American borders and promote intercultural understanding and respect" (BorderLinks website, 2009).

This course is considered a short-term study abroad course at PSU, and is a university studies (general education) junior cluster course that has a clear and stated focus on sustainability. As a University Studies course, it meets the core university studies goals including: inquiry and critical thinking, communication, the diversity of human experience, and ethics and social responsibility. Before teaching and conducting research in this course in 2009 , I had already taught this course twice (in 2007 and 2008) with a co-instructor, who originally developed the course and invited me to teach it with her. The co-instructor is a faculty member within the Center for Science Education and teaches a variety of service-learning capstone courses within the University Studies program. The syllabus for this course can be found in Appendix D. The following description of this course is organized by the dimensions of the 
Burns model of sustainability pedagogy, in order to provide an overview of how the course was designed using this model. A summary of major Design elements for Course One "the Border Course" are outline in Figure 5.

Figure 5. The Burns model: Summary of design for "the border course."

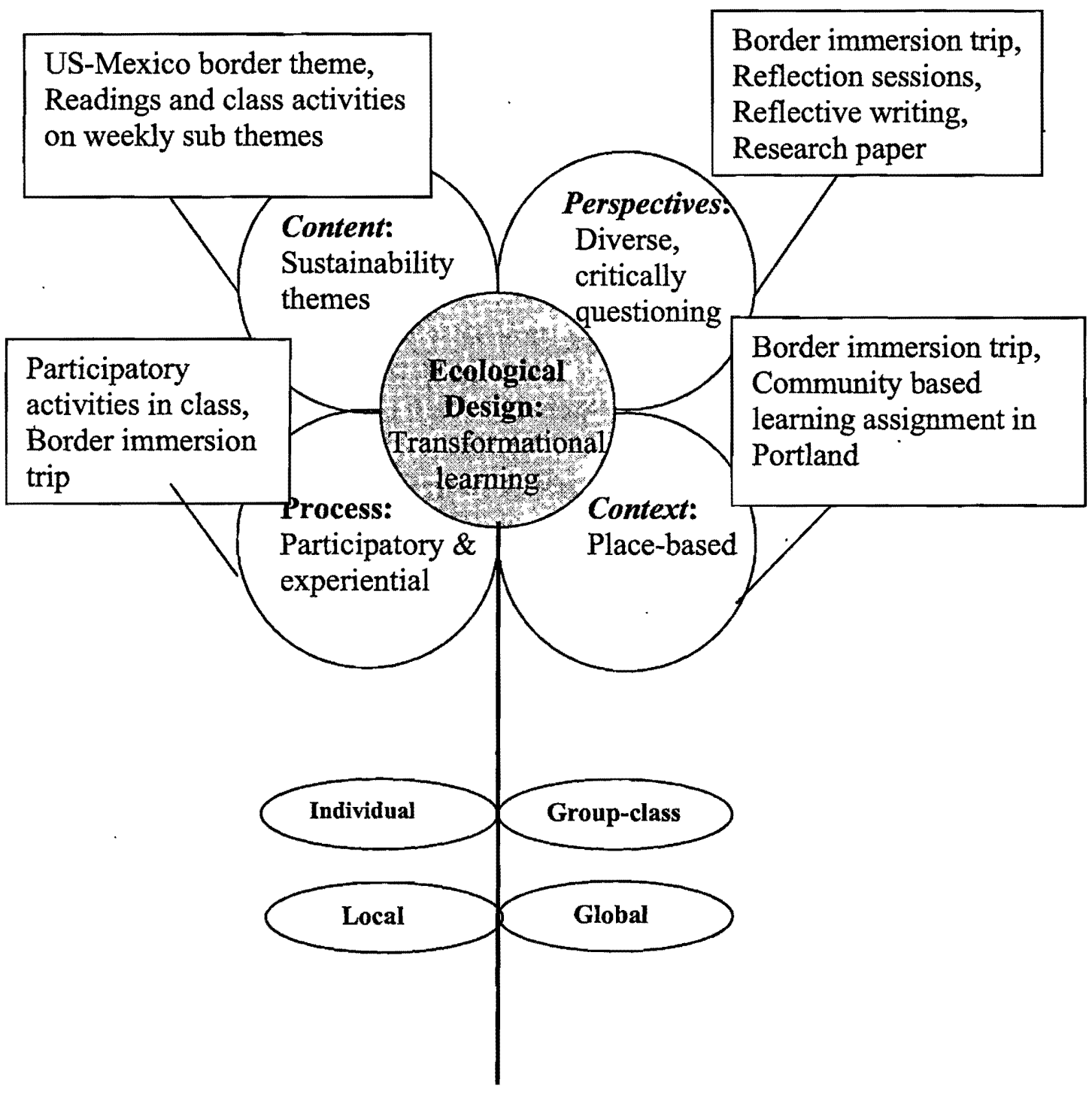

\section{Organic Nature of Classrooms, Communities and Campuses}


First, the sustainability Content of this course was structured around the theme of the US-Mexico border region. Some of the goals that guided the learning around this course theme included: Examining a variety of themes that affect sustainability in the border region as a way to better understand sustainability on a global scale; and considering the role and responsibility of everyday citizens in addressing sustainability issues in everyday practice. This larger theme of sustainability in the US-Mexico border region was broken down into smaller sustainability themes, which were explored in weekly class sessions prior to the border trip. Each week, in preparation for class, students completed readings related to these weekly themes. These themes included: The history of economic globalization in Mexico; US-Mexico immigration history; environmental sustainability and public health; language and culture; and gender issues. In addition to reading about these themes, students explored these themes and their relationship to sustainability through participatory class activities that included small group discussions, a mock town hall activity, an ecological web activity, a matching concepts activity, interactive lectures, a short film, and large group discussions.

Secondly, this course incorporated a variety of diverse Perspectives that related to the course theme, including marginalized voices. During the border trip, participants meet with pioneers in various fields on both sides of the border--including food systems, alternative technology, financing, immigration, and resource management--to get first-hand information on the economic and ecological implications of sustainability within the broader context of global trade. While 
traveling in the border region, learners also participate in homestays with working class Mexican families and stay at a migrant shelter in Mexico. Additionally, students visited an Arizona community committed to sustainable living.

An important element of the Perspectives dimension was including time for reflection sessions, both during the immersion trip and after the trip when the class met several more times on the PSU campus. These sessions allowed time for students to reflect critically on what they were learning from diverse Perspectives, and to apply this learning to their own lives. Additionally, students completed two short reflective writing assignments related to sustainability, which allowed them to explore their own Perspectives on sustainability. For the first reflective writing assignment, which was completed for the second class session, students wrote 1-2 page responses to the prompts: In your own words, describe a sustainable community; What role can you play in supporting sustainable communities locally, in the border region, and beyond? For the second reflective writing assignment, which was due on the sixth week of the term, students wrote responses to the prompt: How have issues connected to the USMexico border region (i.e. immigration, free-trade) touched your own life? What does this have to do with sustainability?

The major assignment in the course was a research paper in which students focused on one aspect of sustainability in the US Mexico border region (of their choice) and incorporated a variety of Perspectives, both textual research and experience gained from the border trip. This allowed for students to be able to examine power relationships and dominant paradigms in relationship to the course 
theme. This assignment was completed in steps. By the forth week of the term, students identified a research question and a list of sources for their research project. By the seventh week of the term, just prior to the trip to the border, students wrote and turned in a summary and analysis of pre-trip background research. In this assignment they summarized the research they had done thus far, and wrote an analysis about how they would answer their research question if they had to do so at this point. On the tenth week of the term, students turned in their final research papers, which incorporated both their pre-trip background research and knowledge gained from the border trip.

Third, incorporating a great deal of participatory and experiential learning opportunities was important to the Process dimension of this course. As described previously, class sessions included many participatory activities. The immersion trip provided direct experience with the course theme, and opportunities to reflect on this experience and conceptualize the concepts students were learning about. This course also included a number of in-class participatory activities designed to help students get to know one another on a personal level.

Fourth, this course focused on the Context of sustainability, and this focus was reflected by rooting the course theme and immersion trip in a specific place. Besides learning in Context at the border, students also completed a community based learning project in Portland in which they participated in a 5 hour community activity related to US-Mexico border related issues, and wrote a reflection paper about this experience. 
Students each shared their experiences and what they learned with the rest of the class, providing exponential learning about the Context of sustainability.

Fifth, the Design dimension of this course sought to intertwine these four dimensions and was based on ecological principles. This course was originally designed by my co-instructor. For the purpose of this research, we used Hemenway's (2000) five steps to Design the course. We began by observing how we had implemented the course in the past, and spent time visioning how we could adapt the Design to the Burns model. We then planned the syllabus and assignments, and began to develop the plans for each class session. In the implementation of the Design, we made a variety of adaptations based on observation and visioning as the course unfolded. This Design process will be discussed in greater detail in subsequent chapters.

Course Two: "College Writing"

This course is a fifteen-week course taught every semester at the University of Portland (UP) that is "aimed at the development of writing skills and practice in writing the college essay and library research paper" (UP bulletin, 2007-2008). This course is a required foundational writing course for students of certain majors. This course has no stated connection to learning sustainability and thus provided an example of how sustainability pedagogy can be implemented within a skills-based disciplinary course. Before teaching this class and conducting this research in the fall of 2008, I had never taught ENG 107, but had taught a similar writing course for international students, ENG 101, since 2001. The University of Portland is a small, 
private, catholic university whose mission is embodied in the slogan, "Teaching, Faith, and Service." Because this course is not inherently focused on sustainability, it provided an opportunity to study this model of sustainability pedagogy within a nonsustainability course. The following description of this course is organized according to the dimensions of the Burns model of sustainability pedagogy. A summary of major Design elements for Course Two "College Writing" are outline in Figure 6. 
Figure 6. The Burns model: Summary of design for "college writing."

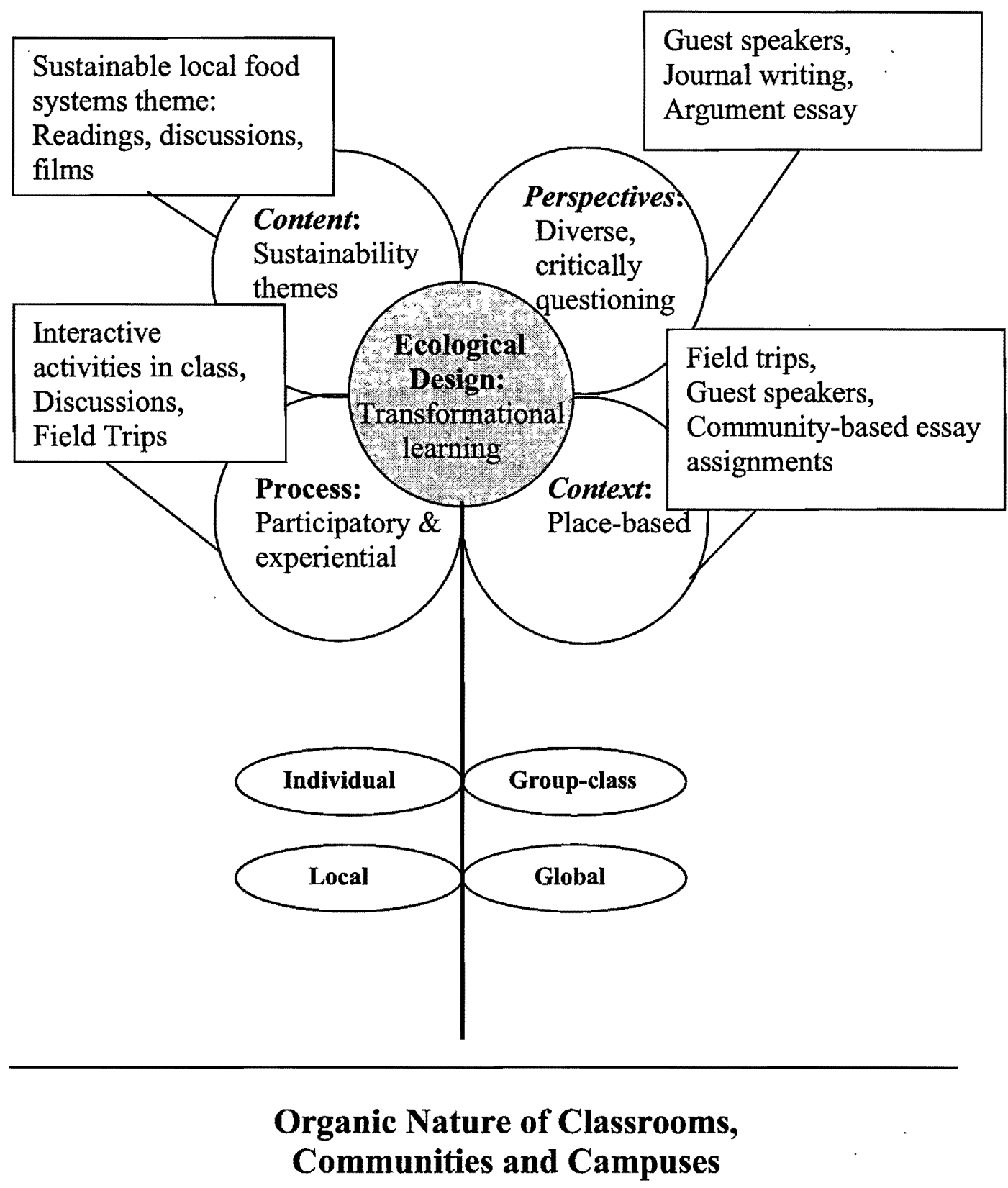

First, I designed the Content for this course around the sustainability theme "Sustainable Local Food Systems." Students were asked to complete several major 
writing assignments including an expository essay, an interpretive analysis essay, a research-based argument essay, and a personal reflection final essay, all of which were related to the course theme. For the expository essay, students researched and wrote about local organizations that are working to support sustainable local food systems in some way. For the interpretive analysis essay, students wrote about the differences between global industrial food systems and sustainable local food systems, supporting their analysis with evidence. For the argument essay, students created an argument of their choice that related to the course theme. They then conducted research and crafted an essay using sources to support their argument. For the final personal reflection essay, students reflected on their own learning about both writing and sustainable local food systems.

Other assignments included weekly reading from the book Animal, Vegetable, Miracle, which is also focused on the theme Sustainable Local Food Systems. Students wrote six 2-3 page journal entries based on the readings, and two mini essays that had to do with the community context of the course theme. The first mini essay was an assignment to visit and write a short expository essay about a local farmer's market. For the second mini essay students were asked to write a two-page argument essay that addressed the following questions: What is one of the underlying causes of the problem of food insecurity? What is a possible solution to this problem? This assignment was to be completed based on information gained from a guest speaker, a field trip, and readings on the topic of food insecurity. Weekly discussions also 
focused on the course theme, as did other in-class activities such as a matching concepts game, and a structured controversy activity.

Secondly, a variety of Perspectives were incorporated into this course in a number of ways. Guest speakers were invited to class and field trips were organized in order to provide numerous Perspectives and contextual learning about sustainable local food systems. For example, the class visited the campus Student Led Unity Garden (SLUG) for a tour and a discussion with the president of this student group. The class also visited New Seasons Market, a local grocery store that promotes the importance of local and sustainable foods, and conducted a food insecurity activity on site. This activity highlighted the marginalization of poor and working class people in Sustainable Local Food Systems. One assignment also required that students visit a local farmer's market and write about the experience.

Guest speakers included Kirk Mustain, manager of the campus food service company, Bon Appetit. This company is known for developing relationships with local farmers and promoting sustainable food. Martin Barrett, one of the founders of a new local company, City Garden Farms, also visited the class and talked about his business, which uses backyards to farm vegetables for a Community Supported Agriculture (CSA) project. A representative of the Oregon Food Bank also visited the class to talk about community food security and the OFB's related initiatives concerning Oregon state legislation and community projects. Weekly discussion sessions were led by students, providing their Perspectives. Several films were also used to introduce lesser known Perspectives. Furthermore, the students frequently 
asked me questions related to my experience with organic farming, as I am an organic farmer with a small Community Supported Agriculture business. All of these experiences provided a variety of Perspectives from which to consider dominant paradigms and power relationships.

Additionally, students' argument essays were focused on a sustainability problem and solution related to Sustainable Local Food Systems. For this essay, students researched a problem and incorporated a variety of Perspectives in an argument related to a problem with the dominant (global industrial) food system. They also included a variety of Perspectives in the proposed solution to the problem.

Third, a number of experiential and participatory activities were incorporated into the Process of this course, as previously described. Time for discussion and reflection was included in the course Design, as a way for students to make sense of their experiences. Regular journal writing also allowed students to reflect on their participation in the course, and ask questions about what they were learning. An informal atmosphere, sitting in a circle, and a number of interactive activities also contributed to the participatory Process of this course.

Fourth, the Context of this course was focused on the University campus and the local community, in order to root the Content, Perspectives and Process in a sense of place. Learning about Sustainable Local Food Systems was firmly grounded in a sense of what is happening in the students' own local community. As previously mentioned, guest speakers and field trips contributed to the sense of place-based learning and knowing. Additionally, an expository essay assignment required that 
students research and write about a local organization that is somehow involved in the development of a Sustainable Local Food System.

Fifth, the Design dimension of this course sought to intertwine these four dimensions and was based on ecological principles. I used Hemenway's (2000) five steps to Design the course. I chose Sustainable Local Food Systems as a course theme after observing that this was a topic into which campus and community resources could be easily integrated. I then envisioned that I wanted learners to understand what Sustainable Local Food Systems are, and to be able to apply their learning to their own lives. I also wanted them to learn about this topic in an atmosphere that was supportive and inclusive. In the planning stage I wrote the syllabus, contacted guest speakers, and planned field trips. As I developed the course, I considered the sequencing of course activities and assignments and made the weekly class plans for the course. In the implementation stage I assessed student learning and reflected on my Design, making adaptations as necessary. The Design dimension of this course will be discussed in further detail in subsequent chapters. The syllabus for this course can be found in Appendix D.

These courses took place at different times. The college writing course took place in the Fall semester of 2008, while the border course took place during the Winter term of 2009. As such, this action research project provided an opportunity to implement a plan (the Burns model) in the college writing course, to observe the effects of this action, and to reflect on these effects as the basis for the subsequent action of applying the Burns model in the border course (Kemmis, 1982). For 
example, after reflecting on the experience of implementing the Burns model in the college writing course, I proposed to the co-instructor of the border course that we add a community-based learning assignment in order to strengthen the Context dimension of the border course. After teaching the college writing course I also reflected a great deal on the importance of helping learners to develop critical thinking and reflective judgment skills as will be discussed further in chapter four. Additionally, I reflected on the developmental level of students in the college writing course, and considered how their socio-economic backgrounds, choices of majors, and level in college (mostly first year) impacted their sustainability learning. This allowed me to be very purposeful in planning for the border course, especially in designing class activities and later in leading group reflection sessions. The sequencing of these two courses allowed for an iterative and reflective action research process.

\section{Research Participants}

There were 12 student participants in the border course, 8 of whom were women. The participants ranged in age from 20 to 30 years old, and all were full time students. The majority of students were White (10) and 8 different majors were represented in the class. All students lived off campus, commuting to school and in most cases working 20 hours or more per week while in school. Most students had work and travel experience before they came to college. The demographics of the participants in this course are represented in the table below. All names have been changed to protect confidentiality. 
Table 1

Participants in the Border Course

Name Age Ethnicity

Year

Major

Work-

hrs/week

\begin{tabular}{llllll}
\hline Anne & 24 & White & Senior & Anthropology & 0 \\
Ethan & 24 & White & Junior & Comm. Dev. & 20 \\
Liam & 29 & White & Senior & Social Science & 25 \\
Emily & 24 & White & Junior & Comm. Dev. & 30 \\
David & 30 & White & Soph & Anthropology & $20-25$ \\
Jessica & 25 & White & Senior & Liberal Arts & $30+$ \\
Lily & 21 & White & Junior & Anthropology & $20-25$ \\
Mia & 21 & N/A & Senior & Spanish & $0-5$ \\
Isabel & 20 & Latina & Soph & Intl Studies & 14 \\
Alexis & 20 & White & Soph & Liberal Studies & 6 \\
Sarah & 25 & White & Junior & Vocal Performance & $20-25$ \\
Andrew & 22 & White & Soph & Economics & 30 \\
\hline
\end{tabular}

In the college writing course there were also 12 students, 9 of whom were women. A total of 9 students were in their first semester of college as Freshmen at the University of Portland. The students ranged in age from 17 to 19 years of age. The majority of these students were White (8) and most were nursing majors (8). All but one of these students lived on campus, and only 4 of these students worked while in 
school. Most reported paying for school through a combination of scholarships, grants, loans and parental help. All but one student had come straight to college from high school. The demographics of these participants are represented in Table 2. All names have been changed to protect confidentiality.

Table 2

Participants in College Writing

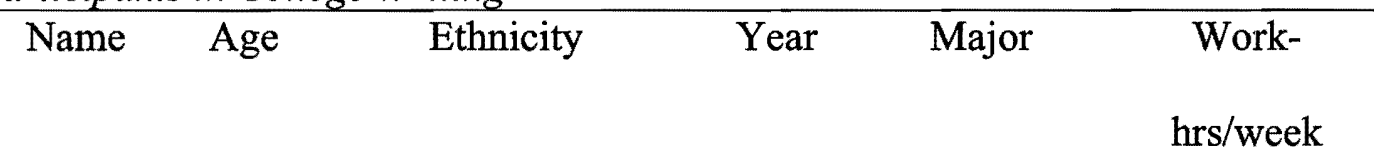

\begin{tabular}{lcllll}
\hline Kaitlin & 18 & White & Fresh & Nursing & $6-15$ \\
Katrina & 17 & Filipino & Fresh & Nursing & 0 \\
Keegan & 19 & White & Fresh & Undecided & 0 \\
Sophie & 19 & White & Fresh & Nursing & 0 \\
Miley & 18 & Japanese/Hawaiian & Fresh & Nursing & 0 \\
Bill & 19 & White & Soph & Undecided & 0 \\
Ben & 19 & Chinese & Soph & Business & 0 \\
Jill & 19 & White & Soph & Biology & 0 \\
Natalie & 18 & White & Fresh & Nursing & $10-20$ \\
Kylie & 18 & White & Fresh & Nursing & 10 \\
Emilia & 18 & Latina & Fresh & Nursing & $5-10$ \\
Emma & 18 & White & Fresh & Nursing & 0 \\
\hline
\end{tabular}

Since this research focused on the implementation of the Burns model of sustainability pedagogy in the two previously described courses, the participants in 
this action research study included students enrolled in these courses as outlined above. While the students were not researchers, they were key participants in the process. Participants also included myself as action researcher, and my co-instructor at PSU in the border course. As an action research project, this research was a collaborative effort that drew on the experiences of all participants.

\section{Data Collection}

Before beginning this research I submitted an application to the Human Subject Review Committee at Portland State University, and a separate application to the Human Subject Review Board at the University of Portland. Once I received approval from both institutions, I began my research. The purpose of the study was explained to students in both courses and each student was asked to voluntarily sign an informed consent form. The data collection required a number of strategies, which varied for each dimension and for each course. For each of the first four dimensions, Content, Perspectives, Process, and Context, I identified the general goal of the dimension. These goals were developed based on the conceptual and theoretical literature, as overviewed in chapter 2 , about what sustainability teaching and learning should accomplish. Then for each dimension and each course, I identified a benchmark outcome that describes what students would know or be able to do as a result, and one or two data collection strategies for each course that focused on this benchmark.

The benchmark outcomes are grounded in Bloom's Taxonomy of learning, which assigns various levels to different kinds of cognitive learning. Within Bloom's 
taxonomy, there are six hierarchical levels of cognitive learning including knowledge, comprehension, application, analysis, synthesis, and evaluation (Bloom \& Krathwohl, 1956). Each level builds on previous levels so that a student functioning at the evaluation level has also mastered the material at other levels. Therefore, the benchmark outcomes (or goals) of student learning for the Burns model are primarily focused at the highest levels of the taxonomy, synthesis and evaluation. This is because these levels best reflect the goals of learning about complex sustainability issues. Synthesis refers to combining ideas to create new meaning, while evaluation refers to making value decisions, interpretations and developing opinions and solutions.

The data collected for this study are both qualitative and quantitative. However, because of the small number of participants and the descriptive nature of this research, the qualitative data has more potential to provide the thick description necessary to deeply understand the connections between the Burns model of sustainability pedagogy and student learning.

\section{Content}

The first dimension of the Burns model of sustainability pedagogy is Content and the goal of this dimension is to increase learners' systemic understanding of complex sustainability issues.

Course One: "The Border Course"

Benchmark Outcome: Learners will create a new understanding of sustainability that reflects multiple, interrelated dimensions (such as immigration 
policy, environmental policy, cultural values, economic history, politics, and ethical issues).

This benchmark falls into the synthesis category of Bloom's taxonomy, meaning that learners are able to creatively apply prior knowledge and skills to produce a new or original understanding. This benchmark reflects the overall goal of the Content dimension of the Burns model, which is for learners to gain a more systemic and multidimensional understanding of sustainability through the use of thematic sustainability Content. In addition, the benchmark definition reflects a constructivist perspective by focusing on the creation of a new perspective, built on previous learning and understanding. Rather than learning about sustainability though the lens of just one discipline, students can synthesize what they have learned about various aspects of a sustainability issue, and create a new understanding of sustainability through this synthesis. This synthesis requires the ability to recognize patterns, relationships, and cause and effects between various aspects of sustainability in the US Mexico border region.

Data Collection Strategy: (1) Students completed a one-page pre and post reflective writing assignment with the following prompts: "In your own words, define a sustainable community." The pre and post reflective writing assignment gave students an opportunity to express their understanding of sustainable communities both at the beginning of the course and at the end. This assignment also gave them a chance to reflect on their own connection to sustainability both at the beginning and at 
the end of the course. I created and made use of a rubric in order to assess changes in students' understanding of sustainability as reflected in their writing.

Stevens and Levi (2004) posit that rubrics can be useful tools for systematically assessing student learning. A rubric aided me in effectively comparing writing assignments using the same criteria. Rubric 1 was used for assessing the pre and post reflective writing.

Figure 7. Rubric 1.

\begin{tabular}{|l|l|l|}
\hline Rating & Description & Notes \\
\hline 4- highest & $\begin{array}{l}\text { A sustainable community (or } \\
\text { sustainability) is described as having } \\
\text { multiple and interrelated dimensions. } \\
\text { These relationships are explored and } \\
\text { connections are made between various } \\
\text { dimensions. }\end{array}$ & \\
\hline 3 & $\begin{array}{l}\text { A sustainable community (or } \\
\text { sustainability) is described as having } \\
\text { multiple dimensions, but the relationships } \\
\text { between these dimensions are not fully } \\
\text { described. }\end{array}$ & \\
\hline 2 & $\begin{array}{l}\text { A sustainable community (or } \\
\text { sustainability) is described as having } \\
\text { multiple but unrelated dimensions. }\end{array}$ & \\
\hline 1 & $\begin{array}{l}\text { A sustainable community (or } \\
\text { sustainability) is described as one } \\
\text { dimensional (i.e. environment, recycling) }\end{array}$ & \\
\hline
\end{tabular}

In addition, I asked each student to reflect in writing on the comparison between their own pre and post writing. (2) Students who chose to do so participated in a post-course focus group. At the end of the course after grades had been given, all students were invited to participate in a focus group interview conducted by the researcher. Three students participated in the focus group which took place at my 
home. The majority of students from the border course expressed interest in participating, but scheduling the focus group proved difficult. The following interview question was used for this dimension: "How did your understanding of sustainability in the US Mexico border region change as a result of this course?" This focus group question gave students a chance to express in their own words how their conceptions of sustainability changed.

Course Two: "College Writing"

Benchmark Outcome: Learners will create a new understanding of sustainability that reflects multiple, interrelated dimensions.

Data Collection Strategy: (1) Students completed a pre and post brainstormed list and concept map about sustainability. Students were asked to create a brainstormed list of all the things that came to mind with the term sustainability. Then, students were asked to create a concept map of this term. At the end of the course, after students completed the activity a second time, they were given a copy of their first version and were asked to write about the differences they saw. This allowed students to think about and comment on changes that may have taken place in their conceptualization of sustainability. By comparing the pre and post assignments, and using the rubric developed for this purpose, I assessed if students were able to create a new multidimensional understanding of sustainability after taking this course. See Rubric 1 above.

(2) Four students from this class volunteered to participate in a post course focus group, which took place in a student lounge at the University of Portland. The 
focus group included the question: How did your understanding of sustainability in Portland change as a result of taking this course? The focus group question gave students the opportunity to describe if and how their understanding of sustainability changed. The goals, benchmark definitions and data collection strategies for the Content dimension are summarized in Table 3. 
Table 3

Content Dimension: Data Collection

$\begin{array}{lccc}\text { Goal \& related } & \text { Benchmark } & \text { Course 1 } & \text { Course 2 } \\ \text { learning theory } & \text { definition } & \text { data collection } & \text { data collection } \\ & & \text { strategy } & \text { strategy }\end{array}$

\begin{tabular}{llll}
\hline To increase & Learners will create & 1) Pre and post & 1) Pre and post \\
learners' systemic & a new & reflective writing. & brainstorm list and \\
understanding of & understanding of & Reflective writing & concept map. \\
complex & sustainability that & on the comparison & Reflective writing \\
sustainability & reflects multiple, & of pre and post & on the comparison \\
issues & interrelated & 2) Post-course & of pre and post \\
& dimensions & focus group: How & 2) Post-course \\
Constructivism & & did your & focus group: How \\
& & understanding of & did your \\
& & sustainability in the & understanding of \\
& & US Mexico border & sustainability in \\
& & region change as a & Portland change as \\
& & result of this & a result of taking \\
& & course? & this course? \\
& & &
\end{tabular}




\section{Perspectives}

The second dimension is Perspectives and the goal of this dimension is to provide learners with opportunities to think critically about dominant paradigms, practices and power relationships and to consider complex ecological and social issues from diverse Perspectives.

\section{Course 1: "The Border Course"}

Benchmark outcome: Learners will have the opportunity to critique the underlying causes of complex problems in the US-Mexico border region, comparing and contrasting diverse Perspectives in the region. This benchmark reflects the evaluation stage of Bloom's taxonomy in which learners make judgments about material, and form opinions. Learners are able to both show they have had a chance to think critically about dominant paradigms and power relationships that are root causes or hurdles to sustainability, and may be able to make initial suggestions about how the region can move toward sustainability based on comparing a variety of diverse Perspectives. This benchmark definition reflects critical theory in that non-dominant Perspectives, root causes and power relationships will be uncovered.

Data Collection Strategy: Students wrote an 8 page research paper which demonstrated the ability to examine one issue related to sustainability in the border region in depth, including identifying and critiquing underlying causes of sustainability problems, and comparing and contrasting various Perspectives about the sustainability issue. 
Asking students to research and write about one sustainability issue of their choosing in the border region provided a focused opportunity for students to express their learning about the topic from diverse Perspectives based on reading, research, speakers and travel. By writing about one sustainability issue from multiple Perspectives, and showing that they understand how dominant practices and power relationships have affected this issue, they demonstrate that the course has provided opportunities to think critically about these issues and to be exposed to diverse Perspectives. Rubric 2 was used for assessing this essay in relationship to the benchmark definition.

Figure 8. Rubric 2.

\begin{tabular}{|l|l|l|l|l|}
\hline & 1 & 2 & 3 & 4 \\
\hline $\begin{array}{l}\text { Research assignment } \\
\text { critiques underlying } \\
\text { causes of complex } \\
\text { problems }\end{array}$ & $\begin{array}{l}\text { Doesn't mention } \\
\text { underlying } \\
\text { causes }\end{array}$ & $\begin{array}{l}\text { Underlying } \\
\text { causes } \\
\text { mentioned but } \\
\text { not explained }\end{array}$ & $\begin{array}{l}\text { Underlying } \\
\text { causes referred } \\
\text { to and explained } \\
\text { simplistically }\end{array}$ & $\begin{array}{l}\text { Critiques } \\
\text { underlying } \\
\text { causes; shows } \\
\text { clear } \\
\text { understanding of } \\
\text { power } \\
\text { relationships \& } \\
\text { dominant } \\
\text { paradigms }\end{array}$ \\
\hline $\begin{array}{l}\text { Research assignment } \\
\text { offers sustainability } \\
\text { recommendations } \\
\text { based on multiple, } \\
\text { diverse perspectives }\end{array}$ & $\begin{array}{l}\text { Offers no } \\
\text { recom- } \\
\text { mendations, } \\
\text { shows only one } \\
\text { perspective }\end{array}$ & $\begin{array}{l}\text { Offers simplistic } \\
\text { recom- } \\
\text { mendations } \\
\text { based on one or } \\
\text { two perspectives }\end{array}$ & $\begin{array}{l}\text { Offers recom- } \\
\text { mendations } \\
\text { based on several } \\
\text { perspectives }\end{array}$ & $\begin{array}{l}\text { Offers } \\
\text { sustainability } \\
\text { recom- } \\
\text { mendations } \\
\text { based on a } \\
\text { variety of } \\
\text { diverse } \\
\text { perspectives }\end{array}$ \\
\hline
\end{tabular}

\section{Course 2: "College Writing"}

Benchmark Outcome: Learners will be able to critique the underlying causes of complex problems, and make recommendations about sustainability based on comparing and contrasting diverse Perspectives. 
Data Collection Strategy: students wrote a five-page argument essay in which they identified a sustainability problem and made an argument for a sustainable solution based on an understanding of diverse Perspectives.

In this argument essay, students had the opportunity to express critical thinking about unsustainable paradigms, practices and power relationships in relationship to a sustainability issue of their choosing. They also had the opportunity to offer suggestions for sustainable change based on their understanding of diverse Perspectives gained through reading, class activities, visits and speakers. Rubric 2 was the assessment rubric used for this dimension. The goals, benchmark definitions and data collection strategies for the Perspectives dimension are summarized in Table 4. 
Table 4

Perspectives Dimension: Data Collection

\begin{tabular}{|c|c|c|c|}
\hline Goal \& related & Benchmark & Course 1 & Course 2 \\
\hline \multirow[t]{2}{*}{ learning theory } & definition & data collection & data collection \\
\hline & & strategy & strategy \\
\hline To provide learners & Course 1: Learners & 8 page research & 5 page argument \\
\hline with opportunities & will have the & paper which & essay which \\
\hline to think critically & opportunity to & demonstrates the & identifies a \\
\hline about dominant & critique the & ability to examine & sustainability \\
\hline paradigms, & underlying causes & one issue related to & problem and makes \\
\hline practices and & of complex & sustainability in the & an argument for a \\
\hline power relationships & problems in the & border region from & sustainable \\
\hline and to consider & US-Mexico border & diverse & solution based on \\
\hline complex ecological & region, and & perspectives & an understanding \\
\hline and social issues & compare and & & of diverse \\
\hline from diverse & contrast diverse & & perspectives \\
\hline perspectives & perspectives in the & & \\
\hline & region & & \\
\hline Critical Theory & Course 2: & & \\
\hline & Learners will have & & \\
\hline & the opportunity to & & \\
\hline & critique the & & \\
\hline
\end{tabular}


underlying causes

of complex

problems and make

recommendations

about sustainability

based on

comparing and

contrasting diverse

perspectives

Process

The third dimension of the Burns model is Process and the goal of this dimension is to provide opportunities for active participation and experience, and in doing so to enhance learners' civic responsibility and intentions to work toward sustainability.

\section{Course 1: "The Border Course"}

Benchmark Outcome: Learners will relate sustainability in the border region to their own lives and will express an intension to act for sustainable change. This benchmark also reflects the evaluation stage of Bloom's Taxonomy because learners will relate what they have learned to themselves and make decisions based on what they have learned. In this case, students show that their civic responsibility and intensions to work towards sustainability are enhanced if they can relate sustainability 
in the border region to sustainable action in their own lives. Civic responsibility and intentions to work for change are enhanced through active participation in the class sessions, and by direct experience in the US Mexico border region. The Process by which this change takes place is rooted in experiential learning. Throughout the course, students have opportunities for direct experience as well as reflection and conceptualization. They will then be ready to make decisions about what actions they might take, based on this experience.

Data Collection Strategy: (1) Students wrote 3-5 page end of term reflections in which they were asked: How might your experience in this course affect your future involvement in sustainability issues at the border or locally?

(2) An after course focus group included the question: How do you think what you experienced in this course will affect your life in the future?

Both of these data collection strategies gave students the opportunity to express if and how active participation and experience in the course led to any intentions to take action based on what they learned, thereby showing enhanced civic responsibility and intentions to work toward sustainability through the active and experiential learning Process. A rubric was used for assessing the end of term reflections. See Rubric 3. 
Figure 9. Rubric 3.

\begin{tabular}{|l|l|l|}
\hline Rating & Description & Notes \\
\hline 3 - highest & $\begin{array}{l}\text { A specific intention to act for change is } \\
\text { expressed based on experience in the class } \\
\text { and personal connection to sustainability }\end{array}$ & \\
\hline 2 & $\begin{array}{l}\text { Connection is made between sustainability } \\
\text { and own life }\end{array}$ & \\
\hline 1 & $\begin{array}{l}\text { No personal connection to sustainability } \\
\text { and no intention expressed to work for } \\
\text { change }\end{array}$ & \\
\hline
\end{tabular}

\section{Course 2: "College Writing"}

Benchmark Outcome: Learners will relate sustainability to their own lives and will express an intension to act for sustainable change. Students will show that their civic responsibility and intensions to work towards sustainability are enhanced if they can relate sustainability to sustainable action in their own lives. Throughout the course, students participated in an experiential learning Process in which they had opportunities for direct experience as well as reflection and conceptualization. They were then ready to reflect on what actions they might take, based on this experience.

Data Collection Strategy: (1) Students wrote 1-2 page end of term reflections in which they were asked: How might your participation and experience in this course have an effect on your life and your involvement in sustainability issues?

(2) The focus group included the question: How do you think what you experienced in this course will affect your life in the future?

These strategies gave students the opportunity to express if and how active participation and experience led to intentions to take action, thereby showing enhánced civic responsibility and intentions to work toward sustainability as a result 
of the participatory and experiential learning Process. Rubric 3 was used to assess the end of term reflective writing assignment. The goals, benchmark definitions and data collection strategies for the Process dimension are summarized in Table 5.

Table 5

\section{Process Dimension: Data Collection}

Goal \& related Benchmark

Course 1

definition

learning theory
Course 1

data collection

strategy

\section{Course 2}

data collection

strategy

\begin{tabular}{|c|c|c|c|}
\hline To provide & Course 1: Learners & 1) End of term & 1) End of term \\
\hline opportunities for & will relate & reflections: How & reflections: How \\
\hline active participation & sustainability in the & might your & might your \\
\hline and experience, & border region to & experience in this & participation and \\
\hline and in doing so to & their own & course affect your & experience in this \\
\hline enhance learners' & communities or & future involvement & course have an \\
\hline civic responsibility & lives and will & in sustainability & effect on your life \\
\hline and intentions to & express an & issues at the border & and your \\
\hline work toward & intension to act for & or locally? & involvement in \\
\hline sustainability & sustainable change & 2) Focus group: & sustainability \\
\hline & Course 2: Learners & How do you think & issues? \\
\hline Experiential & will relate & what you & 2) Focus group: \\
\hline Learning Theory & $\begin{array}{l}\text { sustainability to } \\
\text { their own lives and }\end{array}$ & $\begin{array}{l}\text { experienced in this } \\
\text { course will affect }\end{array}$ & $\begin{array}{l}\text { How do you think } \\
\text { what you }\end{array}$ \\
\hline
\end{tabular}




\begin{tabular}{lll}
\hline will express an & your life in the & experienced in this \\
intension to act for future? & course will affect \\
sustainable change & your life in the \\
& future? \\
\hline
\end{tabular}

\section{Context}

The fourth dimension of the Burns model of sustainability pedagogy is Context and the goal of this dimension is to increase learners' understanding of and connection with the geographical place and the community in which they live.

\section{Course 1: "The Border Course"}

Benchmark Outcome: Learners will connect their understanding of sustainability issues in the border region with their own geographical place and community. This benchmark correlates to the synthesis level of Boom's taxonomy in which learners are creating new understandings by combining what they are learning with other knowledge. In this case, what learners already know about their home community and place may have been increased by understanding how their community is connected to sustainability in the US Mexico border region.

Data Collection Strategy: At the end of the course, students were asked to complete a reflective writing assignment in which they answer the question: Having completed this course, what connections do you see between sustainability in the US Mexico border region and sustainability in your community? Has this course increased your sense of connection to the Portland area? 
Asking these question allowed the researcher to assess if students have gained an increased understanding of how sustainability issues at the border connect to the Context where the majority of learning in this course happened (Portland, OR). These questions also helped to assess if learners gained an increased connection to place, by emphasizing the learning Context in this course. Rubric 4 was helpful in making this assessment.

Figure 10. Rubric 4.

\begin{tabular}{|l|l|l|}
\hline Rating & Description & Notes \\
\hline 4 highest & $\begin{array}{l}\text { Specific connections between } \\
\text { sustainability and own place/community } \\
\text { Personal connections to place have been } \\
\text { enhanced }\end{array}$ & \\
\hline 3 & $\begin{array}{l}\text { Some connections made including some } \\
\text { personal connections }\end{array}$ & \\
\hline 2 & $\begin{array}{l}\text { Some connections made, no personal } \\
\text { connections to place }\end{array}$ & \\
\hline 1 & No connections to place/community & \\
\hline
\end{tabular}

\section{Course 2: "College Writing"}

Benchmark Outcome: Learners will understand sustainability in the Context of the ecosystems and communities of Portland and will make personal connections to place. This benchmark is based in the synthesis level of Blooms taxonomy. Students revise their understanding of sustainability based on new knowledge and experience within a specific Context. This synthesis takes place within a specific Context.

Data Collection Strategy: In end of term reflections, students answered the following question: How has your understanding of the Portland area changed as a result of the speakers, visits, and readings in this course? How has your connection to 
this bioregion/community changed (if at all) as a result of taking this class? Student responses were assessed with the use of rubric 4 . The goals, benchmark definitions and data collection strategies for the Context dimension are summarized in Table 6. Table 6

Context Dimension: Data Collection

$\begin{array}{cccc}\text { Goal \& related } & \text { Benchmark } & \text { Course 1 } & \text { Course 2 } \\ \text { learning theory } & \text { definition } & \text { data collection } & \text { data collection } \\ & & \text { strategy } & \text { strategy }\end{array}$

\begin{tabular}{llll}
\hline Increase learners' & Course 1: Learners & End of term & End of term \\
understanding of & will connect their & reflective writing: & reflective writing: \\
and connection & understanding of & Having completed & How has your \\
with the & sustainability & this course, what & understanding of \\
geographical place & issues in the border & connections do you & the Portland area \\
and the community & region with their & see between & changed as a result \\
in which they live & own geographical & sustainability in the & of the speakers, \\
& place & US Mexico border & visits, and readings \\
Critical Theory of & Course 2: Learners & region and & in this course? \\
Place; & will understand & sustainability in & How has your \\
Situated & sustainability in the & your community? & connection to this \\
Experiential & context of the & Has this course & bioregion/communi \\
Learning Theory & ecosystems and & increased your & ty changed (if at \\
& communities of & sense of connection & all) as a result of \\
\hline
\end{tabular}




Portland and will to the Portland taking this class?
make personal area?
connections to
place

\section{Design}

The fifth dimension of the Burns model of sustainability pedagogy is Design. Within this model, ecological course Design is an important dimension that effectively ties the other dimensions together. In order to understand how the proposed pedagogical Design was implemented within two postsecondary courses and if this would be a transformative learning experience for students, I kept a research journal that included my reflections on the process of course Design, including the writing of syllabi and the planning of course activities and assignments. Throughout the course, my written reflection on the implementation of the Design and its implications in class was important for exploring the research questions. I structured my own reflection of the course planning using Hemenway's (2005) ecological design process, which includes observation, visioning, planning, and development as discussed in chapter 2 . In addition, I structured my observations and reflections of the courses in two ways. First, I used a table with the dimensions of the model as a guide for note taking and reflection. For each class session, I recorded observations about each dimension of the Burns model, how the dimensions were included in the session, and reflections on student responses. See Rubric 5. I also used a researcher journal in which to record my 
thoughts and reflections on the teaching and research process. My research journal includes thick descriptions of class activities and discussions as well as other critical incidents that help to describe the ongoing effects of the Design process.

Figure 11. Rubric 5.

\begin{tabular}{|l|l|l|l|}
\hline Dimension: & $\begin{array}{l}\text { Planned } \\
\text { activity }\end{array}$ & $\begin{array}{l}\text { Observations and reflections } \\
\text { on students response }\end{array}$ & $\begin{array}{l}\text { Observations and } \\
\text { reflection on my } \\
\text { own actions }\end{array}$ \\
\hline Content & & & \\
\hline Perspectives & & & \\
\hline Process & & & \\
\hline Context & & & \\
\hline
\end{tabular}

Furthermore, an interview with my co-instructor for Course One ("The Border Course") provided insight into the research questions related to the Design dimension. This peer interview added to the validity of this study by supplying another perspective on the Burns model besides students' and my own, thus providing triangulation for data collection on the Design dimension.

This interview explored the following questions in depth: (a) How do you think using the Burns model of sustainability pedagogy in the design of this course impacted student learning? (b) Which pedagogical strategies had the greatest impact on learners? (c) How applicable is the Burns model of sustainability pedagogy to other courses that you teach? The post-course focus group interviews with students were 
also a place to ask questions about the Design dimension of this model. I included the following questions in student focus groups: (a) What teaching strategy (ie readings, class activities, speakers, field trips) had the greatest impact on your sustainability learning? (b) Do you think that the way this course was taught—with a focus on the Content, Perspectives, Process and Context and Design dimensions of sustainability learning--could be applied to other courses you are taking?

Asking these questions helped me better understand what students thought of the Design process and implementation, the effect it had on their learning, and whether or not they thought this way of learning sustainability is transferable to other courses. The goals, benchmark definitions and data collection strategies for the Design dimension are summarized in Table 7. 
Table 7

Design Dimension: Data Collection

$\begin{array}{cccc}\text { Goal \& related } & \text { Benchmark } & \text { Course 1 } & \text { Course 2 } \\ \text { learning theory } & \text { definition } & \text { data collection } & \text { data collection } \\ & & \text { strategy } & \text { strategy }\end{array}$

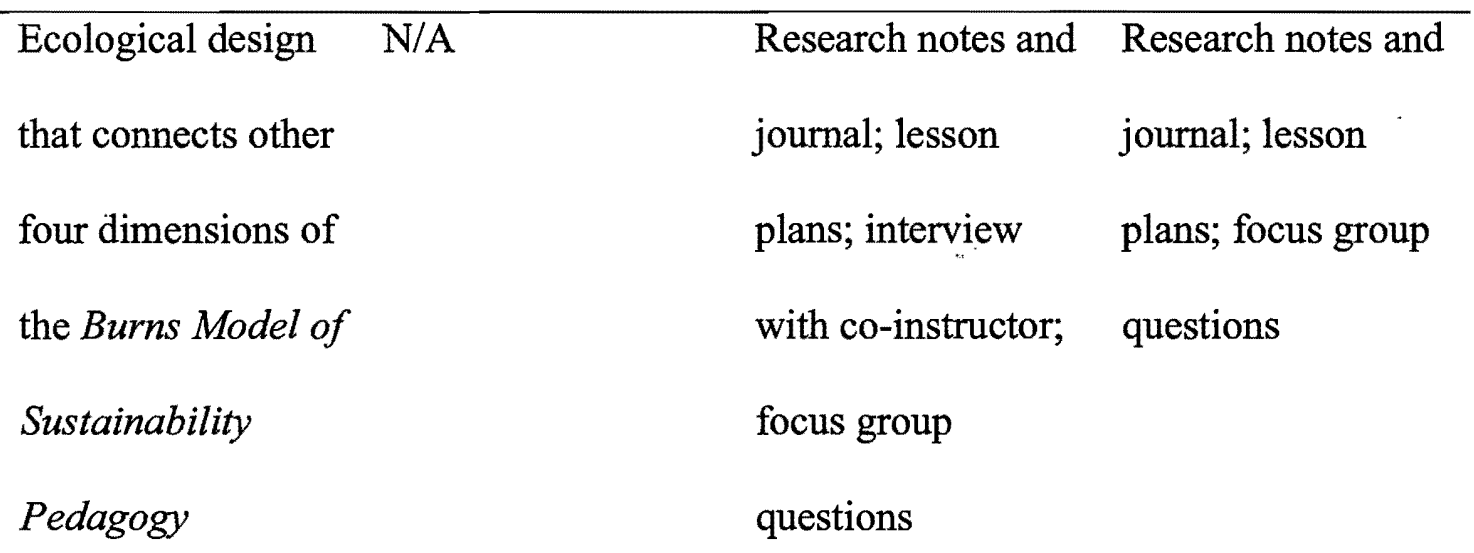

Transformational

Learning Theory

Surveys

In addition to the data collection strategies that are specific to each dimension of the Burns model, several surveys were used to collect information about student participants and their learning within the courses. At the beginning of each course, I administered a student characteristics and subject knowledge survey in order to understand more about participants and the subject knowledge they had prior to taking the course. See "Student Characteristics \& Pre-Post Subject Knowledge Survey" in appendix $\mathrm{C}$. The subject knowledge survey was re-administered at the end of the 
course to determine if there was a self-reported change in subject knowledge. This pre-post subject knowledge survey helped to show if students gained key subject knowledge in a course in which the Burns model of sustainability pedagogy was applied. Additionally, an end of course survey measured students' self-reported learning based on various on learning/teaching techniques. This survey listed an outcome goal for each of the first four dimensions of the Burns model, Content, Perspectives, Process, and Context, and asked students to rank their learning in relation to each goal. See "Post course evaluation of teaching techniques $\&$ dimensions of Burns model" survey in Appendix C. These surveys were adapted from a "Post Course Inventory and Evaluation" survey created and used by Rosalyn McKeown (personal communication, June, 14, 2008).

\section{Data Analysis}

This research was centered on testing the applicability of a theory, in this case the Burns model of sustainability pedagogy. However, this research is also rooted in grounded theory, meaning that additional data arose from, or was grounded in, the data that was collected (Glaser \& Strauss, 1967). This is important because theory that arose from the data helped to further shape the Burns model of sustainability pedagogy. As described, data was collected in a variety of ways including: pre and post reflective writing and mapping assignments; essays; researcher class notes and lesson plans; a co-instructor interview and focus group interviews, which were transcribed. All of these forms of data were collected and coded on an ongoing basis by the researcher. According to Coffey and Atkinson (1996), coding is a mixture of 
data reduction, breaking data into general categories, and is used to expand the data, to ask new questions, think creatively about the data and generate theories. Strauss (1987) explains that coding is the process of beginning the inquiry and moving toward interpretation.

As data were gathered, the process of beginning to analyze and interpret the results was ongoing. Thus, I used the constant comparative method of analysis in order to continually review existing data and compare and categorize new data based on the coding of that data (Glaser \& Strauss, 1967). As categories and theories emerged from the data in which they were grounded, I wrote researcher memos about this process. According to Maxwell (2005), researcher memos are important because they capture the researcher's analytic thinking about the data, and stimulate analytic insight.

\section{Validity}

Since the validity of action research is sometimes questioned, Herr and Anderson (2005) have developed validity criteria for action research, which are linked to the goals of action research. They describe these goals as, "(a) the generation of new knowledge, (b) the achievement of action-oriented outcomes, (c) the education of both researcher and participants, (d) results that are relevant to the local setting, and (e) a sound and appropriate research methodology" (pg. 54). The validity criteria for action research are: dialogic and process validity, outcome validity, catalytic validity, democratic validity and process validity. Acknowledging issues of validity and 
incorporating appropriate measures to address each of these measures of validity, is an important part of this action research design.

Process validity has to do with whether or not the process of the research is sound. The triangulation of data, using a variety of methods and multiple perspectives, serves to validate findings. As described in the previous section, I used variety of data collection strategies in order to triangulate data as much as possible and provide multiple perspectives on each dimension of the Burns model in relationship to student learning.

Outcome validity has to do with the integrity of the action that comes from the research. Outcome validity acknowledges that action research does not simply solve a problem, but reframes the problem in a more complex way over a sustained period of inquiry. Based on the outcomes of this action research, I am now able to reframe the problem of sustainability pedagogy and make adjustments to the Burns model.

Catalytic validity refers to the extent to which the research process reorients participants' (including the researcher's) understanding of reality. A research journal can play an important role in documenting the researcher's own change process and thus validating the research. I kept a detailed research journal throughout this action research study, which helped to document my learning process. Students' learning processes and changes in understanding of reality are reflected in the data, since this research focuses specifically on student learning.

Democratic validity has to do with the extent to which research is done in collaboration with those who have a stake in the problem, and the degree to which the 
products of the research are relevant to the participating group. This research was conducted in collaboration with students, who have a stake in their own learning. The degree to which the research has affected students' learning process and lives is reflected in the data, since much of the data collection focuses on this. My collaboration with a co-instructor also contributed to the democratic validity of this study. As an educator of sustainability, she also had a stake in the problem, and learning about implementing the Burns model of sustainability pedagogy was relevant to her current and future work.

\section{Limitations}

This research is limited to the results that were generated from the study of just two courses and thus will not be generalizable to all postsecondary courses. In addition, this study does not attempt to identify and quantify specific student learning outcomes that result from the Burns model of sustainability pedagogy, but rather looks descriptively at the relationship between the model and student response. As such, the research is limited.

Another limitation is that since I designed and taught the courses, I needed to carefully monitor how my own assumptions, expectations, biases and feelings influenced the research process. My research journal helped me to be able to reflect back on my assumptions and expectations and carefully monitor my process. In addition, collaboration and an interview with a co-instructor in the border course provided me with a perspective outside of my own. My many years of teaching 
university courses, through which I have developed a reflective teaching practice, has been a significant asset to this process.

\section{The Positionality of the Researcher}

My personal interest in sustainability education and pedagogy initially developed from the experience of living many of my early years in the Global South (in Cote d'Ivoire, W. Africa) where I became aware of the deep connections between social inequity, ecological degradation, and economic policy. Through additional learning experiences in Latin America as an undergraduate student and later as a graduate student, I gained not only a more in-depth understanding of global sustainability issues, but also a clear understanding of the need for education that addresses these issues. Through these educational experiences I also gained first-hand knowledge of the power of experiential learning for creating change.

My commitment to sustainability education is also grounded in 15 years of professional experience in postsecondary education, during which I have come to realize that postsecondary learning in the United States does not, on the whole, promote a deep and interconnected understanding of complex issues. As such, I believe that postsecondary education is not effectively educating learners about their social and ecological responsibilities, or preparing them adequately for sustainable and thoughtful livelihoods in the places where they live. As an ecofeminist educator, I feel that postsecondary education has a responsibility to protect the earth, and to help develop sustainable and equitable communities that respect both people and places. My own previous research has focused on social justice pedagogy in postsecondary 
settings. The study of sustainability pedagogy has thus been a natural extension of my personal commitment and my previous academic work. Therefore, as an insider committed to action for success (for change in educational culture), I seek to maintain a scholarly yet passionate commitment to the exploration of the theory and practice of sustainability pedagogy.

\section{Significance of the study}

In light of our current ecological and socio-cultural crises, postsecondary educators have a responsibility to prepare learners to address sustainability. Testing the Burns model of sustainability pedagogy has provided important new insight about how sustainability can be incorporated into the design of a course, and what effects this has on learners. In the process of conducting this research, I discovered how the Burns model of sustainability pedagogy can be applied to postsecondary settings, and how this model can be implemented for most effective sustainability teaching and learning. This study is important because a strong model of sustainability pedagogy could be useful for a variety of postsecondary educators from many different disciplines who seek to incorporate sustainability into their courses, not just as information about sustainability, but as a learning process that empowers and prepares learners to be active leaders and change makers in their community places. This study may be a start in recognizing that there can be a shift from teaching about sustainability to teaching and learning as sustainability. The following chapters discuss the results of this study and its further implications. 


\section{CHAPTER IV}

\section{RESULTS}

The following chapter is organized according to the results from the data collection and analysis process in relationship to the research questions that guided this study. The research questions for each of the five dimensions of the Burns model of sustainability pedagogy are addressed, in addition to the benchmark outcomes for each dimension.

The first question, What are the effects of implementing the Burns model of sustainability pedagogy in university courses? is divided into sub-questions according to the dimensions of the Burns model.

\section{Content: Understanding Sustainability}

The first of these sub-questions is (1) How do learners understand sustainability issues? The benchmark outcome for both courses was: Learners will create a new understanding of sustainability that reflects multiple, interrelated dimensions. The following table gives an overview of the Content dimension and the findings of this study. 
Table 8

Content Dimension: Results

Dimension Content findings

Research Question How do learners understand sustainability issues?

Benchmark Outcome Learners will create a new understanding of sustainability that reflects multiple, interrelated dimensions

Course One: "The

1. Students understood sustainability more holistically

Border Course" and concretely

2. Students understood sustainability personally and emotionally

Course Two:

1. Students came to understand sustainability through a

"College Writing" change in values

2. Students understood sustainability through the course theme

3. Students understood sustainability as multidimensional

Data Sources for

Findings

Pedagogical

Implications
Pre and post reflective writing and comparison writing, post course focus group, co-instructor interview, research observation/journal

Connecting Content and constructivism 
Course 1: "The Border Course"

In the border course students began with a fairly complex understanding of sustainability but came to understand sustainability more holistically and concretely, primarily through a process that included thematic classroom learning and experiential learning in the border region. Secondly, students in the border course came to understand sustainability very personally and emotionally, primarily through the opportunity for shared group reflection on their experiences.

First, students began the course having a fairly multidimensional understanding of sustainability. Many had taken courses related to sustainability before, or were involved in sustainability issues in their personal lives. Most were drawn to this elective course due to the title: Sustainability in the US Mexico border region. Thus, it was not surprising that I assessed most students' pre-course reflective writing on the question How would you describe a sustainable community? to fall within the 3 or 4 range on the Content research assessment rubric 1 (See Rubric in Appendix B. 3- sustainability is described as having multiple dimensions but these relationships are not fully described; 4- sustainability is described as having multiple and interrelated dimensions. These relationships are explored and connections are made between various dimensions).

Most students wrote about the connections between various dimensions of sustainability including ecological, economic, social, cultural, economic and political. In addition, according to my research journal notes, during a class discussion on the concept of sustainability during the second class session of the term, themes generated 
by students included comprehensive terms such as "cyclical process, communityoriented, and living within our means." I wrote, "There seemed to be a greater understanding (than in past years) of sustainability as a process, as a concept, and not just a rote model of three circles [economic, social, environmental]" (Research journal, 1-16-09). As a subject to understand, students' self reported knowledge of sustainability increased, but only slightly, as shown in the pre and post subject knowledge survey. Students on average rated their knowledge of sustainability at a 4 out of 5 at the beginning of the course, as shown in Table 9. 
Table 9

Comparisons: Pre and Post Student Knowledge Survey (Course One: "The Border Course")

\begin{tabular}{llll}
\hline \multicolumn{1}{c}{ Topics } & \multicolumn{1}{c}{ Pre course } & Post course & Increase \\
& average scores & average scores & In scores \\
\hline Sustainability & 3.91 & 4.16 & .25 \\
Sustainable Food Systems & 3.41 & 3.91 & .5 \\
Alternative Technology & 3.66 & 3.66 & 0 \\
Immigration Policy & 2.83 & 4.08 & 1.25 \\
Economic Globalization & 3.91 & 4.16 & .25 \\
Illegal Immigrants & 3.5 & 4.5 & 1 \\
US Mexico Border Policy & 2.91 & 4.16 & 1.25 \\
Communicating Complex & 3.66 & 3.91 & .25 \\
Issues & & & \\
\hline
\end{tabular}

Note. The scale used for this survey is as follows:

$5=\mathrm{a} \mathrm{lot} ; 4=$ adequate amount; $3=$ some; $2=\mathrm{a}$ little; $1=$ none

$\mathrm{n}=12$

1. Understanding Sustainability Holistically and Concretely

Still, students reported that their understanding of sustainability did change as a result of this course and they began to understand sustainability differently than they had before, with new dimensions. Students came to understand sustainability more holistically and concretely, primarily through their experience in the border region and the examples they encountered of people and organizations that are working for 
sustainability. In the end of course reflection assignment (outlined in the syllabus in Appendix D) Alexis wrote, "My understanding of sustainability changed to include more diverse, human centered systems like business, living situations and food. I also gained many more concrete examples of what sustainability can actually look like." On the same assignment Jessica wrote, "Sustainability in Portland is such a bumper sticker slogan; it was difficult at first to think of it in a concrete and perceivable way. Now, I understand sustainability as more solid and understandable."

In their course reflection assignments, almost all students noted specific examples of people they had met or experiences they had had at the border in describing their understanding of sustainability, showing the importance of this experiential learning approach to their overall understanding of sustainability. Emily wrote, "I feel that in absorbing the information, beliefs, perspectives and stories of people we met in the border region, I view sustainability as the conscience maintenance of the web of life, human and environmental, for today and for the sake of the future."

During the focus group interview, students noted that their concepts of sustainability changed from being more focused on environmental aspects such as recycling or organic farming, to encompassing a larger systemic view of sustainability. Andrew noted that he now placed more of an emphasis on "sustainability from a general perspective, whether that be cultural, financial, or communal" (focus group interview, April 25, 2009). Additionally, in the focus group interview Mia noted 
specific examples of speakers and visits in the border region that widened her perception of sustainability to encompass food cycles and global relationships.

On the last day of class when students completed reflective writing comparing their pre and post reflective writing about sustainable communities, several students expressed that what changed for them was not so much their understanding of sustainability, but that they "believe in it more" or that "the words have more meaning." This was likely due to their trip to the border region, in which they experienced first hand real people and organizations who were facing and addressing sustainability challenges in their day to day lives.

In my co-instructor interview with Celine, she also expressed her opinion that the meaning of sustainability had changed for students in this course. Celine noted,

I think that by the end of the course they really got it, that sustainability is much more than environmental sustainability and were able to see that it has to do with culture and social networks, economic issues, political issues. So they saw from a much broader perspective no doubt about that. And they saw how those pieces are linked. So rather than just isolating one aspect of sustainability, by the end of the term they could see that sustainability is much more complex and that those areas are related (interview 4-11-09).

Students came to understand sustainability as a more multidisciplinary and interconnected concept by the end of the course, and this was largely due to the experiential nature of the course. However, focusing on one sustainability theme, and examining various aspects of this theme week by week also allowed for a very multidimensional exploration of sustainability that went beyond environmental issues. 
In particular, students came to understand that learning sustainability thematically was a complex and non-linear process, one that was messy and confusing at times. Especially during and after the trip to the border, various students reported understanding sustainability as "messy, textured, holistic, interconnected, integrated, having many levels, and confusing." During a reflection session while in the border Lily commented, "I remember in class when you and Celine told us that it would get even more confusing when we were in the border region and now here we are and you were right" (Reflection session, 2-21-09). Students grappled with how to make sense of sustainability in the midst of complicated issues such as poverty and immigration policy. During the trip, I met with each student individually to talk about how they were connecting their learning from the trip to their research topic. These meetings often reflected students' sense of confusion as well as excitement about new concepts and ideas they were experiencing. In my conversations with them, I often found that students were struggling to make sense of new concepts, and construct new meaning about sustainability. However, by the end of the course, this complex and sometimes confusing experiential and thematic learning process contributed to a more holistic and concrete understanding of sustainability. In the post reflective writing, David wrote, "I have a clearer understanding of how the themes of sustainability are actually interconnected with each other, my life in Portland, as well as the lives of those living in the border regions...the issues of sustainability are textured and complex." 


\section{Understanding Sustainability Personally and Emotionally}

Secondly, students in the border course began to understand sustainability very personally and emotionally primarily through critical reflection in a group setting. This reflection led to changes in personal values or the renewal of previously held personal values, and direct connections of the course to their personal lives in a variety of ways. During the trip to the border, students reflected on their experience and related it directly to themselves, asking questions such as "how can I make change?" and "what can I do about this?" Students questioned their own complacency in the light of meeting working-class Mexicans working 6 days a week at low-paying factory jobs to make ends meet, or Mexicans who felt their only hope for a future was to cross into the United States and look for work. In her course reflection assignment Emily wrote, "it was easy at times to feel overwhelmed by the circumstances so many people are faced with... and the ambiguity associated with complex issues at the border."

During the trip, the concept of sustainability shifted from being something academic, to something that was a personal responsibility. Sarah wrote in the course reflection assignment, "In my opinion it is impossible to participate in an experience such as this one and not think about how your own life plays into what is going on in the world." During group reflection sessions at the border, students were often emotional about their experiences and talked about the fear, helplessness, anger and uncertainty they were experiencing. One student reaffirmed his life-long desire to live simply and sustainability, and decided to make concrete changes to this end when returning home by moving and ending a personal relationship. Similarly, another 
student Ethan wrote in his course reflection, "this particular experience (class structure, style of teaching, trip and group dynamics) was pivotal in cementing my desire for personal sustainability; something that I have always struggled with." Many other students expressed intentions to make personal changes in their lives as a result of their new understanding of sustainability and this travel experience. This will be more fully discussed in the Process section.

Having the opportunity for group reflection, primarily during and after the trip to the border, was an important part of how students came to understand sustainability personally and emotionally. Sharing their thoughts and emotions with others in their learning community gave students a chance to make sense of what they were learning, to listen to others who were experiencing similar emotions, and to ask each other questions. On the trip, students talked about looking forward to the next reflection session, because it was an opportunity for them process what they were learning on a personal level.

\section{Course Two: "College Writing"}

Within the college writing course, the answer to this first question, How do learners understand sustainability issues? is somewhat different. Learners began the course understanding sustainability in a very limited way or not at all and expressed a lack of confidence in learning sustainability. However, as a result of this course learners came to understand sustainability through a change in values, and their understanding of sustainability was significantly impacted by the use of a course 
theme. In the end, students' understanding of sustainability as multidimensional increased.

To begin, sustainability was a new concept for most students in college writing and the course represented their first opportunity to learn about this topic in any depth. At end of the course, students expressed just how uncertain they had felt about this topic at the beginning of the course. In the post course focus group interview Miley said, "I didn't really have an understanding of sustainability at all before I took this course. That's why I was a little worried when we started off the course with that" (26-09). In a personal reflection essay at the end of the course, Natalie wrote, "I was shocked to learn that the class would be based around the topic of sustainability. I had no idea what sustainability really meant, and I was almost certain I would not be able to improve my writing skills while writing papers on a subject I didn't know much about." Similarly, Sophie wrote, "At the beginning of the semester when I heard the word sustainability I thought I was going to fail the class miserably because I had no knowledge whatsoever in this topic." Indeed, in pre-course brainstorming and mapping on the concept of sustainability, nearly all student responses fell in the 1 or 2 range on the Content research assessment rubric 1. (See Appendix B. 1-Sustainability is described as one dimensional; 2- Sustainability is described as having multiple but unrelated dimensions). Most students wrote words or concepts that had to do with the environmental aspect of sustainability such as, "green, environment, windmills, water conservation, and organic." 


\section{Understanding Sustainability Through a Change in Values}

However, during the course students began to gain an increased understanding of sustainability, and notably they began to describe sustainability through a change in values. In their post-course brainstorming and mapping of the concept of sustainability, 11 out of 12 students included value-laden language to describe sustainability, while only 2 students had used any value-laden language in the precourse brainstorming and mapping activity. This language included terms such as "better for the environment" or "good land stewards" or "less pollution" or "less oil" or "healthy, community-friendly, earth-friendly." In the post course reflective writing exercise in response to the question, How has your understanding of sustainability changed over the course of this semester? Sophie wrote, "I went from knowing absolutely nothing to knowing a lot. I have gained a whole new appreciation for the people that keep this subject close to their hearts and live like this on a daily basis."

On a deeper level, many students commented that their understanding of sustainability changed their personal values about what is important. In the focus group interview, Emilia discussed her shift in values as it relates to growing her own food and spending time with her family:

For me [the class] changed my perspective because when I was in Mexico I remember, we had a big garden and we were growing Maiz and all this stuff there and I just got tired, this was so hard labor. And when I got [to the U.S.] and was able to go to the store and get everything I wanted in a limited time without having to work for it. I would be like this is good, see this is better, this is a better life. And after the class it just made me realize that convenience doesn't always mean it's something better and ironically, even though before I wouldn't like to [grow vegetables], it would be nice if I was able to go back and do it with my family....it does really give you the opportunity to work with your family and get together (2-6-09). 
Other students also noted a change in their values by stating their desires or intentions to buy locally produced food, and spend time cooking and preparing food with others.

Students came to understand sustainability as a change in values, primarily due to the opportunity to relate the theme of the class to their lives personally. Although they did not know much about sustainability at the beginning of the course, over time students were able to connect what they were learning about food systems to their own lives and families, and gained confidence in their ability to learn something new and meaningful.

\section{Understanding Sustainability Through the Course Theme}

In their end of course reflective writing exercise, students reported that their understanding of sustainability as a whole was significantly shaped by the course theme Sustainable Local Food Systems. Ben wrote, "At the start of the course I only had a vague understanding of what sustainability means, but at this point I think I have a deeper understanding of sustainability, particularly food sustainability and how it affects our daily lives." Emma wrote, “While learning important tools to successful writing, I was also able to widen my knowledge of sustainable food systems..." Another student, Miley, expressed her process of understanding sustainability through the Sustainable Local Food Systems theme in a poem she wrote for her final analysis essay and presentation:

At the beginning of class Heather went over her goal

To teach us sustainability as a whole

We brainstormed, we free wrote, we did it all

To learn this topic throughout the fall

It was still a little fuzzy, I didn't quite see 
How truly important sustainability would be.

The major thing I have learned about this

Is how local food choices may lead us to bliss....

Sure it's more expensive but take a look at this

The environmental friendliness in which you can't miss

The variety in crops leads to healthy soil

The food they produce is not drenching in oil...

Eating local is healthy. You know where food's grown

No chemicals, added ingredients, or other things shown

Making sure humans and soil are both in good health

We are ensuring something so much better than wealth.

While students did gain an increased understanding of sustainability through the sustainable food systems theme, several students noted that they grew tired of the theme, and wanted to have the opportunity to learn in other ways. This idea of using just one sustainability theme (Sustainable Local Food Systems) was discussed in the focus group interview:

Bill: Maybe on the first or second paper it was nice to write about this but after that it was like I've already written about this, I've told you how I feel and I was trying to stretch. It kind of got a little boring....

Heather: Do you have any suggestions about how that could be structured differently?

Bill: I don't really know. It's hard to get off the topic of sustainability since we're studying it. Maybe try to focus it more on instead of sustainability as far as food systems maybe some other types of sustainability. In a way it's all related to sustainability...(2-06-09).

Other students responded to this issue somewhat differently.

Jill: ...just writing about sustainable food systems wasn't always that interesting to me, so I found something else to write about that was related to it. It was kind of more on the outskirts of the topic but it was still interesting to me.

Emilia: I actually feel the same way, [the course theme] was pretty flexible because sustainability is such a big topic relates to everything not just food but energy and everything. We weren't forced to write about it...I did feel there was a great opportunity for different topics. We started out small on just about one aspect at the farmers market and it expanded from there we just had a little 
more freedom to write about other aspects but like I said it's such a broad topic (focus group interview, 2-06-09).

As noted, there were a variety of opinions about focusing on one sustainability theme for the entire semester. While some students got bored, others saw it as an opportunity to branch out and explore interrelated topics. Still, exploring one theme in depth through reading, writing, and discussion did create a lens through which all students learned something about sustainability.

\section{Understanding Sustainability as Multidimensional}

On the whole, students did come to understand sustainability as more multidimensional and interrelated than they had previously thought. In the personal reflection essay Emilia wrote, "I not only learned about academic writing...I also learned about a very important topic, sustainability, that should be of interest to everyone. Sustainability is interlinked with every problem, even food insecurity." Katrina wrote, “I learned that sustainable food systems are also about being supportive of the economy, environment, social and nutritional well-being of others with concern and moral values toward the earth, workers, and food." In the focus group interview, I asked students how their concepts of sustainability had changed over 16 weeks. Jill commented, "Now I realize it seeps into everything, goes into farming, industry and food...it is part of all aspects of society, even though the parts that are presented by the media mostly have to do with food and energy. It's a bigger concept than I thought it was" (2-06-09).

In my assessments of the post-course brainstorming and mapping activity, Students mostly fell within the 2 or 3 range on the rubric for assessing this Content 
dimension (Rubric 1 in Appendix B: 2-sustainability is described as having multiple dimensions; 3-sustainability is described as having multiple dimensions but these relationships are not fully described). This represented a change from the pre-course activity in which students mostly fell into the 1or 2 range, as previously described. While students did show an increased understanding of sustainability as having multiple dimensions, their understanding of sustainability was not yet expressed as an understanding of the full connections between multiple interrelated aspects of sustainability. On the post-course reflective writing exercise, all students noted a change in their understanding of sustainability. In addition, comparisons of the pre and post student knowledge survey show an increased understanding of sustainability topics in every area, the greatest increases in the areas of food miles, community food security and Sustainable Local Food Systems, the major theme of the course. This increased knowledge is represented in table 10. 
Table 10

Comparisons: Pre and Post Student Knowledge Survey (Course One "College Writing")

$\begin{array}{lccc}\text { Topics } & \text { Pre course } & \text { Post course } & \text { Increase } \\ & \text { average scores } & \text { average scores } & \text { in scores }\end{array}$

Sustainability

2.25

3.91

1.66

Local Sustainable Food

1.75

4

2.25

Systems

$\begin{array}{llll}\text { Global Food Systems } & 1.83 & 3.91 & 2.08 \\ \text { Local Economies } & 2.25 & 3.35 & 1.1 \\ \text { Food miles } & 1.16 & 3.75 & 2.59 \\ \text { Community Food Security } & 1.25 & 3.75 & 2.5 \\ \text { The Writing Process } & 3.33 & 4.08 & .75 \\ \text { Writing about Complex Issues } & 2.83 & 3.91 & 1.08\end{array}$

Note. The scale used for this survey is as follows:

$5=\mathrm{a}$ lot; $4=$ adequate amount; $3=$ some; $2=\mathrm{a}$ little; $1=$ none

$\mathrm{n}=12$

Students expressed that they arrived at this increased and multidimensional understanding of sustainability through the guest speakers they met, the field trips they participated in, the farmers' markets they visited, the local organizations they researched and wrote about, and the text that we read, all of which were related to our course theme. Learning thematically provided not only new information about 
sustainability, but examples, inspiration and a sense of the possibilities for living sustainably.

\section{Pedagogical Implications: Connecting Content and Constructivism}

These results about how learners came to understand sustainability Content through their participation in these courses point to the importance of adopting a constructivist learning stance in sustainability courses. Constructivism requires beginning with what learners already know and believe about sustainability, and then helping them to build a stronger understanding of sustainability issues. This is particularly important because knowing what students already know or don't know about sustainability can shape the direction of a course. In the case of college writing, students knew very little about sustainability and thus needed more time to develop a basic understanding of this issue, and to process the learning experiences they were having and link them to their existing values, beliefs and attitudes. This is because knowing is based on previously constructed knowledge, "the building up of structures from pre-existing pieces..."(Ernest, 1993, p.2). Without much pre-existing knowledge of sustainability from which to build upon, the emphasis of the course turned to building that basic understanding through a variety of learning experiences. Using a course theme helped to create an entry point (food systems), to which everyone could relate and build upon.

On the other hand, students in the border course did come to the course with a fairly well constructed understanding of sustainability. In the case of this course, more emphasis fell to providing opportunities for students to construct a deeper 
understanding of sustainability through interaction and conversation with other around the course theme, a social constructivist stance. For this group, learning sustainability in the US Mexico border region really was, as Philips (2004) puts it, an active process. Students learned about this theme in relationship and participation with others in the class, and with community members both in Portland and in the border region. This social constructivist aspect was especially linked to students' increased understanding of sustainability in a personal way, or as a change in values.

Using themes to teach sustainability Content is but one dimension of the Burns model of sustainability pedagogy and thus cannot in reality be separated from the other dimensions of the model. These results show that while using sustainability themes can be an effective approach to teaching sustainability, this Content dimension of the pedagogy must be integrated with the other dimensions in order for effective transformative learning to take place.

Perspectives: A Critical Examination from Multiple Epistemologies The second sub-question that guided this research was How do learners think about dominant paradigms, practices and power relationships, and consider complex sustainability issues from diverse perspectives? The benchmark outcome for this dimension for the border course was: Learners will have the opportunity to critique the underlying causes of complex problems in the US-Mexico border region, comparing and contrasting diverse Perspectives in the region. For college writing it was: Learners will be able to critique the underlying causes of complex problems, and make recommendations about sustainability based on comparing and contrasting 
diverse Perspectives. The following table provides an overview of the results of the Perspectives dimension.

\section{Table 11}

Perspectives Dimension: Results

Dimension Perspectives findings

Research Question How do learners think about dominant paradigms, practices and power relationships, and consider complex sustainability issues from diverse Perspectives?

Benchmark Outcome Learners will have the opportunity to critique the underlying Course One: "The causes of complex problems in the US-Mexico border region, Border Course" comparing and contrasting diverse Perspectives in the region.

Benchmark Outcome Learners will be able to critique the underlying causes of Course Two: complex problems, and make recommendations about "College Writing" sustainability based on comparing and contrasting diverse Perspectives.

Course One: "The

1. Students learned sustainability from Perspectives at Border Course" the border and from each other

2. Gaining hopeful Perspectives was important to learning sustainability

3. Students understood power relationships and dominant paradigms through research

Course Two:

1. Students learned sustainability from community 
"College Writing"

"College Writing"

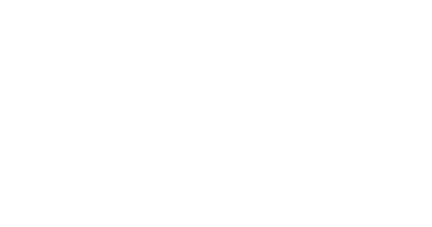

Data Sources for

Findings

Pedagogical
2. Perspectives

3. Learning to think critically was necessary before being able to consider dominant paradigms and power relationships

Surveys, research observation/notes, student assignmentsresearch paper and argument essays, end of term reflective writing, co-instructor interview

Connecting Perspectives and Critical Theory

\section{Course One: "The Border Course"}

For students in the border course, gaining a variety of diverse Perspectives from the border trip as well as from class experiences and assignments was extremely important to their learning process in several ways. First, being exposed to a variety of Perspectives in the border region and within their own learning community provided new ways to consider sustainability issues in relation to power and privilege. Secondly, these new these Perspectives inspired hope. Third, the research project which the students conducted throughout the term and wrote about in their final papers, gave them the opportunity to critique dominant power systems and to consider one sustainability issue in depth from a variety of Perspectives. 


\section{Learning Sustainability from Perspectives at the Border and Each Other}

Learning from a variety of Perspectives in the border region helped students understand the issues we were learning about and opened their own Perspectives to issues of power and privilege. In the co-instructor interview, Celine provided an overview of the concept of providing multiple Perspectives through the trip to the border region:

There are a few themes that Borderlinks seminars are rooted in. One is the importance of hearing from multiple perspectives. Another is the importance of hearing from marginalized voices. A third is that the seminars are experiential in nature so they involve direct dialogue with resource people in the region and they involve students living in some cases with people in their homes in the border region... Those are the key themes (2-19-09).

Based on her experience at the border, Isabel wrote in her end of course reflection assignment about how various visits, such as the visit with a sustainable rancher, and the visit to a sustainable community shattered her stereotypical viewpoint of sustainability, and it became "more inclusive of other ideas and perspectives." Emily wrote about how her experience in the border changed her perception of justice. She notes, "I feel that I will not be able to live my life with suspended emotion and apathy toward people and places which support my way of life...I view myself as connected to the people of the border region, aware of their plight and striving to find ways...to work for justice and equity."

In addition to learning from the Perspectives of those in the border region, students also leaned a great deal from the Perspectives of one another. Group activities in class and group reflections at the border region were important in that students listened to one another, and gained new Perspectives from each other. Having a 
chance to reflect on a variety of Perspectives in a trusting group setting was very important. During the trip I wrote in my research journal, "Personal relationships and connections as well as group reflection are key to meaning-making" (2-25-09). In her course reflection, Emily wrote about the group reflection process saying, "I can honestly say that I have never known the power of group reflection until this trip...talking in a circle, listening to one another and sharing our frustrations, observations, emotions and things we found hopeful and inspiring was a tremendous help for me. The reflections offered insight, individual perspective and support." Similarly, Anne wrote, "I loved how our group came together...I could have never expected that the group would form the bond that it did."

As evidenced in table 12, on average students reported that they learned almost as much from each other and large group discussions, as they did from the overall trip to the border. Creating opportunities for relationship building with one another was clearly central to this pedagogical dimension, and provided a safe space for students to consider dominant practices, paradigms and power relationships. 
Table 12

How much was learned from the following teaching and learning techniques (Post

Course Survey Results- Course One: 'The Border Course")

Teaching/learning technique Average class score

Border Trip

Classmates

Large Group Class Discussions

Participatory Class Activities

Graded Assignments

Small Group Class Discussion

Reflective Writing

\section{5}

4.8

4.5

4.37

4.08

4

3.91

Note. The scale used for this survey is as follows:

$5=\mathrm{a}$ lot; $4=$ =adequate amount; $3=$ some; $2=\mathrm{a}$ little; $1=$ none

$n=12$

\section{Gaining Hopeful Perspectives}

Some students also noted that being exposed to various Perspectives helped them to feel hopeful about making change. In her end of course reflection assignment Emily wrote that she was “inspired by Suzanna and Nick's garden project at BorderLinks, and Michelle and Amanda's work at the [Tucson] food bank to grow vegetables...our visit to Just Coffee has sparked my awareness about fair trade and our conversation with Duncan Blair concerning sustainable ranching practices was enlightening." In my research journal I wrote about our visit to Cascabel, a sustainable community: "The visit was so good, a sense of hope was instilled, a sense 
that it can be different...seeing David and Pearl's house, harvesting from the community garden, cooking and eating together, hearing how community members seek to live in a way that is right for them, all this inspires others in the process of learning" (2-24-09). I also wrote, "hopeful perspectives are so important to include.

It's really important for moving from confusion and frustration to hope and confidence to act on learning" (Research journal, 2-25-09). In the co-instructor interview, Celine also commented on the importance of hopeful Perspectives:

... BorderLinks has embraiced this theme of sustainable futures and they are actively seeking out resource people in the border region who can provide concrete examples of how to live in a hopeful or sustainable manner. I think that's a shift for BorderLinks from past seminars which have been a little more focused on the problems and the perspectives surrounding those problems than solutions or hopeful thinking, and I think those additions... really have improved the seminar. Because the way the seminar is set up it allows the students to come full circle on an issue and not just be left with lots of questions or anger or hopelessness" (2-11-09).

In my experience with students on this trip, this was indeed the case. Students left the border trip having been exposed to confusing and overwhelming issues, and yet the feeling within the group was one of hopefulness and desire to be a positive force for change.

\section{Understanding Power Relationships and Dominant Paradigms through Research}

Students taking the border course also came to understand power relationships and paradigms through their final research assignments. For this assignment students wrote about one sustainability issue in the border region based on the research they had conducted during the term around a particular research question. According to my analysis of these essays, all students showed the ability to critique underlying causes 
of sustainability problems and were able to show a clear understanding of some of the power relationships and dominant paradigms at play (highest level on the Perspectives assessment rubric 2 in Appendix B). Although not required for this assignment, most students were also able to offer recommendations for sustainable change, based on their research. For example, one student wrote in depth about the inequities and hardships caused to the Tohono O'odham nation by current US immigration policy, and suggested policy changes that could be enacted. Another student critiqued US neo-liberal economic policy, and explored the proposal that the use of microcredit may eliminate the need for some Mexicans to migrate to the U.S. Yet another student examined the environmental consequences of the construction of the border wall, and examined the dominant paradigm of not taking ecological effects into account when making economic and political decisions. On the whole, researching and writing these papers throughout the term gave students a chance to focus their learning based on their own particular interests, and provided a chance to critique the underlying causes of complex problems in the US-Mexico border region, comparing and contrasting diverse Perspectives in and about the region.

\section{Course Two: "College Writing"}

For students in the college writing course, learning from a variety of Perspectives, especially in the local community, was very important to their learning. Additionally, learning how to think critically turned out to be an unanticipated important element of the pedagogy in this course, and a key aspect of learning to 
consider dominant paradigms, practices and power relationships from diverse Perspectives.

\section{Learning from Community Perspectives}

First, students noted again and again that the guest speakers, field trips and class discussions were very important to their learning, especially as it related to gaining new information about the sustainability theme. In the focus group interview Jill noted, "I think speakers and class discussions were most beneficial, cause we got to see from the outside perspective what actual people in our community are doing" (2-6-09). In the post course reflective writing assignment Isabel wrote, "As a result of the speakers, visits and the reading I now know the huge attempts that people in Portland and here at UP are making to further develop a sustainable food system. I know where to find different farmers markets and I have visited some of them myself." Similarly, Miley wrote, "Thanks to the guest speakers I learned that UP has a local sustainable garden and that most of the food they serve is local." Katrina wrote, "Learning about the Oregon Food Bank and City Garden Farms was interesting...cool to see what organizations do to contribute to local sustainable food systems in Portland."

Hearing the stories and Perspectives of local people and organizations really stood out for these students, and made learning more interesting and meaningful. As shown in table 13, students on average reported these experiences to be the most influential in their learning. 


\section{Table 13}

How much was learned about the course theme, Sustainable Local Food Systems, from the following.Teaching and Learning Techniques (Post Course Survey ResultsCourse Two: "College Writing")

Teaching/learning technique Average class score

\begin{tabular}{ll}
\hline Guest Speakers & 4.41 \\
Class Discussions & 4.25 \\
Field Trips & 4.08 \\
Assignments & 4.08 \\
Journal Writing & 3.83 \\
Participatory Class Activities & 3.75
\end{tabular}

Note. The scale used for this survey is as follows:

$5=\mathrm{a}$ lot; $4=$ adequate amount; $3=$ some; $2=\mathrm{a}$ little; $1=$ none

$n=12$

On the midterm and final evaluations, many students noted guest speakers and discussions to be what they enjoyed most about the class. Having access to a variety of Perspectives gave students a chance to explore a relatively new topic in a number of different ways, and students appreciated this opportunity. Kylie wrote, " the class did not seems to force any specific views, but instead would present a problem or aspect of sustainable local food systems then a multitude of solutions or organizations that focus on that aspect of discussion." 


\section{Learning to Think Critically}

However, when it came to looking at these Perspectives critically, and questioning dominant paradigms and practices, students were more reluctant. Not having taught first-semester freshman before this class, I was somewhat surprised by their lack of ability or desire to think critically about sustainability issues. Early on in the course I noted, "Looking back over the last few weeks, what I realized is that not only are students dealing with new topics and learning in my class, but they're really still transitioning from high school. So, I'm keeping in mind that developmentally, most of them are not yet in college mode" (research journal, 9-20-08). About a month into the course I noted in my research journal, "I sense some uneasiness with the messiness of learning about these sustainability issues. Students seem to want to look at these issues as black and white" (10-4-08).

In the seventh week of the course (of 16 weeks) we played the "why game." The game begins with a general question, and then each answer is followed by the question "why?" The game is designed to get to the root of an issue and to encourage critical thinking about it. I asked the question, "Why do you think only $5 \%$ of food consumed in the Willamette Valley comes from the Willamette Valley?" The discussion was lackluster and stayed very much on the surface. I began to get frustrated in general by students' lack of abilities to ask or answer critical questions in class discussions. We played this game again several weeks later and this issue came to a head; students were downright resistant as I pushed them harder to think critically. 
The following excerpt from my research journal is a description of this critical

incident about learning to think critically and my reflections:

Students who were leading the discussion today posed the following question: What would you do with a surplus of vegetables like tomatoes? This didn't generate much discussion (I was reminded of the need to find a way to teach them how to create good open-ended discussion questions-talking about it isn't enough). The second question was: Why do supermarkets want all the tomatoes to look the same? Answers included:

Easier to price that way; People like consistency; We're conditioned by the media to like the way it looks (a certain way); We just want it that way; Easier to use/prepare; We don't want something that looks different (it might be bad or rotten).

I jumped in at this point and asked. OK, but what made us become so picky? Why do we want to have things this certain way---like all the tomatoes the same size and shape? Why is this the norm?

Answers included: We're just used to it; Brand competition- advertisers; People are likely to use something again that they've used before; When the industrial agricultural system took over the market one shape became prevalent.

So, in response to these answers I asked, But why? Why do we accept this one norm? Who has the power to say what is normal, and what we should want to buy, or what things should look like? Let's use the analogy of supermodels. What do they mostly look like in this country? (students answered: white, tall, skinny) So, why is this the standard of beauty instead of something else? (i.e. short, black) Who has the power to say what is normally accepted as beautiful? Some answers included: the media, lots of general reference to a vague "they." At one point someone referred to all of us (as white). I commented that not everyone is the room is a white US American and so we can't generalize. I felt some tension or a sense of discomfort in the room at raising the issue of race.

I pushed more and asked, why does someone/some entity have the power to say what is normal?

At this point, many students stared fidgeting and becoming visibly distressed and frustrated. There were sighs, eye rolling, looks to each other, faces made.

Comments included: We don't know what you mean; What are you getting it? We already talked about that; What's the point here? is there a point?

One student was making faces and I asked if she wanted to make a comment. She did. She said she felt like we had already talked about these things: community food systems are good and corporations are bad, "it's like beating a dead horse." 
One of the discussion leaders then said that we should move on to the next topic. But I said that we can't just have a conflict or a controversy and then move on. We need to resolve the issue. So we talked more about the root of the issue, what I was getting at was who has the power and the money or the privilege to set norms (usually associated with race or class). They listened but I'm not sure if they really got it.

We moved on to the next discussion question and after the discussion, another activity. Students calmed down and things were fine, but this class session really made me think: For one, most of these white middle-upper class students either have not been introduced to the idea of white privilege and class privilege, or don't want to face or acknowledge it. There was a lot of resistance to looking critically at this power issue. Developmentally, these students are at low levels of being able to critically think about these issues. It's still very black and white for many (or they want it to be, even though they do acknowledge that sustainability issues are confusing and not straight-forward) (Research journal, 11/12/08).

This critical incident, as well as others, made me realize that being introduced to diverse Perspectives and having space and opportunity to reflect on these experiences was not enough for this class. They had not yet been taught to, or were personally not developmentally able to, reflect critically about dominant paradigms, perspectives and practices. Once I understood this, I began to think about class activities that would to help them learn to look at issues from various perspectives and to begin to accept ambiguity. Additionally, I also was able to better accept their current developmental levels and to be more encouraging of their process, instead of remaining frustrated. Interestingly, in one of the last weeks of the class, one student whose turn it was to lead discussion, chose to use the why game. Students responded more positively and he pushed them to go deeper with their answers. I realized that modeling critical questioning and reflection was an important step in the process. 
In the focus group interview, Jill reflected on her experience with the why game, noting her understanding that this was a teaching technique, but acknowledging that she still just wanted to be given answers:

Jill: The why game was really frustrating to me, because I just wanted an answer, but that's a teaching strategy in itself (laughter from others).

Heather: Do you want to say more about that? Jill: I hated it.

Emilia: Why?

Jill: I'm a very analytical person and I just wanted the answer. It was frustrating. I didn't know where we were going...it felt like we were going in circles....(2-6-09).

Jill's response to the why game reflects the uneasiness this class often showed at not having direct answers, dealing with ambiguity, or not understanding the messy process of learning about complex issues.

In the final reflection essays, some students noted that through the class they learned to think about things differently. Natalie noted, "I found myself analyzing things that I do on a daily basis. I tried to figure out why I do the things that I do." Jill reflected that through writing assignments she learned to "communicate my own opinions and formulate papers from my own angle....rather than regurgitating facts." In my analysis of my notes about class discussions, I noted a progression from student thinking about sustainability in very black/white terms, and mostly related to personal health, to thinking about the values that underlie these issues, exhibiting more curiosity about others' Perspectives, and showing a willingness to consider an issue from more than one or two Perspectives.

One way that students learned to improve their critical reflection skills was through writing assignments. Students' argument essays, which were their last essays 
of the course, demonstrated an ability to look at one sustainability problem from a variety of Perspectives, synthesis these Perspectives, and to propose a solution. One student wrote about the problem of the high number of miles that food travels from farm to plate and proposed the hundred-mile diet as a solution (all food is procured within 100 miles of where one lives). Another student wrote about the lack of federal support for small sustainable farms and the need for new national farm policies. Yet another student wrote about the issue of food insecurity and the need for a national living wage. On the whole, the essays showed that students were able, in the end, to consider various Perspectives and write an informed argument about one sustainability problem and solution.

\section{Pedagogical Implications: Connecting Perspectives and Critical Theory}

The results of this section point to the importance of developing critical thinking skills as an important element of sustainability pedagogy. As noted by King and Kitchener (1994) reflective judgment builds in a sequence, and there are multiple stages that people move through in the process of justifying beliefs about complex problems. In the college writing course, students fell into the early stages of this process, in which knowledge is seen as coming from authorities, and problems are dualistic. Helping learners to move through these stages to higher stages, and to build reflective thinking skills will be important to learning sustainability. Critical theory (Freire, 1970), one of the learning theories in which the Burns model of sustainability pedagogy is rooted, relies on learners' abilities to question ways of knowing, and their own contexts including the realities of racism, sexism, classism, and 
anthropocentrism. I began teaching college writing with the incorrect assumption that students would be able to do this if provided with diverse Perspectives and opportunities for reflection. Instead, I learned that these students needed to first be given opportunities to learn how to question critically, and to develop a reflective way of thinking.

In the border course, however, students' levels of reflective judgment were higher and they were able focus on naming and exposing mechanisms of power in order to find ways to resist them (Fenwick, 2000). What these students needed were opportunities to reflect upon the diverse people and experiences that they were exposed to, and make meaning of these experiences for themselves. Making these personal sustainability connections to broader trends, helped learners recognize that we are all reflections of the norms and values of the larger society (Merchant, 1992). Opportunities for critical reflection in the border course not only allowed for a multidimensional understanding of power issues surrounding sustainability, but allowed for the creation of hopeful thinking in the spirit of communal reflection.

While learning from a variety of Perspectives and questioning dominant paradigms and power structures is not unique to the Burns model, it is an important dimension of this model and one that is often left out of sustainability learning. Without having the opportunity to hear from a variety of Perspectives, including marginalized ones, learners may not be able to fully understand the implications of sustainability issues and decisions. Without questioning dominant paradigms and power structures, systemic ecological and social injustices may be left out of the 
dialogue about sustainable solutions. This research points to the need for the Perspectives dimension, in conjunction with the other elements of the Burns model of sustainability pedagogy. In particular, this research shows the importance of incorporating a variety of community Perspectives including hopeful ones, creating opportunities for students to learn from one another, providing learners with opportunities to increase their abilities to think and reflect critically which includes written assignments that incorporate multiple Perspectives.

Process: Learning through Participation and Experience

The third question related to the Process dimension of the Burns model is: What are the learners' intentions to work toward sustainability? The benchmark outcome for the border course was: Learners will relate sustainability in the border region to their own lives and will express an intension to act for sustainable change. For college writing it was: Learners will relate sustainability to their own lives and will express an intension to act for sustainable change. An overview of this dimension and the results of this study are provided in the following table. 
Table 14

Process Dimension: Results

Dimension Process findings

Research Question What are the learners' intentions to work toward

sustainability?

Benchmark Outcome Learners will relate sustainability in the border region to their

Course One: "The own lives and will express an intension to act for sustainable

Border Course" change.

Benchmark Outcome Learners will relate sustainability to their own lives and will

Course Two: $\quad$ express an intension to act for sustainable change.

"College Writing"

Course One: "The 1. Students expressed intentions to buy locally

Border Course" 2. Students expressed intentions for direct action for change

Course Two:

1. Students expressed feeling a lack of agency

"College Writing"

2. Students expressed desire to buy locally

Data Sources for End of term reflective writing, focus group interviews,

Findings surveys

Pedagogical Connecting Process to Experiential Learning Theory

Implications 


\section{Course One: "The Border Course"}

Because of their active participation and experience in this course, all students in the border course expressed intentions to act for sustainable change in several ways. First, many students expressed that they will change their consumer habits to buy more locally. Secondly, students expressed their intensions to act for change through direct action by volunteering, educating others or becoming politically active.

\section{Buying Locally}

In their post-course reflective writing, most students in the border course wrote about their intentions to buy local products, especially local food, as a way use their power of consumption to support sustainable practices. Sarah wrote, "I have the choice to buy products that contribute to local economies and do not perpetuate the global disaster cause by multinational companies exploiting people from other countries." Lily wrote, " Rather than letting my food travel thousands of miles and leaving a huge eco-footprint, I try to buy local and support my local farmers...every decision I make about what I buy and where I buy it can carry over to life along the border." Through this class experience, students gained a sense of empowerment in their personal choices and saw greater connections between their choices and sustainability issues at the border. Jessica wrote, "Small choices such as buying locally and advocating for fair trade in things I purchase are not easily recognizable as impacting border issues. Prior to this course, I did not see the results of these decisions as far reaching or connected to greater issues." Liam wrote that he had joined the course expecting to be "bombarded with just another depressing humanitarian issue 
that he could do nothing for." Instead he wrote, "With the direct hands-on approach, I was able to see how my life, my choices, and my network of people can make a difference on a small scale and a large one."

These expressed intentions to buy locally and make an impact on sustainability through consumer choices were due in large part to students' experiences at the border. A number of visits and speakers on the trip provided examples of how individual consumer choices can impact sustainability. In the focus group interview, students all talked about how what they saw and experienced in the border region, especially how people were living, impacted their personal choices about buying food locally. This experiential learning trip also caused them to make new choices such as riding their bikes, traveling less by airplane, and consuming less water and electricity.

\section{Direct Action for Change}

Another way in which students expressed their intentions to act for change was by volunteering, or getting involved with local immigrants. Some students expressed this as a general intention to get more involved, while others made specific decisions about their intentions. Isabel wrote, "I plan to volunteer for two weeks for 'No More Deaths' at the migrant resource center on the Mexican side of the border this summer." Andrew wrote, "I plan to rekindle my relationship with volunteer organizations such as Voz and American Field Service....Working or volunteering for BorderLinks appeals, and taking this course has reaffirmed my desire to join the Peace Corps shortly after graduating..." Liam wrote, "I want to volunteer at the day labor center to get an idea of what [immigrants] are going through and how the job market is 
affecting them....I have also started wondering about hiring migrants for my business in the future." Ethan wrote. "I am positively excited in my endeavor to live down in Cascabel this summer...I am also driven to involve myself in a community-owned energy utility [in Portland]."

Other intentions to act for change included educating friends and family about the issues they had learned about, writing letters to political representatives, and continue learning about sustainability issues. Mia wrote, "I feel I can give my friends, family and neighbors an idea of my experience in the border and help them understand issues going on...I also believe that learning about sustainability has helped me to think about these issue and what I might want to do in the future as a career and lifestyle..." Alexis wrote, "My experience in this course motivates me to travel further and get to know more people and their experiences, since it's a great way to learn...I also want to learn about farming, get outside this summer, continue to learn about wild edibles and just try harder to get involved."

The trip to the border, during which students gained first-hand experience of sustainability issues in a complex setting, motivated them to take action based on what they were learning. Listening to speakers who were directly involved in making change inspired them to take action themselves to help local immigrants. Seeing the suffering caused by immigration and economic policy inspired students to want to tell others about the issues, to be more informed, and to make their voices heard to political representatives. Without having had this direct personal participation in issues 
of sustainability in the US Mexico border region, it is doubtful that students would all have expressed such strong desires to act for sustainable change.

In an end of course survey about the dimensions of the Burns model, students on average rated Process (their intentions to participate in sustainability) as the highest aspect of their learning in the course. This is represented in Table 15. 


\section{Table 15}

How students rated their learning based on the dimensions of the Burns model of sustainability pedagogy (From Post Course Survey-Course One: "The Border Course")

\begin{tabular}{lll}
\hline Dimensions of Burns model & \multicolumn{1}{c}{ Question to students } & Average scores \\
\hline Content & My understanding of sustainability & 4.41 \\
& at the US-Mexico border region & \\
Perspectives & What I know about this issue from & 4.5 \\
& diverse Perspectives & \\
Process & My intention to participate in & 4.8 \\
& sustainability in some way & \\
Context & My connection to & 3.9 \\
& community/ecosystems of Portland \\
Context & My connection to & \\
& community/ecosystems of border & \\
& region
\end{tabular}

Note. The scale used for this survey is as follows:

$5=\mathrm{a}$ lot; $4=$ adequate amount; $3=$ some; $2=\mathrm{a}$ little; $1=$ none $\mathrm{n}=12$

Course Two: "College Writing"

In college writing, the response to the Process dimension was somewhat different. While some students expressed intentions to act for sustainable change, there was also a lack of agency reflected in their responses. Students expressed more future- 
oriented intentions to act for sustainable change, although some students did express intentions to buy local food.

\section{Lack of Agency}

Perhaps because they were mostly 18 or 19 years old and mostly living on campus, students in college writing felt that their choices, especially related to lifestyle, were mostly dictated by others. Ben wrote, “ My involvement will probably be limited as I do not make my own food choices. However if given the chance to choose, I will probably favor things that are sustainable." This lack of agency was reflected in the focus group interview. When asked if they thought the class would affect their lives in the future, students focused mostly on their post-college life. Jill reflected on her desire to grow her own food saying, "If I had ....my own house and my own yard it would be cool to try something like Barbara Kingsolver did [grow her own food]" (focus group interview 2-06-09). Similarly Miley responded, “Growing a garden and eating from it, that's something that you can do with your family...seems like it would bring families closer together, not every family does that, spending time in the garden and cooking...seems like a good family opportunity" (focus group interview 2-06-09). Although she is 18 and doesn't have her own family, Miley focused on how her learning might affect her future family.

In the same way Bill, who is 19 and doesn't have children, focused on the impact his learning might have on his kids saying, "The nutritional values are greater [in local sustainable foods] than processed foods so I would want to make sure my 
kids eat healthy, get the proper nutrition....instead of fast food" (focus group interview, 2-06-09).

Emilia focused on how her learning might impact her future career:

I know for me as a nursing major it might be something that I might use, especially when it comes to nutrition for kids and families just being able to explain to them the differences, the advantages of local versus industrial food would be something I would use in the future (focus group interview, 2-06-09)

Although careers and family lives would most likely occur after college, which for these students was two to three years away, student responses were telling. While students did think that their participation in this course would have a long term effect on their lives, they didn't feel that had enough decision making power in their current lives as college students to take much action for sustainable change.

\section{Buying Locally}

A few students did express more immediate and specific intentions to make changes: to pay attention to where their food comes from, to shop at farmers' markets, or to try the 100 mile diet. In her end of term reflective writng Keegan wrote, "I have already started to eat more local and sustainable food...I am more mindful of what I eat and that will carry on to wherever I live." Emma wrote, "When I was writing my argument paper I wrote about the hundred-mile diet. After researching what it meant, I was inspired to try it out." Miley wrote, "I probably won't totally change the way I live and the things I eat, but I will consider going to farmers' markets more."

On the whole, students expressed more general awareness or understanding of sustainability issues and that these issues are directly related to their lives, rather than expressing specific intentions of change. In her post-course reflective writing Sophie 
wrote, "Experience in this class has opened my eyes to the various types of things that I can do for my community. I can take all this information home with me and apply it to my everyday life."

In contrast to the border course, students rated their learning in relation to the Process dimension (intentions to participate in sustainability) as third highest as shown in Table 16. The results of this end of course survey perhaps reflect the newness of the topic for these students. Their greatest learning, on average, was in their understanding of sustainability Content. Making specific intentions to participate in sustainability or act for change may require more time and experience with these concepts. 
Table 16

How students rated their learning based on the dimensions of the Burns model of sustainability pedagogy (From Post Course Survey-Course Two: "College Writing") Dimensions of Burns model Question to students Average scores

\begin{tabular}{lll}
\hline Content & My understanding of local & 4.16 \\
& sustainability food systems \\
Perspectives & What I know about this issue from & 3.95 \\
& diverse Perspectives & \\
Process & My intention to participate in & 3.29 \\
& sustainability in some way & \\
Context & My connection to \\
& community/ecosystems of Portland
\end{tabular}

Note. The scale used for this survey is as follows:

$5=\mathrm{a}$ lot; $4=$ adequate amount; $3=$ some; $2=$ a little; $1=$ none

$\mathrm{n}=12$

Pedagogical Implications: Connecting Process to Experiential Learning Theory

The results of this section definitely point to the importance of experiential and participatory learning as an impetus for change, at least in the border course. In relation to Kolb's (1984) theory of experiential learning, students did have Concrete Experiences in the border region followed by Reflective Observation, which in turn led to Abstract Conceptualization of sustainability, and finally led to Active Experimentation, or at least stated intentions for such. Through the process of taking this course, students' conceptions about sustainability changed, and as a result, they 
gained increased sense of civic responsibility and desire to take action towards sustainability. The experience that impacted students the most in this course was the immersion trip in the border region. This situated learning allowed for interaction with the community, and real life conditions, activities and problems for learners to work through (Fenwick, 2001). The opportunity for some kind of real life experience with sustainability topics cannot be overstated. This has a tremendous impact on student learning and intentions to make sustainable change.

However, unlike students in the border course, students in college writing did not have an experiential immersion trip. Their learning took place mostly in a college classroom and although we had a variety of guest speakers, class activities, and field trips, learners did not have any kind of ongoing or in depth experience with one community partner. This may account for the difference in learners' stated intentions to act for sustainability, which were much more tentative or future-oriented. Upon reflection, an ongoing service learning experience may have done more to provide an experience that would engage learners and provide more incentive or desire for change. Their ages and lack of perceived agency may also have had an effect on this aspect of sustainability learning, as well as their low levels of knowledge about sustainability at the beginning of the course. In light of Kolb's experiential learning theory, students in this course mostly stayed at the reflective observation stage, or perhaps the abstract conceptualization stage, somewhat. As noted previously, students' lower levels of reflective judgment may have impacted their abilities, at this point in their lives, to practice the full cycle of experiential learning. Although their intensions 
to work for sustainable change were not high, students did report that they learned the most in the class through participatory learning activities such as guest speakers, discussions and field trips, as previously shown. Therefore, experiential and participatory learning did have an overall positive effect on their overall sustainability learning.

Based on this study, a learning Process through active experience and participation seems to be a significant dimension of the Burns model of sustainability pedagogy. In fact, this study seems to point to the importance of extended experiential learning opportunities within a particular community, as this may have a strong impact on students' desire to make sustainable changes in their own lives. Active participation gives learners the opportunity to learn with one another in a way that is real and thus makes an impression of their lives. But an active and experiential Process must be combined with the other dimensions of the Burns model in order for holistic sustainability learning to take place. Learners must also have the opportunity to learn Content multidimensionally and from a variety of Perspectives. The Burns model of sustainability pedagogy combines the Process of experiential learning with the other dimensions in order to inspire learners to make sustainable change.

Context: Learning in Place

The research question for the Context dimension of the Burns model was: How do learners understand their personal connections to the place where they live? The benchmark outcome for the border course was: Learners will connect their understanding of sustainability issues in the border region with their own geographical 
place and community. For college writing it was: Learners will understand sustainability in the Context of the ecosystems and communities of Portland and will make personal connections to place. The following table provides an overview of the results of the Context dimension of the Burns model of sustainability pedagogy. 
Table 17

Context Dimension: Results

Dimension Context findings

Research Question How do learners understand their personal connections to the place where they live?

Benchmark Outcome Learners will connect their understanding of sustainability

Course One: "The issues in the border region with their own geographical place

Border Course" and community.

Benchmark Outcome Learners will understand sustainability in the Context of the

Course Two: ecosystems and communities of Portland and will make

"College Writing" personal connections to place.

Course One: "The

1. Some students made stronger connections to their

Border Course" home community

Course Two:

1. Students expressed increased sense of connection

“College Writing to local food

2. Students who were new to the area did not necessarily experience a greater sense of place

Data Sources for End of term reflective writing, research journal, Community

Findings Based Learning assignments, surveys

Pedagogical Connecting Context to Place-Based Learning Implications 


\section{Course One: "The Border Course"}

Within the border course, some students experienced an increased sense of connection to Portland, while others did not. However, student responses show that their understanding of sustainability issues in the border region is connected to their own lives in Portland. This learning mostly occurred because of the trip to the border region, and a community based learning assignment in Portland.

\section{Stronger Connections to Home Community}

First, some students in the border course experienced a somewhat heightened sense of connection to their home community of Portland OR. In answer to the question, Has this course increased your sense of connection to the Portland area? on their end of course reflective writing assignment, a few students wrote in general about an increased connection to the Portland area or an increased desire or get more involved in the community. Liam said, "[the course] made clear the power of coming together with those around you in your community." Sarah similarly commented, "Seeing all the local community members in the border region getting involved in their neighborhoods was truly inspiring and encouraged me to seek out opportunities to help my own community." This direct connection between what students experienced at the border region and what was being done or could be done in their home community was a common theme in student responses to the end of course reflective writing assignment.

Others noted an increased sense of connection to Portland and pride in the many efforts, as Emily put it, "to bring theories of sustainability into practice and I 
envision that I can take part in this revolution..." Liam also echoed this sentiment noting, "I feel a renewed sense of connection to all the students, teachers, and wonderful non-profits that fight for justice against insurmountable odds." Jessica wrote, "In Portland, I feel more drawn to the issues of sustainability... and I see why so many Portlanders make good choices..."

One student, Alexis, noted that the community based learning experience, in which she chose to conduct a neighborhood assessment, made her feel more connected to her own neighborhood and explained "it just goes to show how much one can learn by getting nose to nose with people, places and its issues." Before going to the border, all students shared their experiences of community based learning with each other in the classroom. This experience gave students the opportunity to learn from one another and hear real stories that were rooted in place. David shared his experience of working with migrant day laborers and how they struggled with access to health care in Portland. Isabel told stories of undocumented immigrants and their struggles finding work in Portland, and of having family members deported. Sarah told the class about her experience doing a neighborhood assessment in a wealthy neighborhood and finding many immigrants working behind the scenes. These examples and more gave students the opportunity to experience a sense of connection between what they were learning about sustainability in the border region to their own city.

At least four students noted that they did not feel an increased sense of connection to the Portland area, and no students made any connection to the Portland area in an ecological sense, except to say that they were interested in purchasing more 
locally produced food. As noted in Table 15, Context (connection to the Portland area) was the area that students in the border course rated lowest as it related to their overall learning in the course. On the other hand, students rated their learning a little higher in the area of Context as it related to their connection to the border region, perhaps reflecting their sense of direct connection with the border region as a result of their trip. Several students also noted their desire to return to live or study in Arizona as a result of this course.

\section{Course Two: "College Writing"}

In college writing, some students did experience an increased sense of connection to place, primarily in relationship to food issues. This sense of connection developed primarily through field trips and guest speakers. On the other hand, other students, especially those from other states or counties reported that they did not feel a sense of connection to Portland.

\section{Increased Connections to Local Food}

In college writing, in response to the question, Has your connection to this bioregion or community changed as a result of taking this course? some students wrote general statements about how the class had increased their knowledge about local sustainability organizations, getting involved in the local community, or how their personal actions or food choices affect the local region. Kylie wrote that the course, "exponentially increased my knowledge of sustainable local food systems in this city that I have lived in my whole life...my knowledge of my home city grew more than I thought possible." Emilia noted her increased sense of connection about 
what kinds of food grow in the region. She noted, "I understand better what is grown in Oregon during certain seasons. I also know where to go to get more information about local food."

Another student also commented that his trip to the farmers' market gave him an increased sense of connection to the community. He commented. "I see how involved people are in eating everything local." This sense of understanding new things about Portland and local food mostly occurred due to field trips and guest speakers in the class. Students repeatedly noted how the guest speakers had given them a sense of knowledge about how local food systems are developing, and field trips gave them an opportunity to experience this first hand. As in the border course, a few students noted a sense of pride in the local community upon learning about some of the things that are happening in Portland. Natalie wrote, "I am very proud to say that I live in Portland Oregon because the people of this city genuinely care about the future of the world and this community, and they do this by supporting everything local."

\section{New to the Area}

Several students noted that they didn't know if their connection to this bioregion or community changed as a result of this class. One also noted that he did not yet feel a sense of connection to this community, perhaps due to the fact that he was new to the area and had only arrived several months earlier from another country. In her personal reflection essay Katrina wrote, "The biggest challenge for me [was] the change of environment. Because Portland is so different [from my home], it was 
hard to talk about this different environment that I had never been acquainted with." On the whole, students' sense of connection to place as a result of this course was not particularly strong. As evidenced in Table 16, Context was the dimension that students rated lowest as it related to their overall learning in the course.

\section{Pedagogical Implications: Connecting Context to Place-Based Learning Theory}

Place-based learning theory infers that learning should make use of the history, folk, culture, social problems, economics of a community to create opportunities to confront and grapple with issues of bioregional sustainability (Sobel, 2004), and this underlies the Context dimension of the Burns model of sustainability pedagogy. The results of this study show that this dimension is not yet particularly strong. In the border course, the trip to the border definitely infused learning with meaning, and provided opportunities for being "...challenged to reflect on their own concrete situationaly in a way that explores the complex interrelationships between cultural and ecological environments" (Grunewald, 2003, p.6). Still, while the trip provided opportunities for critical place-based learning in a particular place, students' connections to Portland communities and ecosystems were not particularly strong as a result of this sustainability course. This points to a need to provide more opportunities for the home place to become, as Freire (1970) suggests, a political "text" that can be decoded through personal experience. While we added a community-based learning project to the course this year to try to address this dimension more directly, this one project was not necessarily enough to create a strong sense of connection to place. One possibility for the future is to create an adjoining service-learning course in which 
students who took the border course could then spend a term focusing on connecting and applying that learning to their home place. This extra time would allow for more direct and ongoing interactions with communities and ecosystems in Portland.

In college writing, much of what students learned did, as Kawagley and Barnhardt (1999) suggest, begin with "what the student and community know and are using in everyday life" (p. 119). In learning about what was happening on campus related to food sustainability first, and then learning about what was happening in the local community, students could relate the topic to their everyday lives. Since all of the students but one lived on campus and ate in the college dining hall, what they learned about how Bon Appetit procures food locally and sustainably was applicable to their daily lives. While students appreciated gaining this knowledge and sense of connection, their overall sense of place at the end of this course was not particularly strong. This could be because most of the students in the course did not come from the Portland metro area, and thus did not feel that they had a strong understanding of the place that they were now living. Sense of place and connection with place, may be something that takes more time to develop. This may be especially true for students who come from different countries, other states, or smaller towns where culture, ecology and sense of community are different. While the goal of a critical theory of place is to uncover the relationships at work in a place, and to help learners understand how to best take action to address sustainability problems within their communities and ecosystems, this is difficult when learners don't know anything about their communities or ecosystems. A prolonged learning experience in the community, such 
as a service learning experience, could potentially have helped to increase learners' adaptation and sense of place.

Ecological Design: Education as Sustainability for Transformational Learning The second major research question is about the Design dimension of the Burns model of sustainability pedagogy. The second research question is: How can an ecological Design process bring together the other four dimensions of the Burns model of sustainability pedagogy and create transformational learning experiences for students?

Based on the analysis of the research journal, research notes organized by dimensions of the Burns model, and the interview with my co-instructor, the following themes were important to the ecological Design aspect of this model. The first theme is that in order for the Design to be successful and transformative, it must be a reflective practice that includes assessment of student learning. Secondly, the teaching Design must include relational learning. Relational learning includes aspects of community building and collaborative processes, helping learners gain confidence and creating ample space for learning through reflection, relationship building and humor. However, the most important aspect of the ecological Design is that it must be the organic core to which the other four dimensions of the model are connected and which allows these dimensions to blossom together into a learning experience that is transformative for learners. 


\section{Reflective Practice and Assessment}

One common element in the Design aspect of these courses was that the Design was not a one-time project. There was an initial stage that included four of the five basic steps of ecological Design including observation, visioning, planning, and development (Hemenway, 2000) that resulted in a general plan and syllabus for the courses. However, the process of connecting the four dimensions of the Burns model into the course Design, and sequencing learning activities to reflect this was an ongoing one.

A reflective practice was particularly necessary in college writing because I had not taught this course before, and because students' knowledge about sustainability and abilities to reflect critically on sustainability issues were lower than I had initially expected. This ongoing reflection and assessment process is in line with ecological Design, which considers systemic relationships, both between the dimensions of sustainability pedagogy, but also between learners and their own life cycles. As Galbraith (1998) points out, effective teaching requires that "we are forever changing and evolving, making new assumptions about our practice, our thinking, our learners...It is a matter of constantly wondering what effect the teaching process is having on the learners and on their learning" (p. 17).

I had already developed a reflective teaching practice, making detailed class plans and taking notes on how these changed in actual practice, and what should come next. Additionally, because of this action research study in these courses, I reflected extensively on my learning through a written journal and conversations with other 
educators. I also assessed my own plans for each class session according to the dimensions of the Burns model. In this way I could monitor if and how I was connecting the dimensions of the model into the course Design on a daily basis.

However, in addition to this reflective process, I also sought to increase inclass assessment in these courses. In-class assessment in the border course usually referred to quick reflective writing prompts at the end of some class sessions. For example, for the "muddiest point" assessment we asked students to write about which points from class were still muddy or unclear to them. By reading students' responses, we could gage how to adapt future class sessions to address what students still felt was unclear. This was also an effective way to assess whether I was actually addressing each dimension of the Burns model on an ongoing basis.

In college writing I also provided opportunities for many quick end of class reflective writing assessments, but additionally asked students to write me a note each time they received a graded assignment back from me. I asked them to write to me about their feelings about their work, their grades, and to include questions or comments that they had. For all of these in-class assessments, I placed emphasis on students writing whatever they felt like, and being honest. I found that students asked me questions that they wouldn't necessarily have asked, if they had just glanced at their graded work and slipped it into a notebook. These questions and comments invariably helped me to revise class plans to address issues that were still unclear. Having a form of ongoing in-class assessment was very valuable to the dynamic ecological Design process. This process is part of step five of Hemenway's (2000) 
design process, implementation. This step refers to teaching the course, and in doing so, making adjustments based on further applications of the first four steps in the Design process: observation, visioning, planning, and development. Implementing the Design also involves ensuring that it is flexible. This became clearly apparent in college writing when I discovered the need to provide more opportunities for learning and practicing critical thinking based on the students' developmental levels in this area. I wrote the following in my research journal:

After thinking about this issue more, I talked with a colleague... She suggested doing some reflective writing on the topic in the next class, which I did. She also suggested a structured controversy activity, in which students would have to take on different stakeholder positions, and would most likely really see the ambiguity within the issue (11-12-08).

Although these activities had not been a part of my original class plan, I adopted them in order to meet students' developmental learning needs, and to create an on-going Design that enhanced learning. In this case, ongoing assessment helped to ensure that the Perspectives dimension of the Burns model was being effectively incorporated into the course Design.

\section{Relational Learning}

Secondly, this study points to the importance of the relational aspect of the ecological Design in these courses. This was something that wasn't necessarily expected, as it's not explicit in Hemenway's (2000) ecological design process. However, it is an essential part of sustainability pedagogy. The relational aspect of ecological Design includes aspects of developing a sense of community and 
relationship building in class, as well as helping learners gain confidence in their learning and in their relationships with others.

In college writing, developing a sense of community was initially not easy. Although we developed group norms together and sat in a semi-circle (the classroom was a narrow room with wide tiered steps which made sitting in a circle difficult), students had a difficult time working together. Side-talking was an issue for much of the semester, despite the active learning format of the class (small group activities, field trips, etc). Near the beginning of the semester I wrote in my reflective journal: "The group activity was OK but there were lots of side comments and laughing (private jokes). They really seemed like teenagers to me today. I want to find a way to get the class to be more respectful and improve the culture, without scolding" (9-9$08)$.

I asked students about their lives and found that at this point many were very stressed out, adapting to a new college life and a new heavier academic workload. A little later in the semester, I wrote: “At the end of week four, most people are opening up more, all are participating and relationships are gelling. There is a great tone and learning is happening" (9-20-08). Although interrupting and talking while others were talking was an ongoing issue, the students gradually became more understanding and respectful of each other as they got to know each other. Informal check-ins at the beginning of class, weekly student-led discussions on the reading, numerous small group activities, and other active learning strategies helped students to feel 
comfortable with each other, less stressed about their performance in the class, and I think this ultimately helped students create a sense of community.

From in-class assessments, I learned that students in college writing did not have much confidence in their writing abilities, about learning sustainability, or even about succeeding in college. I often gave them verbal assurance that I knew they could do well, and that they could succeed. In my research journal I wrote:

I let students know at the beginning of class how proud I am of their work and progress, not only in writing but in exploring a theme that was so new to most of them. Lots of smiles. I felt that they needed to know that I appreciate them, despite my frustration sometimes at their developmental level, both socially and academically, which I hope doesn't show too much. But no one can thrive when they feel that they can't live up to expectations. I wanted them to feel pleased with the progress they're making, because they are making progress and learning a lot (11-21-08).

Creating a positive learning environment and one in which there was space for building self-confidence and supportive relationships was essential to learning in this course.

Within the border course, providing opportunities for students to get to know each other and to learn from each other in each class session was a priority and was reflected in our course Design. Especially during the first few weeks of the term, we facilitated class activities that helped students get to know and trust one another. Early on we played "the name game," a game in which a ball and other objects are tossed around a circle while everyone learns each other's names. The game also is a metaphor for community learning and so served the multiple purposes of helping students get to know each other, providing a framework for learning in community, and providing opportunities to laugh and be silly together. Through activities such as 
small group discussion, a mock town hall activity, a human timeline activity, and a border terms and definitions matching activity, students grew more at ease with one another and addressed each other by name. However, the class only met once a week for two hours and so opportunities for getting to know each other in depth were limited until the trip to the border.

On the border trip relationships grew through the shared experiences of daily van travel, staying in host families, dorms, and migrant shelters together, and daily experiential learning and discussion about border sustainability issues. Students also helped prepare some meals together, gathering and talking in kitchens on several occasions. On their own, the group began playing various "get to know you" games such as two truths and a lie, or charade type games, which infused the atmosphere with humor and a sense of play. Students also asked me to facilitate a yoga class for the group one evening, which I did. On the last night of the trip, when staying at a community center in Cascabel Arizona, students convened informally around a campfire telling stories and laughing with each other. That night, most students also chose to sleep outside together, lined up in their sleeping bags under the stars. The trip to the border offered both time and flexible opportunities for informal group development and relationship building that were often student-initiated.

During the five day border trip, I also facilitated three group reflection sessions, which gave students the opportunity to reflect on what they were experiencing and to discuss their feelings and questions with the group. During these reflections we sat in a circle and began with a prompt that I initiated. I mostly did not 
talk during these reflection sessions, but listened and allowed students space to reflect with one another, offering a bit of my own reflection on the issues or their learning at the end of the sessions. After one of these reflections, I wrote in my research journal, "A key aspect of sustainability learning is personal connection with each other and with the issues, also a sense of the personal responsibility that results. There is a sense that they have to do something now that they've had this experience. Humor and laughter and group relationship are very important to this process" (2-22-09). In the interview with my co-instructor I asked, "What pedagogical strategies had the greatest impact on learners?" Celine responded,

I would say certainly relationship building in the pre-trip sessions, real attention to students as part of a learning community that each one of them brings life experience and understanding of the content into the class, so that's a starting point. That they interact with and learn from each other quite a bit over the course of the term. And that the sessions are experiential. All of that from my perspective that's all about relationship building. We could deliver the same content by having students sit in their chairs for seven weeks and listen to us lecture or show them films on the different topics and they may even gain more information about the topic that we're addressing whether its cultural sustainability or ecological sustainability, but I think the experiential aspect of the classes really helps them gel as a learning community. And then I have to really credit BorderLinks for the other big piece of what impacts them most and that is the BorderLinks trip. I wouldn't say that we as instructors have a heavy hand in what happens as part of the BorderLinks trip. We provide a little bit of guidance to their staff about what issues students are interested in and then they build this amazing five day trip from that that in my experience, always has a very important impact on student learning. And I think that's just the nature of that style of education. You don't have to do much for that style of education to help people learn and be transformed..." $(4 / 11 / 09)$.

Placing emphasis on relationship building was a key aspect of the Design of the border course and was one that seems to be directly related to enhanced sustainability learning. Building relationships and learning relationally also 
contributed to intertwining the four other dimensions of the Burns model. By knowing each other better, students were able to engage better with the topic and each other, learning thematically, reflecting critically, and learning together through participation in place.

This study shows that relational learning is clearly an important part of a course Design with the goal of transformational learning. This is because transformational learning is "not an independent act but interdependent relationship built on trust" (Baumgartner, 2001). Transformational learning is a complex process that involves thoughts and feelings (Baumgartner, 2001) and thus there must be opportunities for exploration and expression of these thoughts and feelings in relationship with others. In a review of 23 studies, Taylor (2000) found that ideal conditions for transformational learning included the need for a safe and trusting environment that allows for collaboration, participation, reflection and feedback. Thus, transformational learning is dependent on relationships and relational ways of knowing. Fostering an environment where relational learning can take place is an important aspect of learning as sustainability.

\section{Transformational Learning}

Through an ecological Design that favors ongoing reflection and assessment and a focus on building relationships, transformational learning for sustainable change is more likely to occur. This ecological Design brought together the four other dimensions of the Burns model to create a potentially transformative experience for students. Transformational learning is central to learning as sustainability because it 
encourages learners to adopt values such as social justice, tolerance, and empathy as they participate in critical reflection through discourse (Mezirow, 2000). But more than this, transformational learning also helps learners to "make sense of lives whose fabric of meaning has gone frayed" (Daloz, 1999, p. 4). In a world with increasing ecological and socio-cultural challenges, making sense of unraveling communities and exploring sustainable solutions is an important aspect of transformational learning. In order to make meaning, transformational learning must be holistic and contextually based (Daloz, 1999). Mezirow (2000) notes that learning occurs in the real world in "complex institutional, interpersonal and historical settings and must be understood in the context of cultural orientations embodied in our frames of reference" (p.24).

According to Dirkx's (1998) four lens approach to transformational learning, a course Design should: provide learning about how social structures are oppressive (Perspectives, Content); provide opportunities for change through revised understanding based on experience (Process); pay attention to developmental and interpersonal aspects of learning (Perspectives, Process); and integrate spiritual aspects in which feeling and soul-based learning is emphasized (Process, Context).

The border course, primarily because of the immersion travel experience, was able to provide learning in each of these areas, and thus the experience became transformational for students. College writing, a more traditional disciplinary classroom experience, did provide learning in some of these areas, but did not focus as much on change through direct experience, or feelings and soul-based learning. As such, the experience was somewhat transformative for students in terms of the way 
they thought about one sustainability issue, but perhaps did not transform their lives holistically.

The results of this research indicate that the ecological Design process has the potential to bring together the other four dimensions of the Burns model and facilitate transformational learning. The Design should incorporate a reflective process and ongoing student learning assessment. Relational learning is also an important aspect of ecological Design, as is understanding and applying transformational learning theory. These three aspects of the ecological Design process are key to facilitating transformational learning for students using the Burns model of sustainability pedagogy. The following figure provides a summary of the findings about the Burns model of sustainability pedagogy by dimension. 
Figure 12. The Burns model: Summary of findings.

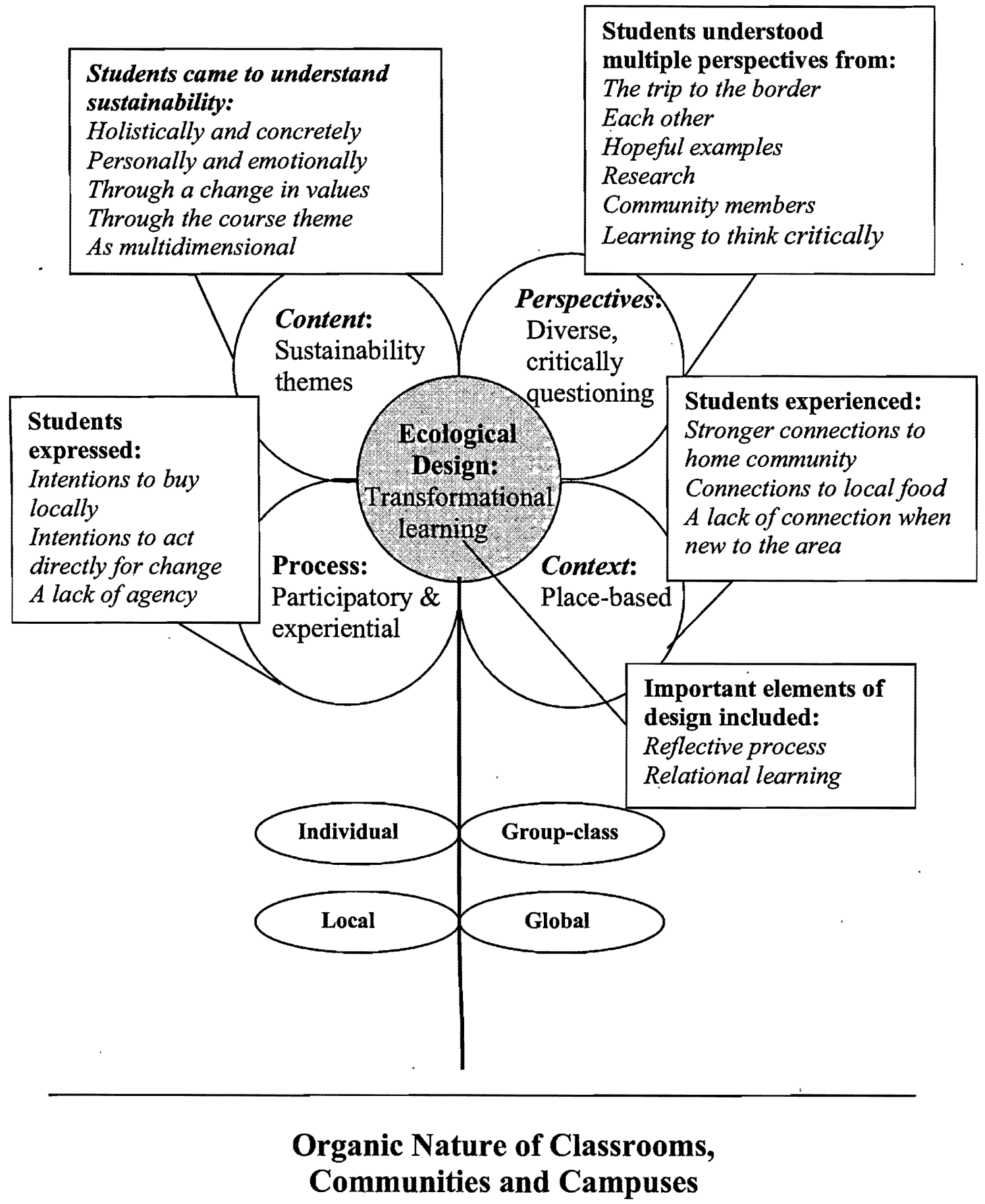




\section{Conclusion}

This chapter has addressed the results of this research as it pertains to the specific research questions related to each dimension of the Burns model of sustainability pedagogy. These findings have shown that the Burns model is a viable way to teach sustainability and can facilitate a transformative learning process for postsecondary learners who are future sustainability leaders. The Burns model facilitates both individual growth and group development, as outlined in Astin and Astin's (2000) 7 C's model of leadership development. Transformational learning that develops capacity and leadership at both individual and group levels is crucial to making sustainable changes in local and global communities. The Burns model seeks to help individuals become Conscious of self through reflective learning, and to develop Congruence and Commitment for sustainability through a thematic, experiential and contextual learning process. Additionally, the Burns model seeks to develop groups with Collaborative skills, Common Purpose and Controversy with civility by incorporating learning from a variety of perspectives in a participatory process. The Burns model also develops Citizenship through learning that is placebased and experiential. These aspects of leadership development are crucial to learning as sustainability. Learners must be prepared to address sustainability challenges as individuals, as groups, and as part of a wider global community. Each dimension of the Burns model provides an important aspect of learning for leadership development and sustainable change making. 
By focusing on an ecological Design process, the Burns model creates transformational learning experiences that inspire learners to take action for sustainable changes. This ecological design creates connections between the other four dimensions of the model. Because of this Design, students came to understand sustainability multidimensionally and personally through thematic sustainability Content. They also understood.multiple Perspectives and were able to critique dominant paradigms. Through an experiential and participatory learning Process, students became inspired to act for change. Students also became somewhat more connected to their communities through a focus on Contextual learning.

The following chapter discusses the pedagogical implications of these results in more detail, and includes a discussion of policy considerations for the implementation of the Burns model. Recommendations and considerations for applying the Burns model of sustainability pedagogy in other university courses are also addressed. 


\section{CHAPTER V \\ DISCUSSION OF FINDINGS}

The following discussion builds upon the results as reported in the previous chapter and explores the significance of these findings about the Burns model of sustainability pedagogy. First, a discussion of what was learned about each of the dimensions of Burns model of sustainability pedagogy and how each dimension relates to the goal of creating an inclusive transformative learning process is presented. What was learned about the pedagogical implications of each dimension has been added as an additional layer to the Burns model of sustainability pedagogy as portrayed in Figure 13. Next, pedagogical recommendations are provided for implementing this model into university courses. Finally, considerations of the organizational barriers and facilitators of growth for the Burns model are examined and discussed.

To begin, this study uncovered significant insights about teaching and learning sustainability from the implementation of the Burns model of sustainability pedagogy in these two university courses. Although the implications of some of these findings are discussed in Chapter 4, particularly as they relate to learning theories, this chapter will further examine the pedagogical implications of the findings about each dimension of the Burns model, and the part that this dimension plays, if any, in the goal of the transformational process of learning as sustainability. 
Figure 13. The Burns model: Pedagogical implications.

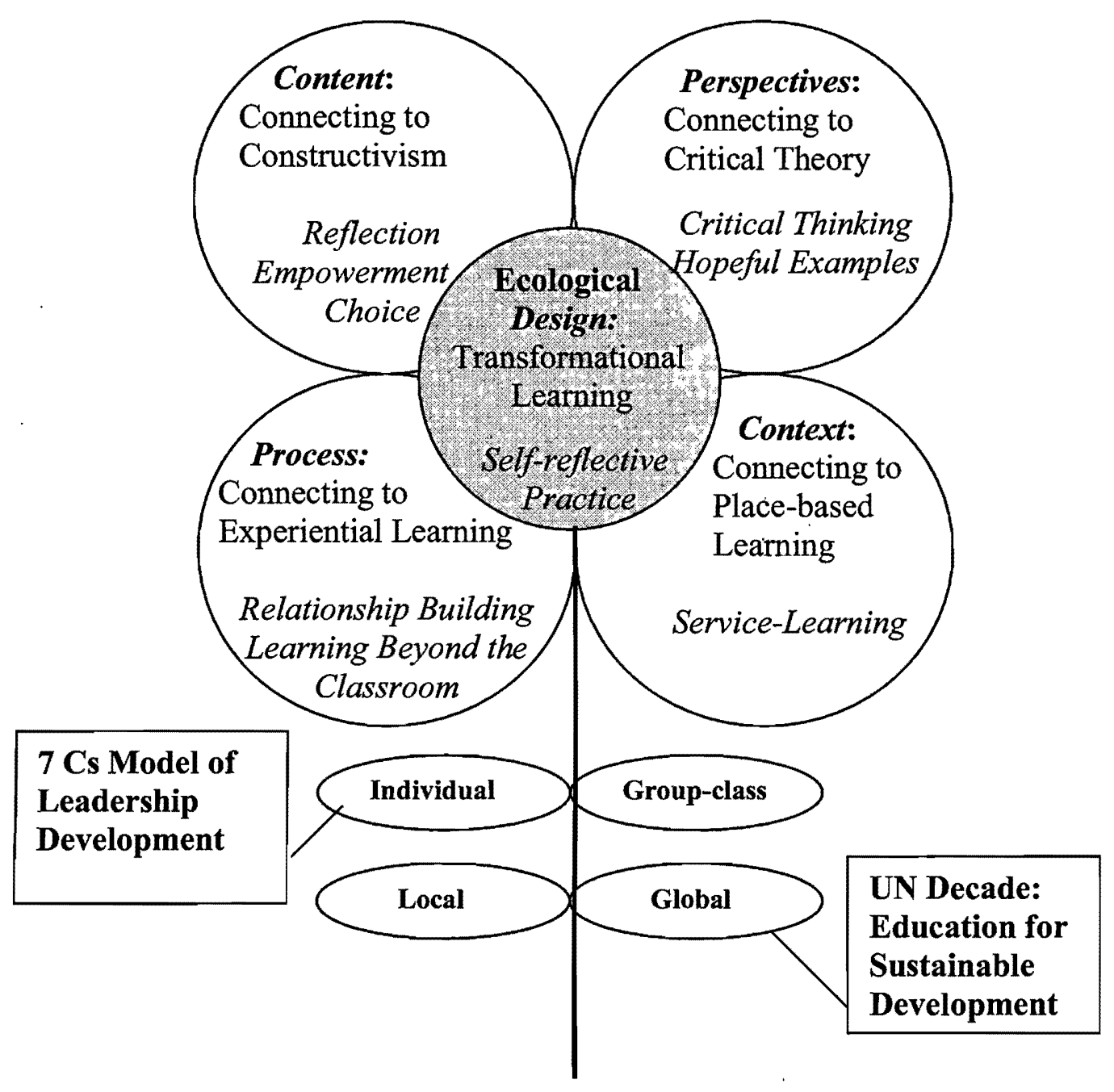

\section{Organic Nature of Classrooms, Communities and Campuses}

\section{Fertile Soil:}

Creating political receptivity by defining problems, creating interest groups and feasible solutions
Optimal Growing Conditions: persistence, building relationships and networks 


\section{Content: Connecting to Constructivism}

After teaching these two courses, it does seem that using a sustainability theme is an excellent way to teach sustainability Content systemically so that learning goes beyond the traditional three-legged stool of sustainability (economics, environment and society) to encompass more complex systems and to capture the ideas of interrelationships between these systems. By learning deeply about one issue or theme, students do start to see the relationships between culture, local ecology, their own families, the money they spend, structures of power, policy formation, economic paradigms, and psychology, to name a few aspects of complex sustainability issues. By being asked to look at a sustainability issue or problem deeply, and to consider solutions and alternatives, students do gain, as Dresner and Semans Blatner (2006) posit, an increased understanding the relationships between systems and contexts that surround them.

In order to offer learners an opportunity to consider their own values and perspectives and to perhaps shift these values toward sustainability, they must be given the chance to see the world through a different and more systemic lens. As Kitano (1997) notes, a transformed course "reconceptualizes the content through a shift in paradigm or standard" (p. 24). Still, this was not always an easy or straightforward process for learners. Many times, students expressed frustration or confusion at the complexity of the issues. However, teaching and learning sustainability Content thematically contributes to the transformative process of learning as sustainability, which embraces emergence, ambiguity, and uncertainty 
(Sterling, 2002). Through the application of a sustainability theme, students in this study did learn sustainability systemically, and came to understand this concept in a multidisciplinary way. However, while offering Content in a thematic manner remains an important part of the Burns model, what was learned from this study is that teaching sustainability Content thematically requires attention to the following: opportunities for reflection, empowerment, and choices about learning.

\section{Reflection}

First, this study points to the importance of offering learners opportunities for reflection while learning sustainability thematically. Learners need rest stops along the way in which they can gather what they know, spread it out, and make sense of what they are learning, to figure out what Sterling (2002) calls the "connections and patterns" (p. 16). Opportunities for reflection about what is being learned is perhaps best done within the learning community, so that students can learn from one another and develop a shared understanding of what sustainability means. Having opportunities for reflection is necessary for learners to be able construct a new understanding of sustainability that is holistic and multidisciplinary. This can be accomplished through reflective writing, journaling, and semi-structured group reflection sessions.

\section{Empowerment}

Secondly, learning Content thematically is often a new or different learning approach for students, and one that is nonlinear. This study points to the need for instructors to give learners plenty of encouragement that they can and will learn 
Content from a thematic focus; starting from the first week of classes. A positive and encouraging learning environment, along with preparation to succeed, and assurances that they will not be alone in the process can go a long way in assuaging the fears that may accompany learning in a new way or about a new topic. Empowering students involves telling them directly that they can succeed, and telling them to expect that a non-linear learning process may be confusing at times. It also involves encouraging learners to feel comfortable by taking time for community-building activities in class. Empowerment also means creating opportunities for open communication between the professor and students. Facilitating open two-way communication between the professor and students may be accomplished through frequent in class assessment activities, and individual meetings with students.

\section{Choice}

Third, this study points to the importance of allowing students ample choices about what Content to explore within the sustainability theme. This is especially true if the Burns model is being used in a course, such as college writing, in which sustainability learning is not an explicit departmental goal. As in college writing, students may have little background or interest in sustainability issues, and will need to feel that they have some choices about their own learning so that they do not feel put off or bored by the learning topic. Allowing students choices in their writing and research assignments, as well as responsibility for class activities such as leading discussion can provide students with autonomous choices while at the same time 
keeping the course focused on one sustainability theme that provides multidimensional sustainability learning.

\section{Perspectives: Connecting to Critical Theory}

The learning that resulted from incorporating a wide variety of Perspectives into these two courses reinforced the importance of this dimension in the Burns model of sustainability pedagogy. The results point out at that learning from a variety of people, places and experiences was important to students' overall sustainability learning in both courses. However, what was perhaps the most unexpected thing that was discovered was that this dimension rests on the assumption that any university student would be developmentally capable of critical questioning diverse Perspectives and dominant paradigms and power relationships. I had not considered the implications to sustainability learning, if students were not yet fully able to do so. Therefore, it is important to consider how to best help learners develop critical thinking skills when designing a course using the Burns model. Additionally, this study points to the importance of including hopeful examples and Perspectives as part of a course focused on sustainability.

\section{Critical Thinking}

What this research uncovered is that critical thinking and reflection is truly a key element of teaching and learning sustainability. Teaching critical thinking means teaching students to challenge reasons and evidence, and to be skeptical of unsubstantiated claims (Weast, 1996). According to Brookfield (1987), the two main activities of critical thinking involve "identifying and challenging assumptions and 
exploring alternative ways of thinking and action" (p. 71). For Kurfiss (1988), critical thinking is "an investigation whose purpose is to explore a situation, phenomenon, question, or problem to arrive at a hypothesis or conclusion about it that integrates all available information and that can therefore be convincingly justified" (p. 2). Posing questions about the status quo (i.e. the destructive industrial food system, white privilege, food insecurity, or immigration policy) initiates confusion, brings up more questions and in some cases causes resistance, the first step in critical thinking. Clearly, helping students become more independent competent thinkers helps them understand social problems (Weast, 1996).

While critical thinking is certainly an important aspect of the Perspectives dimension of the Burns model, what was not anticipated was how students' cognitive development would affect the critical thinking process. In particular, first year college students taking the college writing course were at lower levels of cognitive development than this researcher was anticipating (having taught more upper division classes in the past). So teaching students how to think critically became part of the class as well. At first it was difficult for students to question motives or various points of view. In discussions they wanted to find the "right" answer quickly and then agree with it and move on. When working on their interpretive analysis essay assignment, they were confused about the difference between an opinion and an interpretation, what King and Kitchener (1994) refer to as stage 3 difficulties, and wanted me to give them examples about how to create an analysis and support it with evidence. 
Learning how to think critically was not as much of an issue within the border course. However, understanding how to best support high-level critical reflection in all sustainability courses is an important element of teaching for transformation. This is because helping learners to become critically engaged beings means helping them to examine underlying assumptions about community problems (Cress, 2004). King and Kitchener (1994) suggest a number of ways to promote reflective thinking and judgment in college learners. The following are most applicable to this study:

Show respect for students as people regardless of the developmental level they may be exhibiting; Understand that students differ in regard to their epistemic assumptions (assumptions about knowledge); familiarize students with illstructured problems within your discipline or area of expertise; Create multiple opportunities for students to examine different points of view of a topic reflectively; Create opportunities and provide encouragement for students to make judgments and to explain what they believe; (p. 231-255).

Simply coming to the realization of where college writing students were situated, for the most part, on a reflective judgment continuum helped me to be able to accept their limitations, show encouragement and to create more opportunities for students to develop this aspect of themselves. College writing offered excellent opportunities to learn critical thinking because writing is both a process of doing critical thinking and communicating the results of critical thinking (Bean, 1996). Through writing, students are required to formulate and justify their ideas, learn problem-solving skills, and emphasis is placed on using content rather than acquiring it (Kurfiss, 1988). 


\section{Hopeful Examples}

In addition to the need to develop critical thinking skills, this study points to the importance of providing hopeful examples and Perspectives. As noted in the previous chapter, incorporating hopeful examples gave students a sense of possibility and vision, while learning about challenging sustainability problems. Being exposed to social and ecological degradation can often be demoralizing to students'(Kaza, 1999), and providing some examples of positive change or sustainable solutions can be extremely motivating. Incorporating hopeful Perspectives also gives learners a sense of possibility, and examples of what they could accomplish in their own lives and communities. This step from learning about something to being inspired to do something is a key element of learning that is transformative.

The Perspectives dimension is clearly an important aspect of the Burns model of sustainability pedagogy if learning is to be transformative. In a transformed course, concepts are analyzed and learning focuses on diverse perspectives, reflection, and the personal development and growth of the learner (Kitano, 1997). This study shows that focusing on the development of the learner in the area of reflective judgment and critical thinking, as well as inspiration through hopeful Perspectives are important aspects of this dimension of the Burns model.

Process: Connecting to Experiential Learning

The participatory and experiential Process of these sustainability courses created perhaps the most impact on student learning. This may be because a participatory or experiential course is so different from the norm in college teaching 
and learning. It is known that active pedagogies promote greater abilities to connect abstract concepts to practical applications (Ebert-May \& Brewer, 1997; Springer, 1997) as well as knowledge retention and retrieval (Yazedjian \& Boyle Kolkhorst, 2007), and greater levels of social development, engagement, and general knowledge (Umbach \& Wawrzynski, 2005). All of these qualities are important to sustainability learning. However, active pedagogies are not the norm in university classrooms. In particular, student participants in this research repeatedly talked about not having had opportunities in other courses to form relationships with their classmates, and that they appreciated this. This study thus points to the importance of the following as important considerations of the Process dimension of the Burns model of sustainability pedagogy: relationship building, and learning beyond the classroom.

\section{Relationship Building}

While relationship building is not an explicitly stated part of the Process dimension of the Burns model, this study suggests that this is another significant aspect of sustainability learning. Especially in the border course, relationship building created an atmosphere of trust that was essential for personal reflection about values and intentions about how to live in the future. Relationship building goes beyond providing opportunities for social interaction to providing opportunities to get to know one another personally, to dialogue with each other about learning topics, and to form what bell hooks (1994) calls a community of learners. Within a transformative learning process, learning is dynamic, and engages the whole person (Sterling, 2004). This requires allowing for personalities to emerge from within the academic 
atmosphere, and acknowledging and honoring each person's knowledge and experience. The Process of education as sustainability requires creativity and participation from learners (Sterling, 2004), and true participation requires that learners feel comfortable with and understand each other. This is necessary if transformative learning is to occur.

\section{Learning Beyond the Classroom}

Another important aspect of the Process dimension is learning beyond the classroom. Students reported learning the most from experiences, not surprisingly, that were "rooted in the situation" that they were studying (Fenwick, 2001, p. 41). Learning beyond the classroom involved a community based learning assignment and immersion trip for the border course, and hearing from guest speakers and going on field trips for college writing. The most powerful learning experiences were those that took students out of their comfort zones, such as the assignment in college writing to visit a local farmers' market. Although active learning can effectively happen within a classroom setting, learning through actual personal experience, especially if that experience is new or challenging, may have a greater impact on students' values and intentions to act for sustainable change. Transformative education as sustainability emphasizes the development of the capacity, integrity, and resilience of learners (Sterling, 2004). Providing the opportunity for experiential learning beyond the classroom is a way to encourage the development of capacity and resilience in learners. Thus, learning beyond the classroom is a key element of transformative learning. 


\section{Context: Connecting to Place-based Learning}

This research points out that teaching so that learners develop an enhanced connection to and sense of place can be quite challenging. This is the dimension in which learners expressed the least amount of learning, and which seems to be the weakest aspect of the model. However, since place-based education helps people value the places they live and take care of these places, Context is clearly an important aspect of sustainability pedagogy.

Still, this dimension is perhaps the most difficult to address within college courses. A sense of place develops over time, more time than 10 or 15 weeks. Orr (1992) notes, "knowledge of a place - where you are and where you come from - is intertwined with knowledge of who you are..."(p. 130). But what if where you come from is not where you are living and learning now? Or, what if where you come from is many different places, and you plan to go somewhere else after graduation? Students today grow up in a mobile society, and they themselves have a strong sense of mobility. Many come to a university that is far from their home place, either geographically or culturally, and many want to continue to explore the world through travel or living in other places. In this context, how can appreciation for a particular place, one that is full of complex relationships between "local landscape, community infrastructure, watersheds, and cultural traditions" (Sobel, 2004 p. 9), be nourished?

Within the border course, students did express some increased sense of connection to the US-Mexico border region due to their travel experience there. However, how much lasting connection can be built as outsiders who are only passing 
through for five days? In college writing, some students expressed an increased sense of connection to their university and its sustainable practices. But, they will move on from this particular context in three more years.

The literature about place-based education centers mainly on K-12 settings. This is perhaps because within these settings more time can be allowed to develop relationships with local communities and places through projects. A fifth grade class could feasibly study a local watershed for the entire school year, and in the process develop a stronger appreciation for place. In a university setting there is limited time, and constrictions on getting outside the classroom, making place-based learning challenging. Service-learning could be perhaps the most applicable strategy for placebased sustainability learning because it allows for in-depth exploration of a community place or organization. If, as Steinke, Fitch, Johnson, and Waldstein (2002) posit, service learning is a positive indicator of civic engagement, spiritual values, and community impact, then it would be a clear strategy for learning to value and protect places. Since education as sustainability involves a shift in paradigms and values (Sterling, 2002), it makes sense that this shift could be rooted in real service-learning experience within a local place.

\section{Ecological Design}

\section{Education as Sustainability for Transformational Learning}

Implementing the Burns model of sustainability pedagogy provides more information about how a teaching Design can be and is ecological. Chapter four discussed how the Design was adaptive (based on reflection and ongoing assessment), 
relational, and transformational. All of these aspects of the Design dimension are rooted in the following permaculture principles. Permaculture principles use systems thinking and provide an organizing framework for mimicking patterns and relationships found in nature (Holmgren, 2004). The following permaculture principles relate to all the dimensions of the Burns model, and help to provide a framework for designing sustainability courses ecologically.

One important permaculture principle is to create connections. According to permaculture Design, it is not the number of elements but the number of connections that creates a healthy and diverse system. In designing a course, this principle may apply in a number of ways. In college writing, the number of assigned readings were decreased in favor of more time for discussions that make connections between readings, students' lives and experiences, and the local community. Connecting students to a number of community organizations through guest speakers, field trips, and community-based projects can significantly increase the number of connections that lead to a diverse and healthy learning experience. Connections may in fact be as close as across campus. In college writing, university staff members and students with sustainability interests became guest speakers and significantly increased opportunities for learning. However, attempting to do too much, or including too many elements, is not the point. Rather, it is important to thoughtfully create multiple learning connections between elements may be one of the keys to creating a healthy and diverse learning environment. Through this research experience I was constantly reminded of the paradox "less is more." 
In permaculture, another important principle is that each element performs multiple functions and each function is supported by multiple elements in order to create a stable whole. "Stacking" as many functions as possible creates less work, and redundancy protects against any one element failing. In designing a course around a sustainability theme, an educator can consider how instructional elements can perform multiple functions. For example in a college writing activity, students learned if and how one might support local farmers while on a low income, and at the same time got to know each other better and worked together in small groups. Further, this activity took place in a local grocery store, so students were also learning in context. The activity also included a discussion and writing element, allowing for students to build communication and critical thinking skills. An assessment exercise folded into this activity provided me with information about the learning connections students made, helping me with the sequencing of the course. Each learning experience can thus be "stacked" to provide multiple functions, saving time and assuring that if one aspect of the activity does not work, it still accomplished something useful.

Yet another permaculture principle is to make the least change for the greatest effect. This involves finding ways that the least work can accomplish the most change. This is not to say that there won't be work involved in reorienting a course with a sustainability theme, but thinking about work in terms of greatest effect can improve efficiency. In learning about sustainability, the least change may include starting with students' points of reference, their interests, and what is close at hand. In terms of learning methods, however, moving to a more multidisciplinary, participatory learning 
style may include a fair amount of start up work. The key is to determine what change will make the greatest effect.

In the case of the border course, a new community based learning assignment was added this year. This required minimal time to write the assignment, but created the great benefit of connecting students to the local community in a meaningful way. In college writing small things like asking each student to move their chairs into a circle, or beginning each class with a short participatory activity created a sense of community and opportunity for dialogue and listening. Bigger changes, like including guest speakers, and field visits were more time consuming to organize, and therefore required looking for opportunities like visiting the campus garden (instead of a local farm), or building on community-connections to find speakers for class.

Each of these permaculture principles, and more that were not discussed here, were useful in conceptualizing the Design of a course as ecological. Sterling (2004) refers to the process of education as sustainability as an "ecology of learning" (p. 70). In order for a course to be transformational for learners and embody learning as sustainability, it must be designed around ecological principles that exemplify a new paradigm, rather than trying to teach students to adopt a new sustainability paradigm from the confines of an unsustainable educational paradigm.

\section{Self-Reflective Practice}

When considering what is now known about The Burns model of sustainability pedagogy and how it may be applied to other courses, it is important to emphasize that the entire Design is underscored by a particular philosophy of teaching. The 
practitioner of sustainability pedagogy within postsecondary education will be most effective if able to develop a self-reflective practice about how her/his own teaching philosophy (and underlying values and beliefs) intersect with the teaching philosophy inherent in this pedagogical model. Because it is tied directly to beliefs about learning and decisions about how learning takes place, a personal teaching philosophy has a major impact on how sustainability pedagogy is implemented.

The following is an adaptation of the framework of a personal teaching philosophy offered by Apps (1976) and addresses each of the five elements of this framework in relationship to the Burns model. First, inherent within the Burns model are beliefs about learners and the learning process: Learners are participants in the learning process who reflect on active experience and engage in what they are learning about. In addition, this pedagogy is based in beliefs about the goals of adult education: To be able to understand complex issues holistically and from a variety of perspectives, to reflect critically on the systemic processes and power structures that keep places from being sustainable, and to become empowered to make change for sustainable places. The Burns model of sustainability pedagogy also focuses on what is to be learned: Content is learned systemically and holistically and from a variety of perspectives within a specific place. The role of the educator is to serve as a guide and facilitator who provides opportunities for engagement, participation, and reflection. The primary elements of this philosophy of teaching are reflected in Table 18. 
Table 18

Teaching philosophy: The Burns model of sustainability pedagogy

Elements of a teaching philosophy

Beliefs

Beliefs about the goals of adult education Understand complex problems

holistically, become empowered to make

positive change towards more sustainable

places

Beliefs about learners

Active and engaged participants, critical

thinkers and questioners, connected to

those around them, able to make ethical

decisions and work for change

Beliefs about what is to be learned

Systemic, interconnected, variety of

perspectives, place-based, critically

questioning of dominant paradigms and

power relationships

Beliefs about the learning process

Active, participatory, reflective, place-

based, builds on prior experiences and

knowledge, relationship-based

Role of the Educator

Guide and facilitator who participates in

the learning process, provides a

supportive learning environment and

opportunities for engagement, 
participation and reflection, encourages

higher order thinking, integrates

knowledge and provides opportunities for

problem solving

Implementing the Burns model of sustainability pedagogy in any university course is potentially feasible. However, based on this study it would require a number of commitments on behalf of the professor. First, implementing the Burns model requires a self-reflective practice that includes knowing one's self and one's beliefs. This is because implicit within this Design is a commitment to the values of transformative learning, and to finding ways to create learning situations that embody a sustainability paradigm. As demonstrated in Table 18, beliefs and values are central to one's role as an educator.

Secondly, creating a course, or restructuring a course, with an ecological Design at its center will require openness to new ways of designing and teaching, and this is not always comfortable or feasible, given time and money constraints. Additionally, the multiple dimensions of this model overlap and are constantly in flux, making the teaching and learning anything but a clear-cut linear process. This requires a certain sense of confidence, a "trust the process" mentality. Trusting the process requires some letting go, and in general this model requires giving up much of the traditional power that comes with an educator's role. This also may be uncomfortable 
for many. Self-reflection is an important part of mitigating the fears or lack of confidence that may accompany this ecological Design process.

Third, this model can be challenging to implement within a traditional disciplinary course, although it can be done. It can be time consuming to create or redesign a course based on a sustainability theme, especially if the course is to be community-based. Time and transportation can also be challenges to communitybased learning. Inviting guest speakers to class, and taking field trips on campus can help mitigate this issue. Balancing the course goals of sustainability learning and disciplinary learning can also be challenging. Not trying to do too much at once will be an important element in adding a sustainability theme to a course. Wisely choosing and creating learning experiences and assignments for students, or allowing for cocreation of these experiences, is an aspect of course Design that benefits from multiple applications of a course. Developing a self-reflective practice can help to alleviate the challenges of implementing an ecological course Design.

Summary of Key Pedagogical Implications

The five dimensions of the Burns model of sustainability pedagogy each provided a rich fodder from which to explore the learning that occurred through this action research. By looking deeply at what was learned about Content, Perspectives, Process, Context and Design, this study shows how the Burns model can be further enhanced in order to meet the goal of transformational learning or education as sustainability. In the Content dimension, reflection, empowerment and choice are presented as important aspects to learning sustainability thematically. In the 
Perspectives dimension, providing opportunities for the development of critical thinking skills and providing hopeful examples surfaced as important aspects of exploring diverse Perspectives and critically questioning dominant paradigms and power relationships. In the Process dimension, relationship building and learning beyond and classroom were significant elements of the participatory and experiential learning experience. In the Context dimension, the notion of place-based learning within a mobile society and fast-paced educational system was explored, and servicelearning was identified as a possible antidote in university courses. This study also shows how transformative learning can be fostered by a Design that is rooted in ecological principles and a self-reflective practice. Based on this action research project, the Burns model of sustainability pedagogy is a viable way to teach sustainability in college courses. However, the specific implications of each dimension must be considered, as well as the dynamic interplay between dimensions.

Pedagogical Recommendations for Implementing the Burns Model

In implementing the Burns model into university courses, one might be tempted to rely too heavily on one dimension, such as sustainability Content. The transmissive mode of a typical postsecondary education classroom lends itself well to a focus on Content, and perhaps even Perspectives, but less so on Process or Context. It might be easy to remain in the realm of an exclusive sustainability course, directing learning with minimal learner participation and maintaining traditional, mainstream experiences and perspectives (Kitano, 1997).

Even creating a more inclusive course, one that will add alternative perspectives 
to traditional ones, use a variety of teaching methods to support active and participatory learning, and engage students in critical thinking (Kitano, 1997), may not be enough to truly alter students' understanding and values of sustainability. More weight may need to be applied to the Process and Context dimensions of the Burns model in university courses, in order to balance the weight that Content and critical thinking already carry in academia. Based on this study, the more action-oriented and participatory a course is, and the more it reconceptualizes paradigms (Kitano, 1997) and turns a student's world upside down through personal experience in a specific context, the more potential it has to truly be a transformative educational experience. This is the kind of transformation that can lead to change, and urgent change is what is truly needed in the world today.

Therefore, when redesigning courses to focus on sustainability, particularly traditional disciplinary courses, there must be a consideration of how transformative sustainability learning will take place, and this may actually require a fundamental restructuring of a course. For example, in implementing the Burns model of sustainability pedagogy into a college writing course, it was my hope that I could fully apply the Burns model and create a transformative learning experience for students. While there were many successes in this process, the course may not have really gone beyond being an "inclusive" course to being "transformative."

If given the opportunity to redesign this course, I would incorporate a prolonged community-based or service-learning experience. However, redesigning the 
course in this manner would be time consuming at the outset, and would require a complete restructuring of the syllabus, course calendar, assignments and readings. Still, it seems that this would be the best opportunity for providing students a meaningful experience which would challenge their personal comfort zones, push the boundaries of traditional classroom learning, and create inspiration for changemaking. Indeed, community based learning is crucial because it helps to develop "critically and civically minded graduates who possess analytical problem solving ability and self identify as community change agents" (Cress, 2004, p. 87).

Thus, designing a course that would emphasize experiential learning in place, while implementing a sustainability theme and paying attention to diverse Perspectives and power relationships, would tip the model so that more weight is placed on the dimensions of Process and Context. This would potentially offer the best opportunity for learning as sustainability, a process that is transformational for learners.

As sustainability curriculum is implemented at all levels of postsecondary education, it must be consistent and connected, although not the same throughout the curriculum. As highlighted in this study, implementing sustainability pedagogy looks different at different levels of the college curriculum, which corresponds roughly to different levels of cognitive development. As Merriam (2004) points out, a certain level of cognitive development is needed in order to be able to engage in the more "developed" level of thinking that leads to transformative learning. Still, sustainability learning can and should be encouraged at all course levels and within all disciplines. 
Of course, implementing transformative sustainability pedagogy will require more in the long term than just committed individuals with an interest in sustainability teaching and learning. This implementation will require incentives and resources in the form of faculty training, release time for faculty to develop or redesign courses, and shared course loads so that faculty can co-teach and learn from one another. All of this will require that institutional priority be placed on sustainability teaching and learning, and strong support will be needed from postsecondary administrators. However, the Burns model of sustainability pedagogy is not a pipe dream. This model is firmly situated within the current goals of higher education (The National Leadership Council for LEAP, 2007), and the goals of the UN Decade of education for sustainable development (UNESCO, 2008). As more postsecondary institutions move towards placing priority on sustainability, as is currently happening, educators will need a leadership-based pedagogical model for all students that has the potential to instill values of civic capacity and justice for a sustainable future.

Organic Nature of Classrooms, Communities, and Campuses:

Barriers and Facilitators of Growth

If the Burns model of sustainability pedagogy is to be planted within the organic nature of postsecondary settings, barriers and facilitators of its growth must be considered. Without fertile soil in the form of political receptivity, the Burns model will not thrive. Successfully planting and growing the Burns model will also require an understanding of optimal growing conditions; that is to say how the organizational structures of postsecondary settings can be both barriers and facilitators of growth. 


\section{Fertile Soil: Creating Political Receptivity}

First, attention to planting sustainability pedagogy in fertile soil will be important. Creating optimal soil conditions will require understanding politics within postsecondary institutions, and making sure that sustainability pedagogy is included on the institutional agenda. According to Kingdon (1995), the probability of a policy item such as sustainability pedagogy rising to an institutional agenda is dramatically increased if three major elements are present at the same time: problem statement, policy proposal, and political receptivity. Lester and Stuart (2000) suggest that the problem statement is concerned with how a problem is defined and how it comes to the attention of the public. The policy proposal refers to the technical feasibility of a proposed solution, and political receptivity has to do with the moods, opinions, and the politics which are likely to make the solution a reality or not.

For institutions of postsecondary education where sustainability pedagogy is just beginning to be implemented, the definition of the problem or need for this pedagogy will be key to the policy implementation process. As local postsecondary institutions seek to implement sustainability pedagogy, they can take advantage of the rising public acknowledgment of the "problem" of sustainability. Faculty, administrators or students who want sustainability pedagogy to be included on the institutional agenda will likely need to be involved in framing the problem statement or in making connections to a known problem statement. This will help to ensure that soil conditions are fertile for planting sustainability pedagogy. 
According to Kingdon (1995), the specific way that a problem is defined may be what brings it to the forefront. Thus the definition of a problem is an essential first step for educational reform and change. However, while the problem must be defined in order for an issue to make it onto the institutional agenda, the feasibility of a policy proposal must also be recognized. Kingdon (1995) suggests that this feasibility includes technical feasibility, which means "congruence with the values of community members, and the anticipation of future constraints including budget constraints, public acceptability and politicians' receptivity" (p. 109).

Implementing sustainability pedagogy must be technically feasible and in line with the political culture and values at a postsecondary institution. Addressing the feasibility of sustainability pedagogy will be an important undertaking that will most likely vary between institutions depending on resources and values. While there are a variety of options as to how sustainability pedagogy can be incorporated into postsecondary institutions, technical restraints such as faculty training and time, budget constraints, community values, and community receptivity are all issues that should be considered when strategizing how to bring sustainability pedagogy to the institutional agenda.

Along with the importance of the problem statement and the policy feasibility in cultivating fertile soil for sustainability pedagogy, it is important that there is political receptivity for policy change in the area of sustainability pedagogy. This receptivity may be fertilized within the institutional culture by interest groups. These groups apply pressure to have items put on the agenda, or to have other items taken 
off. According to Berry (1984) interest groups may also serve as educators and program monitors. Since, according to McKeown and Hopkins (2002), one of the main barriers to reorienting education to address sustainability is a lack of awareness about sustainability among faculty and administration, interest groups may be necessary for educating those who have the power to institute policy change. In any case, political receptivity must be carefully cultivated in order for the Burns model of sustainability pedagogy to be successfully planted.

\section{Optimal Growing Conditions: Understanding Organizational Structure}

In order for the Burns model to successfully grow once planted, optimal growing conditions must be understood. In the case of postsecondary institutions, one of the most important aspects of creating optimal growing conditions is understanding organizational structure. Most postsecondary education institutions demonstrate characteristics of the "organized anarchy" perspective, and this perspective is therefore quite useful in understanding how to develop policy that supports sustainability pedagogy. Birnbaum (1988) posits that the characteristics of an organized anarchy include problematic goals, unclear technology, and fluid participation. Within postsecondary institutions, these characteristics usually exist and will influence the development of academic sustainability programs. For example, faculty, administrators or students who want to take the lead on developing a sustainability agenda may not agree on goals for sustainability pedagogy, and may have varying ideas about how to develop or teach sustainability courses, and how to assess if students are able to apply sustainability. At the same time, technology, what Birnbaum 
(1988) describes as the processes through which organizations convert inputs to outputs, is not always clear. For instance, postsecondary institutions may not know exactly what teaching strategies or combination of required courses (inputs) are most effective at producing the desired output (graduation). In addition to these challenges, students and faculty at postsecondary institutions are participating in numerous formal and informal groups simultaneously. These may include courses, programs, departmental events, campus wide events, strategic planning, committees, forums, etc. This participation is sometimes sporadic and may be constantly changing.

Weick (1976) describes these constantly changing relationships within an organization as "loose coupling" (p.38). He describes coupled events as responsive to one another, while each preserves its own identity and separateness. Characteristics of loose coupling also include impermanence and the ability to dissolve. Students are loosely coupled with each other and with faculty for a term. A course is loosely coupled with a community organization until a project is completed. Departments are loosely coupled as they offer cross-referenced sustainability courses.

This non-linear anarchical functioning is the primary reason that this perspective is useful when strategizing optimal growing conditions related to sustainability pedagogy within postsecondary education. There are so many people, events, factors, and loose couplings involved that it is difficult to have a complete organizational understanding of any one issues, and to advocate for change. Yet as Birnbaum (1988) notes, there are patterns within organizations. Information about sustainability pedagogy can flow, aided by websites and various other networks. There 
are clear roles including formal leadership roles, teaching roles, and community roles, and there are structural rules. There are shared values around academic freedom, and (hopefully) around the importance of sustainability. These patterns and shared values can assist in the development of relationships among those who have an interest in the development of sustainability pedagogy.

Those involved in planting and nurturing sustainability pedagogy within organized anarchies should simply persist. Birnbaum (1988) notes that within an organized anarchy, those who spend time on an issue and persist in their commitment to the issue will see results. He notes, "people who are willing to spend time on any decision are likely to have a disproportionate effect on it. They will know more about it than others and will likely be present when a decision is made" (Birnbaum, 1988, p. 169). In addition, resistance may simply be the result of inertia. The structure of colleges and universities is not generally organized to be conducive to sustainability pedagogy, nor are faculty trained or rewarded for developing multi-disciplinary sustainability programs with multiple partnerships and an experiential focus (Orr, 2004). While sustainability pedagogy is starting to develop within postsecondary education, leaders such as faculty, administrators or students with focus and persistence may be more apt to influence policy development and thus organizational change in the long run.

Understanding the challenges of the "organized anarchy" perspective as applied to postsecondary institutions will not only assist leaders in creating optimal growing conditions that support sustainability pedagogy, but will also help them to 
shape policy in ways that lead to regenerative and systemic organizational change. In particular, administrators, faculty, or students who are leading the development of sustainability pedagogy may want to consider helping their organization to develop characteristics common to that of a learning organization. This is because a learning organization focuses on systems thinking; what Senge (1990) calls dynamic complexity, the ability to see patterns and to recognize systems and relationships, rather than focusing on specific details and outcomes. In focusing on systemic relationships, a learning organization may be more likely to produce cultural and personal transformation through education that acknowledges the systemic interrelationship and holism of the ecological, social and cultural dimensions of life.

Within the organized anarchy of postsecondary institutions, those who want to influence optimal growing conditions for sustainability pedagogy may want to focus on building networks and relationships; between faculty, administrators, students and community organizations. Strong networks, as well as the ability to adapt sustainability courses to the needs of the postsecondary institution and the surrounding community will be key to successful implementation. To develop these networks, Capra (2002) suggests that we should begin to think of human organizations literally as self generating living systems, with small communities of practice that are collectively able to learn, change, and respond creatively to new circumstances.

There are, however, substantial barriers to shifting a postsecondary institution to a systems perspective that might be more conducive to growing sustainability pedagogy. This is primarily due to the machine metaphor of organization, which is 
associated with the dominant paradigm of empirical science and dominates social structures (Capra, 2002), including postsecondary education. While organizations may be slowly changing as a systems perspective emerges within the social domain, there is a strong intellectual heritage that encourages Westerners to see ourselves as separate from nature, and to see things "objectively" (Sahtouris, 1999). Capra (2002) argues that the "unconscious embrace of the mechanistic approach to management is one of the main obstacles to organizational change today" (p. 103). He posits that although the machine metaphor shapes the character of most organizations, in order to make the changes increasingly necessary in organizations, systemic rather than mechanistic solutions are necessary. Understanding the potential for creating learning organizations within the organized anarchy of postsecondary institutions can help educational leaders see the possibilities of systemic solutions to the challenge of creating optimal growing conditions for sustainability pedagogy. Particularly, there is promise for growing and nurturing sustainability pedagogy in the development of networks, relationships and communities of practice, creativity and solving for pattern, and in the art of persistence.

Suggestions for further research

Since this study is limited to the results of the implementation of the Burns model within just two university courses, the possibilities for further research on this pedagogical model are many. First, it would be interesting to implement the model within service-learning courses that focus on sustainability, in order to test the hypothesis that this could offer a transformative learning experience for students 
which would inspire them to act for ecological and socio-cultural changes in local communities. It would also be valuable to study the Burns model as implemented by other educators in other courses, to discover what faculty perceive to be strengths or liabilities to the model, and how the model can best be used to enhance student learning and transformation. Another direction for further study could be to study faculty motivation and challenges to restructuring courses to incorporate sustainability pedagogy. Furthermore, future research could focus on effective policy changes that will lead to curricular change for sustainability. Research on the long-term effects of the Burns model on graduates and their contributions to sustainable communities would also be desirable.

\section{Summary and Conclusion}

Considering the tremendous need to stop destructive ecological, cultural and economic practices in order to preserve earth systems, cultures, and community life, postsecondary educators have a responsibility address sustainability within college courses. Additionally, educators need to go beyond teaching about these serious problems to provide opportunities for learners to reimagine the world and develop the capacity to make change. Students cannot leave higher education without the knowledge, skills or values needed to address complex socio-ecological problems such as global warming, chemical pollution, industrial food systems, species extinction and habitat destruction, rural flight, and more. Students' learning experiences must allow them to develop the leadership capacity to be able to understand and address complex sustainability problems holistically, the ability to ask critical questions and understand 
diverse perspectives, to participate in finding solutions, and to develop personal connections to the places in which their biological, social, and economic lives are grounded. Postsecondary courses must be designed ecologically so that learning is connected and systemic if there is any hope in transformative learning as sustainability. Through their learning experiences, students must come to understand themselves in relationship with everything. As John Muir (as cited in Hawken, 2008) puts it, "when we try to pick out anything by itself, we find it hitched to everything else in the universe" (p. 27).

The Burns model of sustainability pedagogy is an effective framework for transformative sustainability learning within university courses. An ecological course Design can pull together the petals of this model to create transformative learning that includes thematic Content, diverse Perspectives, an experiential learning Process, and Contextual learning. This study has shown that this pedagogical model has the potential to be adapted to various types of courses, and that this model can prepare postsecondary learners to create both the lifestyle changes and systemic changes that are necessary to stave off ecological and social collapse and begin to regenerate local communities and places. Within postsecondary institutions, attention must be given to cultivating political receptivity for The Burns model if it is to be planted and thrive. Understanding how to create optimal growing conditions for the Burns model within the organizational structure of postsecondary institutions is also key to its implementation and success. 
Through their postsecondary courses, students must be inspired to understand as Terrry Tempest Williams (2004) argues, that we can begin to live differently and sustainably, that "we can begin to craft a meaningful life...through the shared engagement of a vibrant citizenry" (p.89). Because postsecondary education must develop leaders that are prepared to focus on sustainability, the Burns model of sustainability pedagogy can and should be transplanted to all institutions. 


\section{REFERENCES}

Allen-Gil, S., Walker, L., Thomas, G., Shevory, T., \& Shapiro, E. (2005). Forming a community partnership to enhance education in sustainability. International Journal of Sustainability in Higher Education, 6(4), 392-402.

Alvarez, A., \& Rogers, J. (2006). Going "out there": Learning about sustainability in place. International Journal of Sustainability in Higher Education, 7(2), 176188.

Apps, J. W. (1976). A foundation for action. In C. Klevins (Ed.), Materials and methods in continuing education (pp. 18-26). Los Angeles: Klevens.

Association of University Leaders for a Sustainable Future. (2008). Retrieved May 5, 2008, from http://www.ulsf.org/programs_talloires.html.

Association for the Advancement of Sustainability in Higher Education (AASHE). (2007, October 26). Bulletin posted to AASHE mailing list, archived at http://www.aashe.org/archives/bulletin.php.

Astin, A.W., \& Astin, H.S. (2000). Leadership reconsidered: Engaging higher education in social change. Ann Arbor, MI: W.K. Kellogg Foundation.

Battistoni, R. M. (2001). Service learning and civic education. Campus Compact Reader 2(1), 6-14.

Baumgartner, L. M. (2001). An update on transformational learning. New Directions for Adult and Continuing Education, 89. 15-24.

Bean, J. C. (1996). Engaging ideas: the professor's guide to integrating writing, critical thinking, and active learning in the classroom. San Francisco: JosseyBass.

Berry, J. (1984). Madison's dilemma. In J. Berry (Ed.), The Interest Group Society (pp. 1-15). Boston: Little, Brown and Company.

Birnbaum, R. (1988). How colleges work: The cybernetics of academic organization and leadership. San Francisco: Jossey-Bass.

Bloom, B. S., \& Krathwohl. D. R. (1956). Taxonomy of educational objectives: The classification of educational goals, by a committee of college and university examiners. Handbook 1: Cognitive domain. New York: Longmans. 
Bodner, L. (2008). All 50 states now represented in the American College \& University Presidents' Climate Commitment. Retrieved May 5, 2008, from www.presidentsclimatecommitment.org.

Bogan, M. B. (2002). Towards a sustainable future: Advocating best practice in environmental education at the Florida Gulf Coast University. In W. Leal Filho (Ed.), Teaching sustainability at universities: Towards curriculum greening (pp. 165-192). New York: Peter Lang.

BorderLinks. (2009). Mission and values. Retrieved April 3, 2009, from http://www.borderlinks.org.

Bowers, C. A. (1999). Changing the dominant cultural perspective in education. In G. A. Smith, \& D. R. Williams (Eds.), Ecological education in action (pp. 161178). Albany, NY: State University of New York Press.

Brookfield, S. D. (1987). Developing critical thinkers. San Francisco: Jossey-Bass.

Cajete, G. (Ed.).(1999). A people's ecology: Explorations is sustainable living. Santa Fe, NM: Clear Light.

Calder, W., \& Clugston, R. M. (2003). Progress toward sustainability in higher education. Washington, DC: Environmental Law Institute.

Capra, F. (2002). The hidden connections: A science for sustainable living. New York: Anchor.

Carlson, S. (2008, September 5). Colleges get greener in operations, but teaching sustainability declines. The Cronicle of Higher Education, p. A24.

Clinchy, B. M. (2000). Toward a more connected vision of higher education. New Directions for Teaching and Learning, 82, 27-35.

Clouston, T. J. (2005). Facilitating tutorials in problem-based learning: students' Perspectives. In P. Hartley, A. Woods, \& M. Pill (Eds.), Enhancing teaching in higher education (pp. 48-58). New York: Routledge.

Clugston, R. M., Calder, W., \& Corcoran, P. B. (2002). Teaching sustainability with the earth charter In W. Leal Filho (Ed.), Teaching sustainability at universities: Towards curriculum greening (pp. 547-564). New York: Peter Lang.

Coffey, A., \& Atkinson, P. (1996). Making sense of qualitative data. Thousand Oaks, CA: Sage. 
Cooper, J. L., MacGregor, J, Smith, K., \& Robinson, P. (2000). Implementing smallgroup instruction: Insights from successful practitioners. New Directions for Teaching and Learning, 81, 63-76.

Corney, G., \& Reid, A. (2007). Student teachers' learning about subject matter and pedagogy in education for sustainable development. Environmental Education Research, 13(1), 33-54.

Cortese, A. (2005). Learning principles for sustainability: Sustainability curriculum framework for curriculum development. Second Nature: Education for Sustainability. Retrieved December 12, 2005 from http://www.secondnature.org.

Cotton, D. R. E, Warren, M. F., Maiboroda, O., \& Bailey I. (2007). Sustainable development, higher education and pedagogy: a study of lecturers' beliefs and attitudes. Environmental Education Research, 13(5), 579-597.

Council for Higher Education Accredidation. (2007). Student Learning Outcomes. Retreived Oct. 20, 2007 from http://72.14.253.104/search?q=cache:kQ XTxeMy9kJ:www.chea.org/pdf/Stm ntStudentLearningOutcomes903.pdf + Accreditation+goals + for + higher+education $\& h l=e n \& c t=c \operatorname{lnk} \& c d=1 \& g 1$ us.

Cress, C. (2004). Critical thinking development in service-learning activities: pedagogical implications for critical being and action. Inquiry: Critical Thinking Across the Disciplines, 23, 87-93.

Daloz, L. A. (1999). Mentor: Guiding the journey of adult learners. San Francisco: Jossey-Bass.

Davis, B. G. (1993). Tools for teaching. San Francisco: Jossey-Bass.

Davis, S. A., Edmister, J. H., Sullivan, K., \& West, C. K. (2003). Educating sustainable societies for the twenty-first century. International Journal of Sustainability in Higher Education, 4(8), 169-179.

Dewey, J. (1938). Experience and education. New York: Collier Books.

Dirkx, J. (1998). Transformative learning theory in the practice of adult education: An overview. PAACE Journal of Lifelong Learning, 7, 1-14.

Dresner, M., \& Seamans Blatner, J. (2006). Approaching civic responsibility using guided controversies about environmental issues. College Teaching, 54, 213219. 
Ebert-May, D., \& Brewer, C. (1997). Innovation in large lectures: Teaching for active learning. Bioscience, 47, 601-607.

Ernest, P. (1993). Varieties of constructivism: Their metaphors, epistemologies and pedagogical implications. Hiroshima Journal of Mathematics Education, 2, 114.

Fawcett. L., Bell, A., \& Russell, C. (2002). Guiding our environmental praxis: teaching and learning for social and environmental justice. In W. Leal Filho (Ed.), Teaching sustainability at universities: Towards curriculum greening (pp. 223-238). New York: Peter Lang.

Fenwick, T. (2000). Expanding conceptions of experiential learning. Adult Education Quarterly, 50(4), 243-272.

Fenwick, T. (2001). Experiential learning: a theoretical critique from five Perspectives. Columbus, OH: ERIC Clearinghouse on Adult, Career, and Vocational Education. Retrieved on April 6, 2006, from the ERIC database. (Information Series No. 38).

Freire, P. (1970). Pedagogy of the oppressed. New York: Continuum Publishing.

Freire, P. (1998). Pedagogy of freedom. (P. Clarke, Trans.). Lanham, MD: Rowman \& Littlefield.

Galbraith, M.W. (1998). Becoming an effective teacher of adults. In M. W. Galbraith (Ed.), Adult learning methods (pp. 3-19). Malabar, FL: Kreiger.

Giroux, H.A. (1988). Schooling and the struggle in public life: Critical pedagogy in the modern age. Minneapolis, MN: University of Minnesota Press.

Glasser, B. G., \& Strauss, A. L. (1967). The discovery of grounded theory. New York: Aldine De Gruyter.

Greenwood, D. J., \& Levin, M. (2007). Introduction to Action Research $2^{\text {nd }}$ Edition. Thousand Oaks, CA: Sage.

Grunewald, D. (2003). The best of both worlds: A critical pedagogy of place. Educational Researcher, 32(4), 3-12.

Harden, R. M., \& J. Crosby (2000). AMEE Guide No 20: The good teacher is more than a lecturer-the twelve roles of the teacher. Medical Teacher, 22(4), 334347. 
Harmon, A. (2002) Teaching sustainability using the food system as a model. In W. Leal Filho (Ed.), Teaching sustainability at universities: Towards curriculum greening (pp. 239-250). New York: Peter Lang.

Hartley, P. (2005). Developing students' skills in groups and teamworking: moving experience into critical reflection. In P. Hartley, A. Woods, \& M. Pill (Eds.), Enhancing Teaching in Higher Education (pp. 59-68). New York: Routledge.

Hawken, P. (2007). Blessed Unrest. New York: Penguin Group.

Hemenway, T. (2000). Gaia's garden. White River Junction, VT: Chelsea Green.

Hemenway, T. (2005). Ethics and principles of permaculture. Unpublished.

Herr K., \& Anderson, G. L. (2005). The action research dissertation. Thousand Oaks, CA: Sage.

Holmgren, D. (2004). Permaculture: Principles and pathways beyond sustainability. Hepburn, Australia: Holmgren Design Services.

hooks, bell. (1994). Teaching to transgress. New York: Routledge.

Hopkins, C., Damlamian, J., \& Lopez Ospina, G. (2004). Evolving towards education for sustainable development: an international perspective. In W. Scott, \& S. Gough (Eds.), Key issues in sustainable development and learning (pp. 137145). New York: RoutledgeFalmer.

Inglis, T. (1997). Empowerment and emancipation. Aduilt Education Quarterly, 48(1). 3-17.

Institute of Educational Sciences. (2008). Retrieved May 18, 2008 from http://ies.ed.gov.

International Forum on Globalization. (2007). Retrieved May 14, 2007, from http://www.ifg.org/analysis/un/un.htm.

Jickling, B. (2004). Why I don't want my children educated for sustainable development. In W. Scott, \& S. Gough (Eds.), Key issues in sustainable development and learning (pp. 133-137). New York: RoutledgeFalmer.

Kawagley, A. O., \& Barnhardt, R. (1999). Education indigenous to place. In G. A. Smith, \& D. R. Williams (Eds.), Ecological education in action (pp. 117-142). Albany, NY: State University of New York Press. 
Kaza, S. (1999). Liberation and compassion in environmental studies. In G. A. Smith, \& D. R. Williams (Eds.); Ecological education in action (pp. 143-160). Albany, NY: State University of New York Press.

Kemmis, S. (Ed.). (1982). The action research reader. Geelong, Victoria, Australia: Deakin University Press.

King, P. M., \& Kitchener, K.S. (1994). Developing reflective judgment. San Francisco: Jossey-Bass.

Kingdon, J. (1995). Agenda setting. In S. Theodoulou \& M. Cahn (Eds.), Public policy: The essential readings (pp. 105-113). Englewood Cliffs, NJ: Prentice Hall.

Kitano, M. (1997). What a course will look like after multicultural change. In A. Morey, \& M. Kitano (Eds.), Multicultural course transformation in higher education (pp. 18-34). Needham Heights, MA: Allyn \& Bacon.

Knowles, M. (1970). The modern practice of adult education: An autobiographical journey. New York: Association Press.

Kolb, D. A. (1984). Experiential learning: Experience as the source of learning and development. New Jersey: Prentice-Hall.

Kopp, S. J., Seestedt Stanford, L., Rohlfing, K., \& Kendall, J. P. (2003/2004). Creating adaptive learning environments. Planning in Higher Education, $32(2), 12-23$.

Kurfiss, J. G. (1988). Critical thinking: Theory, research, practice, and possibilities. ASHE-ERIC Higher Education Report No. 2. Washington DC: Eric Clearninghouse on Higher Education and the Association for the Study of Higher Education.

Leal Filho, W. L. (Ed.). (2002). Teaching sustainability at universities: Towards curriculum greening. New York: Peter Lang.

Lester, J., \& Stuart, J. (2000). Public policy: An evolutionary approach. Belmont, CA: Wadsworth/Thomson Learning.

Longino, H. (1990) Science as social knowledge. Princeton, NJ: Princeton Universtiy Press. 
Longino, H. (1993). Subjects, power, and knowledge: Description and prescription in feministh philosophies of science. In L. Alcoff, \& E. Potter (Eds.), Feminist epistemologies (pp. 101-120). New York: Routledge.

MacGregor, J., Cooper, J., Smith, K., \& Robinson, P. (2000). Editors' notes. New Directions for Teaching and Learning 81, 1-4.

Maxwell, J. A. (2005). Qualitative research design. Thousand Oaks, CA: Sage.

McCutcheon, G., \& Jung, B. (1990). Alternative Perspectives on action research. Theory into Practice, 29(3), 144-152.

McDonough, W., \& Braungart, M. (2002). Cradle to cradle. New York: North Point.

McKeachie, W. J. (1999). Teaching tips: Strategies, research, and theory for college and university teachers. Boston: Houghton Mifflin.

McKeown, R. (2002). Education for Sustainable Development Toolkit. Retrieved on April 15, 2008, from www. esdtoolkit.org.

McKeown, R., \& Hopkins, C. (2002). Weaving sustainability into pre-service teacher education programs. In W. Leal Filho (Ed.), Teaching sustainability at universities: Towards curriculum greening (pp. 251-274). New York: Peter Lang.

McKeown, R., \& Hopkins, C. (2003). EE $\neq$ ESD: Defusing the worry. Environmental Education Research, 9(1), 117-128.

Merchant, C. (1992). Radical ecology. London: Routledge.

Merriam. S. B. (2004). The role of cognitive theory in Mezirow's transformational learning theory. Adult Education Quarterly, 55(1), 60-68.

Mezirow, J. (1992) Transformation theory: Critique and confusion. Adult Education Quarterly, 42(2), 250-252.

Mezirow, J. (2000). Learning as transformation. San Francisco: Jossey-Bass.

Mollison, B. (2002). Permaculture: A designer's manual 2nd edition. Sisters Creek, Tasmania, Australia: Tagari.

Moore, J. (2005). Seven recommendations for creating sustainability education at the university level. International Journal of Sustainability in Higher Education, 6(4), 326-339. 
Moran, S. (2002) Stream restoration: A senior seminar theme. In W. L Filho (Ed.), Teaching sustainability at universities: Towards curriculum greening (pp. 2544). New York: Peter Lang.

National Leadership Council for Liberal Education \& America's Promise. (2007). College learning for the new global century. Washington, DC: Association of American Colleges and Universities.

Nelson, L. H. (1993). Epistemological communities. In L. Alcoff, \& E. Potter (Eds.), Feminist epistemologies (pp. 121-159). New York: Routledge.

Norberg-Hodge, H., \& Gorelick, S. (2006). Bringing the food economy home. Retrieved August 17, 2006 from http://www.isec.org.uk/articles/bringing.html.

Orr, D. (1992). Ecological Literacy. Albany, NY: State University of New York.

Orr, D. (2004). Earth in Mind: On Education, Environment, and the Human Prospect. Washington, DC: Island Press.

O'Riordan, T., \& Voisey, H. (1998). The politics of Agenda 21 in Europe. London: Earthscan.

O'Riordan, T. (2004). Education for Sustainability. In W. Scott, \& S. Gough (Eds.), Key issues in sustainable development and learning (pp. 33-38). New York: RoutledgeFalmer.

Palmer, P. (1998). The Courage to Teach: Exploring the Inner Landscape of a Teacher's Life. San Francisco: Jossey-Bass.

Peters, J. (2008). Destined for failure: A new foundation for the leaning tower of ivory. Orion, 27(6), 13.

Philips, D. C. (2004). The good, the bad, and the ugly: The many faces of constructivism. Educational Researcher 24(7), 5-12.

Platt, R. (1994). The ecological city: Introduction and overview. In R Platt, R. Rowntree, \& P. Muick (Eds.), The ecological city (pp. 1-15). Amherst, MA: University of Massachusetts Press.

Project: Sustainability. (2008). Concept. Retrieved May 12, 2008, from http://www.moiz.ca/sustainability/concept.html. 
Pruneau, D., McLaughlin, E., Langis, S., \& Gravel, H. (2002). Education for liveable cities-Environmental and pedagogical actions at the university level. In W. Leal Filho (Ed.), Teaching sustainability at universities: Towards curriculum greening (pp.45-60). New York: Peter Lang.

Rauch, F. (2004). Education for sustainability: a regulative idea and a trigger for innovation. In W. Scott, \& S. Gough (Eds.), Key issues in sustainable development and learning (pp. 149-152). New York: RoutledgeFalmer.

Reid, A., \& Petocz, P. (2006). University lecturers' understanding of sustainability. Higher Education, 51, 105-123.

Report of the World Commission on Environment and Development: Our common future. (1987). Retrieved May 20, 2008 from http://www.undocuments.net/ocf-02.htm.

Ryan, J., \& During A. (1997). Stuff: The secret lives of everyday things. Seattle, WA: Northwest Environmental Watch.

Sahtouris, E. (1999) Earthdance: Living Systems in Evolution. Retrieved January 4, 2005 from http://www.ratical.org/LifeWeb/\#EarthDance.

Sarkar, S. (2001). Sustainable development: Rescue operation for a dying illusion. In V. Bennholdt-Thomsen, N. Faraclas, \& C. Von Werlhof (Eds.), There is an alternative: Subsistence and worldwide resistance to corporate globalization (pp. 41-55). London, UK: Zed Books.

Sauvé, L. (2004). Sustainable development in education: consensus as an ethical issue. In W. Scott, \& S. Gough (Eds.), Key issues in sustainable development and learning (pp. 145-147). New York: RoutledgeFalmer.

Savan, B., \& Bell, D. V. J. (2002). Curriculum development for community sustainability. In W. Leal Filho (Ed.), Teaching sustainability at universities: Towards curriculum greening (pp. 303-321). New York: Peter Lang.

Schroeder, C. C. (2003). Supporting the new students in higher education today. Change, 35(2), 55-58.

Schumaker, E. F. (1997). This I believe and other essays. Dartington, UK: Green Books.

Scott, W., \& Gough, S. (2004). Introduction. In W. Scott, \& S. Gough (Eds.), Key issues in sustainable development and learning (pp. 1-3). New York: RoutledgeFalmer. 
Senge, P. M. (1990). The fifth discipline. New York: Random House.

Serrano, I. (2000). Learning sustainability from crisis. Convergence, 33(1), 78-101.

Shiva, V. (2001). Globalization and Poverty. In V. Bennholdt-Thomsen, N. Faraclas, \& C. Von Werlhof (Eds.), There is an alternative: Subsistence and worldwide resistance to corporate globalization (pp. 57-66). London, UK: Zed Books.

Smith, G. A., \& Williams, D. R. (Eds.). (1999). Ecological education in action. Albany, NY: State University of New York Press.

Smith, P. (2004). Curricular Transformation. Change, 36(1), 26-35.

Sobel, D. (2004). Place-based education. Great Barrington, MA: The Orion Society.

Springer, L. (1997). Relating concepts and applications through structured active learning. Paper presented at the annual meeting of the American Educational Research Association, Chicago, IL.

Starhawk. (2003). Sustainability in a nutshell. Retrieved May 12, 2008, from http://www.starhawk.org/permaculture/sustainability.html.

Steingraber, S. (1997). Living Downstream: A scientist's personal investigation of cancer and the environment. New York: Random House.

Steinke, P., Fitch, P., Johnson, C., \& Waldstein, F. (2002). An interdisciplinary study of service-learning: Predictors and outcomes among college students. In S. H. Billig, \& A. Furco (Eds.) Service learning through a multidisciplinary lens (pp.72-102). Greenwich CT: Information Age Publishing.

Sterling, S. (2002). Sustainable education: Re-visioning learning and change. Devon, UK: Green Books.

Sterling, S. (2004). The learning of ecology or the ecology of learning? In W. Scott, \& S. Gough (Eds.), Key issues in sustainable development and learning (pp. 6871). New York: RoutledgeFalmer.

Stevens, D. D., \& Levi, A. J. (2004). Introduction to rubrics. Sterling,VA: Stylus.

Strauss, A. L. (1987). Qualitative analysis for social scientists. Cambridge, UK: Cambridge University Press. 
Taylor, E. W. (2000). Analyzing research on transformative learning theory. In J. Mezirow (Ed.), Learning as transformation (pp. 285-328). San Francisco: Jossey-Bass.

Tempest Williams, T. (2004). The open space of democracy. Great Barrington, MA: The Orion Society.

The Cloud Institute for Sustainability Education. (2008). What is education for? Retrieved May 12, 2008, from http://www.sustainabilityed.org/what/education_for_sustainability/index.htm.

Umbach, P. D., \& Wawrzynski, M. R. (2005). Faculty do matter: The role of college faculty in student learning and engagement. Research in Higher Education, 46, $153-84$.

UNESCO. (1975). The Belgrade Charter. Retrieved May 20, 2008, from portal.unesco.org/education/en/ev.php-URL

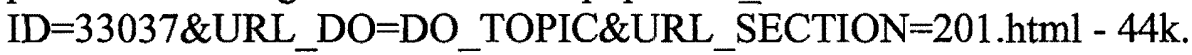

UNESCO. (2002). Education for sustainability-From Rio to Johannesburg: Lessons learnt from a decade of commitment. Paris: UNESCO.

UNESCO. (2005). Guidelines and recommendations for reorienting teacher education to address sustainability. Technical Paper No 2. Paris: UNESCO.

UNESCO. (2008). Education for sustainable development. Retrieved May 12, 2008, from http://portal.unesco.org/education/en/ev.php-

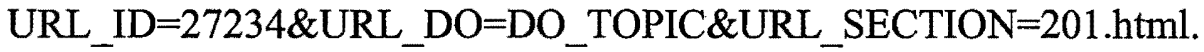

Vela, J. (1994). Learning to listen, learning to teach: The power of dialogue in educating adults. San Francisco: Jossey-Bass.

Vygotzky, L. (1978). Mind in society. Cole, M., John-Steiner, V., Scriber, S., \& Souberman, E. (Eds.). Cambridge, MA: Harvard University Press.

Wals, A. E., \& Jickling, B. (2002). Sustainability in higher education from doublethink and newspeak to critical thinking and meaningful learning. International Journal of Sustainability in Higher Education, 3(3). p.221-232.

Weast, D. (1996). Alternative teaching strategies: The case for critical thinking. Teaching Sociology, 24, 189-194.

Weick, K. E. (1976). Educational organizations as loosely coupled systems. Administrative Science Quarterly, 21(1), 1-19. 
Yazedijan, A., \& Boyle Kolkhorst, B. (2007). Implementing small-group activities in large lecture classes. College Teaching, 55(4), 164-169. 


\title{
APPENDIX A
}

Informed Consent Forms

\section{Doctoral Program in Educational Leadership, Graduate School of Education Postsecondary, Adult \& Continuing Education (PACE)}

\author{
Portland State University
}

\section{Teaching and Learning Sustainability: Using Action Research to Test the Implementation of the Burns Model of Sustainability Pedagogy in two University Courses.}

\section{Dear PSU student,}

You are invited to participate in a research study conducted by Heather Burns, a doctoral student at Portland State University in the Postsecondary, Adult and Continuing Education (PACE) program within the Graduate School of Education. The researcher hopes to learn how a model of sustainability pedagogy can be implemented within university courses, and how students respond to this model. This study is being conducted in partial fulfillment of the requirements for a doctoral degree in educational leadership, and is under the supervision of Christine Cress, Associate Professor of Education.

You were selected as a possible participant in this study because you are enrolled in SCI 357U/ INTL 396 Pollution Carries No Passport: Sustainability in the US-Mexico Border Region at Portland State University. If you decide to participate, no extra assignments or time will be asked of you, but you will be asked to allow the researcher to keep copies of your assignments, and to record some class sessions. In addition, if you decide to participate in this study you will be asked to complete several short reflective writing assignments and surveys in class. Once the class is over, you will also be invited to participate in a recorded focus group session, to talk about your thoughts and feelings about the course and what you learned. This session is voluntary.

While participating in this study, there will not be any risks to you beyond the potential discomfort or stress that comes from participating in a university course. You may not receive any direct benefit from taking part in this study, but the study may help to increase knowledge about teaching and learning sustainability, which may help others in the future. Any information that is obtained in connection with this study and that can be linked to you or identify you will be kept confidential. This information will be kept confidential by assigning pseudonyms to all participants and their work. 
Any recordings of your voice will be erased following the completion of the study. The list of participant names with contact information and pseudonyms will be kept in a locked file cabinet at the home of the researcher.

Your participation is voluntary. You do not have to take part in this study, and it will not affect your grade or your relationship with Portland State University or Heather Burns. You may also withdraw from this study at any time without affecting your grade or relationship with PSU or Heather Burns.

If you have concerns or problems about your participation in this study or your rights as a research subject, please contact the Human Subjects Research Review Committee, Office of Research and Sponsored Projects, 600 Unitus Bldg., Portland State University, (503) 725-4288 / 1-877-480-4400. If you have questions about the study itself, contact Heather Burns at hburns@pdx.edu or 503-280-8044. Your signature indicates that you have read and understand the above information and agree to take part in this study. Please understand that you may withdraw your consent at any time without penalty, and that, by signing, you are not waiving any legal claims, rights or remedies. The researcher will provide you with a copy of this form for your own records.

Signature

Date

Name (Print) 


\title{
Doctoral Program in Educational Leadership, Graduate School of Education Postsecondary, Adult \& Continuing Education (PACE)
}

\author{
Portland State University
}

\section{Teaching and Learning Sustainability: Using Action Research to Test the Implementation of the Burns Model of Sustainability Pedagogy in two University Courses.}

Dear UP student,

You are invited to participate in a research study conducted by Heather Burns, a doctoral student at Portland State University in the Postsecondary, Adult and Continuing Education (PACE) program within the Graduate School of Education. The researcher hopes to learn how a model of sustainability pedagogy can be implemented within university courses, and how students respond to this model. This study is being conducted in partial fulfillment of the requirements for a doctoral degree in educational leadership, and is under the supervision of Christine Cress, Associate Professor of Education.

You were selected as a possible participant in this study because you are enrolled in ENG 107 at the University of Portland. If you decide to participate, no extra assignments or time will be asked of you, but you will be asked to allow the researcher to keep copies of your assignments, and to record some class sessions. In addition, if you decide to participate in this study you will be asked to complete several short reflective writing assignments and surveys in class. Once the class is over, you will also be invited to participate in a recorded focus group session, to talk about your thoughts and feelings about the course and what you learned. This session is voluntary.

While participating in this study, there will not be any risks to you beyond the potential discomfort or stress that comes from participating in a university course. You may not receive any direct benefit from taking part in this study, but the study may help to increase knowledge about teaching and learning sustainability, which may help others in the future. Any information that is obtained in connection with this study and that can be linked to you or identify you will be kept confidential. This information will be kept confidential by assigning pseudonyms to all participants and their work. Any recordings of your voice will be erased following the completion of the study. The list of participant names with contact information and pseudonyms will be kept in a locked file cabinet at the home of the researcher. 
Your participation is voluntary. You do not have to take part in this study, and it will not affect your grade or your relationship with the University of Portland, Portland State University, or Heather Burns. You may also withdraw from this study at any time without affecting your grade or relationship with UP or Heather Burns.

If you have concerns or problems about your participation in this study or your rights as a research subject, please contact the Human Subjects Research Review Committee, Office of Research and Sponsored Projects, 600 Unitus Bldg., Portland State University, (503) 725-4288 / 1-877-480-4400. If you have questions about the study itself, contact Heather Burns at hburns@pdx.edu or 503-280-8044. Your signature indicates that you have read and understand the above information and agree to take part in this study. Please understand that you may withdraw your consent at any time without penalty, and that, by signing, you are not waiving any legal claims, rights or remedies. The researcher will provide you with a copy of this form for your own records.

Signature

Date

Name (Print) 


\section{APPENDIX B}

\section{Rubrics Used for Data Analysis}

Rubric 1: Assessment Rubric for Pre and Post Writing Assignment (Content Dimension)*

Benchmark Outcome: Learners will create a new understanding of sustainability that reflects multiple, interrelated dimensions.

Pre and Post Assignment Course 1: In your own words, what is a sustainable community?

Pre and Post Assignment Course 2: Create a brainstorm list and concept map of the term sustainability.

\begin{tabular}{|l|l|l|}
\hline Rating & Description & Notes \\
\hline 4 - highest & $\begin{array}{l}\text { A sustainable community (or } \\
\text { sustainability) is described as having } \\
\text { multiple and interrelated dimensions. } \\
\text { These relationships are explored and } \\
\text { connections are made between various } \\
\text { dimensions. }\end{array}$ & \\
\hline 3 & $\begin{array}{l}\text { A sustainable community (or } \\
\text { sustainability) is described as having } \\
\text { multiple dimensions, but the relationships } \\
\text { between these dimensions are not fully } \\
\text { described. }\end{array}$ & \\
\hline 2 & $\begin{array}{l}\text { A sustainable community (or } \\
\text { sustainability) is described as having } \\
\text { multiple but unrelated dimensions. }\end{array}$ & \\
\hline 1 & $\begin{array}{l}\text { A sustainable community (or } \\
\text { sustainability) is described as one. } \\
\text { dimensional (i.e. environment, recycling) }\end{array}$ & \\
\hline
\end{tabular}

*This rubric and the following rubrics are based on the work of Stevens \& Levi in their 2004 book, Introduction to rubrics. 
Rubric 2: Assessment Rubric for Research Paper Assignment (Perspectives Dimension)

Benchmark Outcome Course 1: Learners will have the opportunity to critique the underlying causes of complex problems in the US-Mexico border region, and make recommendations about sustainability based on comparing and contrasting diverse Perspectives in the region.

Research Paper Assignment: 7-8 page final paper examines one sustainability topic which synthesizes knowledge gained through classroom, background research and border immersion experiences.

Benchmark Outcome Course 2: Learners will be able to critique the underlying causes of complex problems in Portland, and make recommendations about sustainability based on comparing and contrasting diverse Perspectives in the region.

Argument Essay Assignment: 5 page argument essay which identifies a sustainability problem and makes an argument for a sustainable solution based on an understanding of diverse Perspectives.

\begin{tabular}{|l|l|l|l|l|}
\hline & 1 & 2 & 3 & 4 \\
\hline $\begin{array}{l}\text { Research assignment } \\
\text { critiques underlying } \\
\text { causes of complex } \\
\text { problems }\end{array}$ & $\begin{array}{l}\text { Doesn't mention } \\
\text { underlying } \\
\text { causes }\end{array}$ & $\begin{array}{l}\text { Underlying } \\
\text { causes } \\
\text { mentioned but } \\
\text { not explained }\end{array}$ & $\begin{array}{l}\text { Underlying } \\
\text { causes referred } \\
\text { to and explained } \\
\text { simplistically }\end{array}$ & $\begin{array}{l}\text { Critiques } \\
\text { underlying } \\
\text { causes; shows } \\
\text { clear } \\
\text { understanding of } \\
\text { power } \\
\text { relationships \& } \\
\text { dominant } \\
\text { paradigms }\end{array}$ \\
\hline $\begin{array}{l}\text { Research assignment } \\
\text { offers sustainability } \\
\text { recommendations } \\
\text { based on multiple, } \\
\text { diverse perspectives }\end{array}$ & $\begin{array}{l}\text { Offers no } \\
\text { recom- } \\
\text { mendations, } \\
\text { shows only one } \\
\text { perspective }\end{array}$ & $\begin{array}{l}\text { Offers simplistic } \\
\text { recom- } \\
\text { mendations } \\
\text { based on one or } \\
\text { two perspectives }\end{array}$ & $\begin{array}{l}\text { Offers recom- } \\
\text { mendations } \\
\text { based on several } \\
\text { perspectives }\end{array}$ & $\begin{array}{l}\text { Offers } \\
\text { sustainability } \\
\text { recom- } \\
\text { mendations } \\
\text { based on a } \\
\text { variety of } \\
\text { diverse } \\
\text { perspectives }\end{array}$ \\
\hline
\end{tabular}


Rubric 3: Assessment Rubric for End of Term Reflective Writing (Process Dimension)

Benchmark Outcome Course 1: Learners will relate sustainability in the border region to their own lives and will express an intension to act for sustainable change.

End of Term Reflective Writing Assignment: How might your participation and experience in this course have an effect on your life and your involvement in sustainability issues at the border or locally?

Benchmark Outcome Course 2: Learners will relate sustainability in the Portland area to their own lives and will express an intension to act for sustainable change.

End of Term Reflective Writing Assignment: How might your participation and experience in this course have an effect on your life and your involvement in sustainability issues?

\begin{tabular}{|l|l|l|}
\hline Rating & Description & Notes \\
\hline 3 - highest & $\begin{array}{l}\text { A specific intention to act for change is } \\
\text { expressed based on experience in the class } \\
\text { and personal connection to sustainability }\end{array}$ & \\
\hline 2 & $\begin{array}{l}\text { Connection is made between sustainability } \\
\text { and own life }\end{array}$ & \\
\hline 1 & $\begin{array}{l}\text { No personal connection to sustainability } \\
\text { and no intention expressed to work for } \\
\text { change }\end{array}$ & \\
\hline
\end{tabular}


Rubric 4: Assessment Rubric for End of the Term Reflective Writing (Context Dimension)

Benchmark Outcome Course 1: Learners will connect their understanding of sustainability issues in the border region with their own geographical place and community.

End of Term Reflective Writing Asșignment: What new connections have you made (if any) between sustainability issues at the border and the place/ community where you live? How has this course increased your connection to the U.S. Mexico border region, and/or the Portland area?

Benchmark Outcome Course 2: Learners will understand sustainability in the Context of the ecosystems and communities of Portland and will make personal connections to place.

End of Term Reflective Writing Assignment: How has your understanding of the Portland area changed as a result of the speakers, visits, and readings in this course?

How has your connection to this bioregion/community changed (if at all) as a result of taking this class?

\begin{tabular}{|l|l|l|}
\hline Rating & Description & Notes \\
\hline 4 highest & $\begin{array}{l}\text { Specific connections between } \\
\text { sustainability and own place/community. } \\
\text { Personal connections to place have been } \\
\text { enhanced. }\end{array}$ & \\
\hline 3 & $\begin{array}{l}\text { Some connections made including some } \\
\text { personal connections. }\end{array}$ & \\
\hline 2 & $\begin{array}{l}\text { Some connections made, no personal } \\
\text { connections to place }\end{array}$ & \\
\hline 1 & No connections to place/community & \\
\hline
\end{tabular}


Rubric 5: Researcher Reflection for Each Class Session (Design Dimension)

\begin{tabular}{|l|l|l|l|}
\hline Dimension: & $\begin{array}{l}\text { Planned } \\
\text { activity }\end{array}$ & $\begin{array}{l}\text { Observations and } \\
\text { reflections on students } \\
\text { response }\end{array}$ & $\begin{array}{l}\text { Observations and } \\
\text { reflection on my own } \\
\text { actions }\end{array}$ \\
\hline Content & & & \\
\hline Perspectives & & & \\
\hline Process & & & \\
\hline Context & & & \\
\hline
\end{tabular}




\section{APPENDIX C}

Surveys

Border Course Student Characteristics \&

Pre-Post Subject Knowledge Survey

Name:

(Surveys will be kept confidential)

Please answer the following questions:

Gender:

Age:

Your first language:

Ethnicity:

Year in college:

Major:

Full time or part time student?

Activity prior to college:

Number of hours you work per week while in school:

How do you pay for college? (ie loans, grants/scholarships, parents, work)

Number of children you have:

Do you live on campus or off?

What is your current knowledge base for the following topics? (Circle your response.)

$5=$ A lot $\quad 4=$ Adequate Amount $\quad 3=$ Some $\quad 2=$ A Little $1=$ None

$\begin{array}{lllllll}\text { Sustainability } & 1 & 2 & 3 & 4 & 5\end{array}$

Sustainable food systems

$\begin{array}{lllll}1 & 2 & 3 & 4 & 5\end{array}$

Alternative technology

$\begin{array}{lllll}1 & 2 & 3 & 4 & 5\end{array}$

Immigration policy

$\begin{array}{lllll}1 & 2 & 3 & 4 & 5\end{array}$


Economic globalization

Illegal immigrants

US Mexico border policy

Communicating complex issues $\begin{array}{lllll}1 & 2 & 3 & 4 & 5\end{array}$

$\begin{array}{lllll}1 & 2 & 3 & 4 & 5\end{array}$

$\begin{array}{lllll}1 & 2 & 3 & 4 & 5\end{array}$

$\begin{array}{lllll}1 & 2 & 3 & 4 & 5\end{array}$


ENG 107 Student Characteristics

Pre-Post Subject Knowledge Survey

Name:

(Surveys will be kept confidential)

Please answer the following questions:

Gender:

Age:

Your first language:

Ethnicity:

Year in college:

Major:

Full time or part time student?

Activity prior to college:

Number of hours you work per week while in school:

How do you pay for college? (ie loans, grants/scholarships, parents, work)

Number of children you have:

Do you live on campus or off?

What is your current knowledge base for the following topics? (Circle your response.)

$5=A$ lot $\quad 4=$ Adequate Amount $\quad 3$ =Some $\quad 2=A$ Little $1=$ None

Sustainability

$\begin{array}{lllll}1 & 2 & 3 & 4 & 5\end{array}$

Local sustainable food systems

$\begin{array}{lllll}1 & 2 & 3 & 4 & 5\end{array}$

Global food systems

$\begin{array}{lllll}1 & 2 & 3 & 4 & 5\end{array}$

Local economies

$\begin{array}{lllll}1 & 2 & 3 & 4 & 5\end{array}$

Food miles

$\begin{array}{lllll}1 & 2 & 3 & 4 & 5\end{array}$


Community food security

The writing Process

Writing about complex issues

$\begin{array}{rrrrr}1 & 2 & 3 & 4 & 5 \\ 1 & 2 & 3 & 4 & 5\end{array}$

$\begin{array}{lllll}1 & 2 & 3 & 4 & 5\end{array}$


Border Course: Post Course Evaluation of Teaching Techniques \& Dimensions of Burns Model

Name: (Surveys will be kept confidential)

Please rate the following class activities using a 5-point scale with 1 as low and five as high.

$5=$ A lot $\quad 4=$ Adequate Amount $\quad 3$ =Some $\quad 2=$ A Little $1=$ None (Circle your response.)

\section{Learning/Teaching techniques:}

$\begin{array}{llllllll}\text { What I learned from small group class discussions } & 1 & 2 & 3 & 4 & 5\end{array}$

$\begin{array}{llllllll}\text { What I learned from large group class discussions } & 1 & 2 & 3 & 4 & 5\end{array}$

$\begin{array}{llllllll}\text { What I learned from reflective writing assignments } & 1 & 2 & 3 & 4 & 5\end{array}$

$\begin{array}{llllllll}\text { What I learned from participatory class activities } & 1 & 2 & 3 & 4 & 5\end{array}$

$\begin{array}{lllllll}\text { What I learned from graded assignments } & 1 & 2 & 3 & 4 & 5\end{array}$

$\begin{array}{lllllll}\text { What I learned from guest speakers } & 1 & 2 & 3 & 4 & 5\end{array}$

$\begin{array}{llllllll}\text { What I learned from border trip } & 1 & 2 & 3 & 4 & 5\end{array}$

$\begin{array}{lllllll}\text { What I learned from my classmates } & 1 & 2 & 3 & 4 & 5\end{array}$

\section{Dimensions:}

$\begin{array}{llllll}\text { My understanding of sustainability at US/Mexico border } 1 & 2 & 3 & 4 & 5\end{array}$

$\begin{array}{lllllll}\text { What I know about this issue from diverse Perspectives } & 1 & 2 & 3 & 4 & 5\end{array}$

$\begin{array}{lllllll}\text { My intention to participate in sustainability in some way } 1 & \cdot & 2 & 3 & 4 & 5\end{array}$

My connection to community/ecosystems of Portland $\begin{array}{lllllll}1 & 2 & 3 & 4 & 5\end{array}$

$\begin{array}{lllllll}\text { My connection to community/ecosystems of border region1 } & 2 & 3 & 4 & 5\end{array}$

Comments about my learning in this course: 
ENG 107 Post Course Evaluation of Teaching Techniques

\& Dimensions of Burns model

Name: (Surveys will be kept confidential)

Please rate the following class activities using a 5-point scale with 1 as low and five as high.

$4=$ Adequate Amount

$3=$ Some

$2=A$ Little

$1=$ None

(Circle your response.)

Learning/Teaching techniques:

Please assess how much you learned about our theme, local community food systems, from the following learning activities:

What I learned from class discussions

What I learned from journal writing assignments

What I learned from participatory class activities

What I learned from graded assignments

What I learned from guest speakers

What I learned from field trips

$\begin{array}{lllll}1 & 2 & 3 & 4 & 5 \\ 1 & 2 & 3 & 4 & 5 \\ 1 & 2 & 3 & 4 & 5 \\ 1 & 2 & 3 & 4 & 5 \\ 1 & 2 & 3 & 4 & 5 \\ 1 & 2 & 3 & 4 & 5\end{array}$

\section{Dimensions}

$\begin{array}{lllllll}\text { My understanding of local sustainable food systems } & 1 & 2 & 3 & 4 & 5\end{array}$

What I know about this issue from diverse Perspectives

$2 \cdot 3$

45

(i.e. economy, community, social systems, low-income, ecology, farmers, consumers)

My intention to participate in sustainability in some way 1

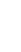

My sense of connection to communities/ecosystems of Portland

2

3

$4 \quad 5$

Comments about my learning in this course: 
APPENDIX D

Syllabi

\title{
Pollution Carries No Passport: \\ Sustainability in the US-Mexico Border Region
}

\author{
SCI 357U, CRN 43188 \\ Winter 2009 \\ Location: BH 219
}

Instructors

Celine Fitzmaurice

celine@pdx.edu

Center for Science Education

Stephen Epler Hall- ${ }^{\text {st }}$ Floor

Phone: 503.725.8260

Office hours: By Appointment

\author{
Heather Burns \\ hburns@pdx.edu \\ Graduate School of Education \\ Educational Leadership \& Policy (ELP) \\ Education Building- $5^{\text {th }}$ floor \\ Office Hours: By Appointment
}

\section{Course Description}

This course will explore sustainability issues in the US-Mexico border region with a particular emphasis on environmental sustainability. The course immersion will take place in the twin towns of Nogales, Mexico and Nogales, Arizona where multinational factories, a free trade zone and a major border crossing provide a rich setting in which to explore topics of global sustainability. During the border trip, participants will meet with pioneers in various fields-including food systems, alternative technology, and resource management--to get first-hand information on the economic and ecological implications of our actions within the broader context of global trade. We will also have the opportunity to connect with members of local communities on both sides of the border to learn about alternative practices that support a sustainable future, and will participate in homestays with working class Mexican families. This class will meet weekly during winter term to gain knowledge of border sustainability topics and prepare for the immersion experience. This will be followed by a 5-day trip to the Arizona-Mexico border region from Friday, February 20th to Tuesday, February 24th. All participants should plan to arrive in Tucson, AZ by the evening of February $19^{\text {th }}$. We will hold class sessions during weeks 9 and 10 to debrief the trip and make final presentations.

\section{Course Goals}

- Establish familiarity with varied understandings of sustainability (critical thinking)

- Gain a basic understanding of the science inquiry process (critical thinking)

- Examine a variety of themes that affect sustainability in the border region as a way to better understand sustainability on a global scale (critical thinking)

- Engage in dialogue with border residents and critically analyze diverse and contradictory perspectives on border sustainability topics (diversity, critical thinking)

- Critically analyze and reflect on your own role in connection to issues facing the borderlands (critical thinking, social and ethical responsibility)

- Conduct an in-depth exploration of one border sustainability topic of your choosing and communicate your findings through a final research paper and presentation (communication, critical thinking) 
- Consider the role and responsibility of everyday citizens in addressing sustainability issues in everyday practice (social and ethical responsibility)

(Note: UNST goals associated with a given course goal are given in italics after the course goal.)

\section{Course Activities}

- Cross-cultural and pre-trip orientation activities

- Classroom survey of sustainability issues in the border region

- Border literature review

- Dialogue with guest speakers of diverse perspectives in the border region

- Visits to some or all of the following settings in the border region: multinational factories, immigration facilities and environmental and social service agencies

- Homestays with working class Mexican families

Assignments

- Weekly reading assignments

- Reflective writing assignments

- Pre-trip community-based learning experience

- Background research and literature review related to sustainability topic of your choosing

- 7-8-page final paper on your sustainability topic which synthesizes knowledge gained through classroom, background research and border immersion experiences

- Final presentation of your research

Community Partner in the Border Region

Our host agency for the border immersion trip is "Borderlinks." Borderlinks is a bi-national organization with facilities in Tucson, $\mathrm{AZ}$ and Nogales, Mexico. Borderlinks' mission is :

- To build relationships and understanding between North Americans and Latin Americans

- To encourage a shared analysis of the implications of the global economy

- To "capacitate" leaders on both sides of the border who work together to foster healthy communities locally and internationally

Borderlinks educational philosophy:

Education at its best combines academic study and reflection with direct personal experience, respects all people as potential teachers, acknowledges complexity and refuses to be satisfied by oversimplification, is enriched by learning in community, and encourages each participant to act on what he or she has learned. To this end, Borderlinks coordinates multiple short-term and semester-long immersion programs in the border region every year. You can learn more about Borderlinks by visiting their website at www.borderlinks.org.

\section{Grading Criteria}

Grades will be based on participation in the class as measured by:

Attendance at class sessions and border trip

Participation in class activities and border trip.

Reflective Writing Assignments

Pre-trip community-based learning experience

Individual Research Project 
$-5 \%$ for Research Question and List of Sources

$-10 \%$ for Summary and Analysis of Pre-trip Background Research

$-30 \%$ for Final Paper and Presentation

The standard $90 / 80 / 70 / 60$ grading scale will be used. There will be no final exam for this course. Assignment guidelines and grading criteria for each assignment are posted on Blackboard. All assignments should adhere to APA style guidelines

\section{Late assignments}

Late assignments will lose $20 \%$ credit unless prior arrangements have been made. Late papers will be accepted for up to one week beyond the due date. No late papers will be accepted after assignments have been returned.

Materials

The following book will be required reading for this course:

Lives on the Line: Dispatches from the US-Mexico Border by Miriam Davidson, University of Arizona Press, 2000.

Articles or web links for additional reading assignments are posted on Blackboard, or placed on electronic reserve. See below for more information about accessing these materials.

\section{On-line Access to Course Information}

The course syllabus, handouts, reflective writing prompts and additional resources will be made available on-line through Blackboard. To access this information, you must have a PSU ODIN account.. You will log into the course by going to http://www.psuonline.pdx.edu and entering your id and username in the "Online Course Login" section to the right of the page.

Instructions for Accessing Readings Placed on Electronic Reserve through the PSU Library:

1. Go to this web site: http://psu-eres.lib.pdx.edu/eres

2. Click on Electronic Reserves

3. Enter the course number (ex. $410,121 \ldots$ ), you can also search by

Department or instructor's last name. Then click Search.

4. Select the course you want

5. Click accept

6. Select a document or a folder

7. Enter password (it's the instructor's last name)

8. Click continue

9. Now you can view or print it out.

Note: you have to have Adobe Acrobat Reader to open or view it.

\section{Academic Integrity \& Plagiarism:}

Students are expected to adhere to college policies. Please take special note of policies regarding plagiarism and course withdrawal. The University's Code of Student Conduct may be found at http://www.pdx.edu/dos/conduct.html. All work should be original. Plagiarism, representing another person's words, ideas, or thoughts as your own, is not acceptable. When using material that is not your own, you must cite your source. Plagiarism is considered a breach of academic integrity and will be addressed with gravity. 
Students with Disabilities

Please see us if you have a disability that may require some modification to the course.

Students with disabilities should register with the PSU Disability Resource Center (503-7254150, TTY or Relay 503-725-4178) to document their need for accommodations and obtain support services. We will work with you and the Disability Resource Center to arrange needed supports.

Weekly Schedule

Our tentative weekly schedule is attached. Please note that the schedule is subject to change.

Weekly Course Schedule, Winter Term 2009

Pollution Carries No Passport: Sustainability in the US-Mexico Border Region

\begin{tabular}{|c|c|}
\hline Date/ Weekly Themes & Due \\
\hline $\begin{array}{l}\text { Week 1- January } 7 \\
\text { Introductions } \\
\text { Course Overview } \\
\text { Syllabus Review and Discussion } \\
\text { Borderlinks Paperwork } \\
\text { Final Paper Overview }\end{array}$ & \\
\hline $\begin{array}{l}\text { Week 2- January } 14 \\
\text { History of Economic Globalization in } \\
\text { Mexico- Part I } \\
\text { Sustainable Communities }\end{array}$ & $\begin{array}{l}\text { Reflective Writing Assignment } 1 \\
\text { (Blackboard) } \\
\text { Assigned Readings: } \\
\text { A Mexican Tragedy (Electronic Reserve) } \\
\text { History of NAFTA (Blackboard) } \\
\text { Find and Read } 1 \text { article of your choosing that } \\
\text { address the topic of sustainability. Please } \\
\text { bring the article to class for discussion. }\end{array}$ \\
\hline $\begin{array}{l}\text { Week 3- January } \mathbf{2 1} \\
\text { History of Economic Globalization in } \\
\text { Mexico- Part II } \\
\text { Sustainability Research themes } \\
\text { The Science Inquiry Process }\end{array}$ & $\begin{array}{l}\text { Assigned Readings: } \\
\text { The case for free trade (ER) } \\
\text { The perils of free trade (ER) } \\
\text { The Zapatista uprising (Blackboard) } \\
\text { The most radical thing you can do (ER) } \\
\text { Read sample student research paper } \\
\text { (Blackboard) }\end{array}$ \\
\hline $\begin{array}{l}\text { Week 4- January } 28 \\
\text { US-Mexico Immigration History }\end{array}$ & $\begin{array}{l}\text { Assignment } 1 \text { due: Research Question and } \\
\text { list of sources you plan to consult } \\
\text { Assigned Readings: } \\
\text { Davidson Chapter } 1 \\
\text { Key events in the history of the US/Mexico } \\
\text { border (from borderlinks reading packet) } \\
\text { Immigration demystified (ER) } \\
\text { Find, read and bring to class a recent article } \\
\text { on immigration }\end{array}$ \\
\hline $\begin{array}{l}\text { Week } 5 \text {-February } 4 \text { ' } \\
\text { US-Mexico Immigration History- "Securing" } \\
\text { the Border }\end{array}$ & $\begin{array}{l}\text { Community-Based Learning Assignment } \\
\text { due (Blackboard) } \\
\text { Assigned Readings: }\end{array}$ \\
\hline
\end{tabular}




\begin{tabular}{|l|l|}
\hline Research Topics Roundtable & $\begin{array}{l}\text { Davidson Chapter 3 } \\
\text { The Angry Patriot (ER) } \\
\text { Our Wall- (Blackboard) }\end{array}$ \\
\hline $\begin{array}{l}\text { Week 6 -February 11 } \\
\text { Invironmental Sustainability: Public Health; } \\
\text { Impact of Immigration Policy and Free Trade } \\
\text { on Wildlife and Land } \\
\text { Final Pre-Trip Preparation }\end{array}$ & $\begin{array}{l}\text { Reflective Writing Assignment 2 } \\
\text { (Blackboard) } \\
\text { Assigned Readings: } \\
\text { Davidson Chapter 2 } \\
\text { Along the Devil's Highway (ER) }\end{array}$ \\
\hline $\begin{array}{l}\text { Week 7- February 18 } \\
\text { Ganguage and Culture } \\
\text { Bender and Family Structure in the }\end{array}$ & $\begin{array}{l}\text { Assignment 2 due: Summary and Analysis } \\
\text { of Pre-Trip Background Research } \\
\text { Assigned Readings: } \\
\text { Davidson Chapter 4 \& 5 } \\
\text { The Politics of Reproduction: Households in } \\
\text { the Mexican Industrial Transition (ER) }\end{array}$ \\
\hline $\begin{array}{l}\text { Immersion trip to the border region } \\
\text { February 20 } \\
\text { (Fly to Tucson by the night of the 19 } \\
\text { finish trip by 6:00p.m. pm on the 24 }\end{array}$ & th
\end{tabular}




\section{English 107-College Writing}

Fall 2008

\section{Eat, Write: Exploring Sustainable Food Systems through Writing \\ T/H 2:30-3:55 \\ Science 203}

Professor: Heather Burns

E-mail: hburns@pdx.edu *note: I check my burns@up.edu account less frequently

Phone: 503-943-7243

Office hours: $1: 15-2: 20 \mathrm{~T} / \mathrm{H}$ and by appointment

Office location: BC 369

\section{Required Textbooks:}

- The Pocket Wadsworth Handbook (2008) by Kirszner \& Mandell

- Animal, Vegetable, Miracle (2007) by Barbara Kingsolver with Steven Hopp and Camille Kingsolver

\section{Course Description:}

This course will help you develop your academic writing skills and prepare you for other courses in a variety of disciplines by enhancing your ability to: understand and practice the writing process, read and think critically, conduct research, participate in and lead class discussion, and conduct peer review of writing. In the process, you will also learn about sustainability in Portland by exploring the theme sustainable local food systems. You will have the opportunity to learn about sustainable local food systems by reading, talking with guest speakers, visiting local places, and through discussion and writing.

\section{Course Outcomes:}

- Develop and write expository, interpretive analysis, argument and personal reflection essays using the process of prewriting, drafting and revision

- Improve your writing through an increased understanding of thesis statements, outlining, paragraph development, organization, supporting evidence and details, transitions, and editing

- Conduct library research in order to write an argument essay using MLA (Modern Language Association) documentation

- Improve your abilities to lead and participate in discussion and to conduct peer review of writing

- Understand how sustainable food systems are connected to local ecology, economy, and culture

- Reflect critically about the underlying causes of complex socio-cultural problems and make recommendations about sustainable solutions based on your understanding of a variety of perspectives

- Relate sustainable local food systems to your own life and the choices you make about food 
- Know more about the place you live, and sustainable local food systems in that place

\section{Background on the Course Theme:}

Why are we focusing our learning and writing on sustainable local food systems? The Willamette Valley (where Portland is located) is home to some of the best agricultural soils in the world and hosts a thriving local food movement that includes CSAs (Community Supported Agriculture), farmer's markets, community gardens, small farms and businesses, and food co-operatives. In Portland, many organizations and citizens consider sustainable local food production to be a critical step to increasing overall sustainability in the region. This is because sustainable local food systems are linked to decreasing global warming, improving physical health, conserving open and healthy lands, enhancing the local economy, and promoting ecological and cultural well being. In contrast, small scale and local agriculture has been on the decline for decades in most of the United States. Big agribusinesses have mostly taken over food production, supplying products that are mass-produced, heavily processed and packaged, and shipped up to thousands of miles to supermarkets. Many people of lower and middle incomes now have limited access to food that is produced sustainably and locally. In this context, we will explore how has Portland managed to build a sustainable local food system, and if the changing food system is making Portland more sustainable overall.

\section{Major Course Projects:}

- Expository essay

- Interpretive analysis essay

- Argument essay

- Reflection journal (every other week)

- Final personal reflection essay and presentation

- 2 Mini essays

\section{Other activities:}

$\checkmark$ Free writing and reflective writing in class

$\checkmark$ Leading and participating in class discussion

$\checkmark$ Reading

$\checkmark$ Writing workshops (peer review)

$\checkmark$ Field trips \& guest speakers

$\checkmark$ Writing center appointments (optional but encouraged)

\section{Participation:}

As a student in this class, you are part of a learning community. You are responsible for your own learning and for the learning process of the whole group. Therefore, attendance and full participation in every class session is expected. Be prepared to share ideas, experience, questions, and to participate in weekly discussions based on reading and class activities. In order to receive full points for class attendance and 
participation, please come to class on time, having done the reading and/or assignment for the day, and be ready to actively participate.

Absences are excused only when you notify me in person, by e-mail or by voice message prior to the class that you will be absent. If you have to be absent from class, you are responsible for finding out what you missed. Unexcused absences will affect your participation grade.

\section{Integrated Writing Center:}

The writing center, located in Franz 119, exists to assist students with their writing. The center is staffed by trained Writing Assistants who can help you improve your writing. To get help with developing, drafting, or revising your writing, you can make an appointment by calling 503-943-8157, emailing writing@up.edu, or by stopping by the writing center. You can also visit the writing center website for other information and lots of great writing resources at

http://www.up.edu/lrc/writing/default.aspx?cid=258\&pid=234.

\section{Plagiarism:}

All work should be original. Plagiarism, representing another person's words, ideas, or thoughts as your own, is not acceptable. When using material that is not your own, you must cite your source. Plagiarism is considered a breach of academic integrity and will be addressed with gravity.

\section{Accommodation for Disability:}

If you have a disability and require an accommodation to fully participate in this class, contact the Office for Students with Disabilities (OSWD), located in the University Health Center (503-943-7134), as soon as possible.

\section{Grading:}

For each assignment I will provide specific instructions and grading criteria.

\begin{tabular}{|l|l|}
\hline $30 \%$ & Class Attendance and Participation \\
\hline $10 \%$ & Expository Essay \\
\hline $15 \%$ & Interpretive Analysis Essay \\
\hline $20 \%$ & Argument Research Essay \\
\hline $10 \%$ & Journal \\
\hline $5 \%$ & Mini Essays (2) \\
\hline $10 \%$ & Final Essay and Presentation \\
\hline
\end{tabular}

\section{Late Assignments:}

Late assignments will lose $20 \%$ credit unless prior arrangements have been made. No late papers will be accepted after assignments have been returned. 


\section{Course Expectations:}

- Get support when you need it. I am available to further discuss, listen, to look over work in progress, and to provide suggestions. Please feel free to visit me during my office hours, or to e-mail me with questions. If you have a draft for me to look at, I prefer to do this in person rather than by e-mail so please schedule an appointment

- Please be open to multiple ways of learning and expression

- Know that your perspective and experience is valid and appreciated. Be prepared to share your experience with others in this course

- Use MLA documentation style for all work

\section{Schedule:}

Note: WH=The Pocket Wadsworth Handbook, AVM=Animal, Vegetable, Miracle

\begin{tabular}{|c|c|c|c|}
\hline Week & Date & Topic & Due on this day: \\
\hline \multirow{2}{*}{$\begin{array}{l}\text { Week } \\
1\end{array}$} & T Aug. 26 & Introductions & \\
\hline & TH Aug. 28 & $\begin{array}{l}\text { The writing process \& } \\
\text { sustainability }\end{array}$ & $\begin{array}{l}\text { Read syllabus carefully-come } \\
\text { with any additional questions } \\
\text { Read WH pgs } 2-9\end{array}$ \\
\hline \multirow[t]{2}{*}{$\begin{array}{l}\text { Week } \\
2 \\
\end{array}$} & T Sept. 2 & $\begin{array}{l}\text { Thesis statements/preparing } \\
\text { for mini assignment \#1 }\end{array}$ & \\
\hline & TH Sept. 4 & $\begin{array}{l}\text { Discussion of reading and } \\
\text { guiding questions }\end{array}$ & $\begin{array}{l}\text { Read AVM pgs } 1-42 . \\
\text { Read article by Anna Lappé } \\
\text { at } \\
\text { http://seattlepi.nwsource.com/ } \\
\text { opinion/354753_tilth13.html } \\
\text { Journal entry \#1 due } \\
\text { Guiding questions: How } \\
\text { would you describe the } \\
\text { sustainable food systems } \\
\text { movement? Do you agree } \\
\text { that "our food choices are } \\
\text { politically charged?..." (p. } \\
\text { 19) What is your own } \\
\text { relationship to food culture? }\end{array}$ \\
\hline \multirow[t]{2}{*}{$\begin{array}{l}\text { Week } \\
3\end{array}$} & T Sept. 9: & $\begin{array}{l}\text { Outlining, organizing } \\
\text { paragraphs, supporting details }\end{array}$ & Read WH pgs $10-20$ \\
\hline & TH Sept 11 & $\begin{array}{l}\text { Discuss mini assignments } \\
\text { Visit Student Led Unity } \\
\text { Garden (SLUG) }\end{array}$ & Mini essay \#1 due \\
\hline $\begin{array}{l}\text { Week } \\
4\end{array}$ & T Sept 16 & $\begin{array}{l}\text { Expository essays- structure, } \\
\text { transitions, intros, conclusions }\end{array}$ & Read WH pgs 20-24 \\
\hline
\end{tabular}




\begin{tabular}{|c|c|c|c|}
\hline & TH Sept. 18 & $\begin{array}{l}\text { Discussion of reading } \\
\text { Watch film }\end{array}$ & $\begin{array}{l}\text { Read AVM pgs } 43-70 \\
\text { Read: Is there slavery in your } \\
\text { chocolate? } \\
\text { http://earthsave.org/newslette } \\
\text { rs/chocolate.htm } \\
\text { Journal entry } \# 2 \text { due } \\
\text { Guiding questions: What is } \\
\text { the importance of seed } \\
\text { diversity and heirloom } \\
\text { varieties of food? What are } \\
\text { some of the concerns related } \\
\text { to GM food? What are some } \\
\text { of the benefits of buying } \\
\text { locally? What do you think } \\
\text { about the movement toward } \\
\text { fair trade imports? }\end{array}$ \\
\hline \multirow{2}{*}{$\begin{array}{l}\text { Week } \\
5\end{array}$} & T Sept. 23 & Peer Writing Workshop & Expository Essay draft due \\
\hline & TH Sept. 25 & $\begin{array}{l}\text { Guest Speaker \& Discussion } \\
\text { of reading }\end{array}$ & Read AVM pages $70-100$ \\
\hline \multirow[t]{2}{*}{$\begin{array}{l}\text { Week } \\
6\end{array}$} & T Sept 30 & $\begin{array}{l}\text { Writing interpretive analysis } \\
\text { essays }\end{array}$ & Expository essay due \\
\hline & TH Oct. 2 & Discussion of reading & $\begin{array}{l}\text { Read AVM pages } 100-154 \\
\text { Journal entry \#3 due } \\
\text { Guiding questions: What are } \\
\text { some of the true costs of food } \\
\text { and who pays for these costs? } \\
\text { Why do you think Kingsolver } \\
\text { says that "cooking is good } \\
\text { citizenship"?(p. 130) Are } \\
\text { you inspired by any aspect of } \\
\text { the Kingsolver story? Why or } \\
\text { why not? }\end{array}$ \\
\hline \multirow[t]{2}{*}{$\begin{array}{l}\text { Week } \\
7\end{array}$} & T Oct. 7 & Peer Writing Workshop & $\begin{array}{l}\text { Interpretive Analysis essay } \\
\text { draft due }\end{array}$ \\
\hline & TH Oct. 9 & $\begin{array}{l}\text { Midterm } \\
\text { discussions/evaluations }\end{array}$ & \\
\hline \multirow[t]{2}{*}{$\begin{array}{l}\text { Week } \\
8\end{array}$} & T Oct. 14 & No Class-Fall Break & \\
\hline & TH Oct. 16 & No Class- Fall Break & \\
\hline
\end{tabular}




\begin{tabular}{|c|c|c|c|}
\hline $\begin{array}{l}\text { Week } \\
9\end{array}$ & T Oct. 21 & Developing argument essays & $\begin{array}{l}\text { Interpretive Analysis essay } \\
\text { due } \\
\text { Read WH pgs } 24-30\end{array}$ \\
\hline & TH Oct. 23 & Discussion/Guest Speaker & $\begin{array}{l}\text { Read AVM pgs } 154-196 \\
\text { Journal entry } \# 4 \text { due } \\
\text { Guiding Questions: what are } \\
\text { some of the impacts of } \\
\text { continual pesticide/herbicide } \\
\text { application to food crops? } \\
\text { What are some of the } \\
\text { advantages of a farmer } \\
\text { "staying small"? What are } \\
\text { some things that average } \\
\text { citizens can do if they are } \\
\text { interested in eating locally } \\
\text { and sustainably? Which do } \\
\text { you think are most feasible? }\end{array}$ \\
\hline \multirow[t]{2}{*}{$\begin{array}{l}\text { Week } \\
10 \\
\end{array}$} & T Oct. 28 & $\begin{array}{l}\text { Argument essays/Mini Essay } \\
\# 2\end{array}$ & \\
\hline & TH Oct. 30 & $\begin{array}{l}\text { Field Trip- Community Food } \\
\text { Security }\end{array}$ & $\begin{array}{l}\text { Read article on Food Security } \\
\text { at: } \\
\text { http://goliath.ecnext.com/com } \\
\text { s2/gi_0199-3300288/Belo- } \\
\text { Horizonte-social-club- } \\
\text { where.html }\end{array}$ \\
\hline \multirow{2}{*}{$\begin{array}{l}\text { Week } \\
11\end{array}$} & T Nov. 4 & Library research & Mini essay \# 2 due \\
\hline & TH Nov. 6: & Discussion & $\begin{array}{l}\text { Read AVM pages } 196-241 \\
\text { Go to www.meatrix.com-read } \\
\text { Journal Entry } \# 5 \\
\text { Guiding Questions: What are } \\
\text { some of the major challenges } \\
\text { for family-owned sustainable } \\
\text { farms? Why do you think that } \\
70 \% \text { of federal agricultural } \\
\text { subsidies support corn and } \\
\text { soybean production? What } \\
\text { are some of the major } \\
\text { concerns with industrial meat } \\
\text { production and what is your } \\
\text { reaction to these concerns? }\end{array}$ \\
\hline \multirow[t]{2}{*}{$\begin{array}{l}\text { Week } \\
12\end{array}$} & T Nov. 11: & $\begin{array}{l}\text { Understanding \& debating } \\
\text { multiple perspectives }\end{array}$ & \\
\hline & TH Nov. 13: & Discussion/Watch Film & Read AVM pgs $242-276$ \\
\hline
\end{tabular}




\begin{tabular}{|c|c|c|c|}
\hline $\begin{array}{l}\text { Week } \\
13\end{array}$ & T Nov. 18 & Peer Writing Workshop & $\begin{array}{l}\text { Argument Research Essay } \\
\text { draft }\end{array}$ \\
\hline & TH Nov. 20 & $\begin{array}{l}\text { Discussion of Reading/Guest } \\
\text { speaker }\end{array}$ & $\begin{array}{l}\text { Read AVM pgs } 277-314 \\
\text { Journal Entry \#6 Due } \\
\text { Guiding Questions: What are } \\
\text { some of your own holiday } \\
\text { food traditions and how are } \\
\text { these traditions connected to a } \\
\text { food system (global-industrial } \\
\text { or local)? How can } \\
\text { celebrations be more } \\
\text { sustainable? What are some } \\
\text { of the challenges to eating } \\
\text { locally grown food year- } \\
\text { round? }\end{array}$ \\
\hline \multirow[t]{2}{*}{$\begin{array}{l}\text { Week } \\
14 \\
\end{array}$} & T Nov. 25 & Personal Reflection Essays & $\begin{array}{l}\text { Argument Research Essays } \\
\text { due }\end{array}$ \\
\hline & TH Nov. 27 & No Class- Thanksgiving & \\
\hline \multirow[t]{2}{*}{$\begin{array}{l}\text { Week } \\
15 \\
\end{array}$} & T Dec. 2 & $\begin{array}{l}\text { Discussion of reading/ Class } \\
\text { Evaluations }\end{array}$ & Read AVM pgs 315-334 \\
\hline & TH Dec. 4 & $\begin{array}{l}\text { Final Evaluations and } \\
\text { discussions }\end{array}$ & \\
\hline $\begin{array}{l}\text { Week } \\
16\end{array}$ & $\begin{array}{l}\text { Dec. 8-11 } \\
\text { Finals Week }\end{array}$ & & Final Presentations \& Papers \\
\hline
\end{tabular}

